\title{
Modifications of Pre and Postnatal Development Due to Placental Efficiency and Maternal Exercise during Gestation in Swine
}

\author{
Tiffany Ann Wilmoth \\ West Virginia University
}

Follow this and additional works at: https://researchrepository.wvu.edu/etd

\section{Recommended Citation}

Wilmoth, Tiffany Ann, "Modifications of Pre and Postnatal Development Due to Placental Efficiency and Maternal Exercise during Gestation in Swine" (2012). Graduate Theses, Dissertations, and Problem Reports. 3596.

https://researchrepository.wvu.edu/etd/3596

This Dissertation is protected by copyright and/or related rights. It has been brought to you by the The Research Repository @ WVU with permission from the rights-holder(s). You are free to use this Dissertation in any way that is permitted by the copyright and related rights legislation that applies to your use. For other uses you must obtain permission from the rights-holder(s) directly, unless additional rights are indicated by a Creative Commons license in the record and/ or on the work itself. This Dissertation has been accepted for inclusion in WVU Graduate Theses, Dissertations, and Problem Reports collection by an authorized administrator of The Research Repository @ WVU.

For more information, please contact researchrepository@mail.wvu.edu. 
Modifications of Pre and Postnatal Development Due to Placental Efficiency and Maternal Exercise during Gestation in Swine

\author{
Tiffany Ann Wilmoth
}

Dissertation submitted to the

Davis College of Agriculture, Natural Resources and Design

at West Virginia University in partial fulfillment of the

requirements for the degree of

\author{
Doctor of Philosophy \\ in \\ Reproductive Physiology
}

\author{
Matthew E. Wilson, Ph.D., Chair \\ Kenneth P. Blemings, Ph.D. \\ Joseph S. Moritz, Ph.D. \\ Kimberly A. Vonnahme, Ph.D. \\ Jianbo Yao, Ph.D.
}

Division of Animal and Nutritional Sciences

Morgantown, West Virginia

2012

Keywords: Placental Development, Fetal Development, Muscle Growth 


\section{ABSTRACT \\ Modifications of Pre and Postnatal Development Due to Placental Efficiency and Maternal Exercise during Gestation in Swine}

Tiffany Ann Wilmoth

In pigs, litter size and developmental competence are crucial for successful production of the meat product. However, the ability of the placenta to produce a developmentally competent pig is vital in the production of meat animals. Placental efficiency (fetal weight divided by placental weight) has been studied as a measure of placental function and litter size. Selection for increased placental efficiency has been shown to increase placental efficiency as well as litter size. Furthermore, formative muscle development occurs entirely during gestation, so that the number of muscle fibers the pig is born with is reflective of the number of fibers of the pork product after harvest of the animal. Following parturition, hyperplasia no longer occurs and muscle growth is entirely hypertrophic. The ratio of secondary to primary muscle fibers is an important marker for pork quality as well. The number of fibers and the size to which the muscle fibers grow, particularly the secondary muscle fibers can affect pork quality. Additionally, the growth of the secondary muscle fibers can be affected by environmental conditions (e.g., housing, stress). As shifts in industry trends take place, the effects these changes will have on the development of the fetuses of pregnant sows and gilts need to be studied. The objectives of the work here were: 1) to determine the effect of placental efficiency on in utero muscle development, 2) to determine the influence of placental efficiency on the postnatal growth performance and muscle development of pigs at market weight, and 3) to investigate the effects of exercise of second parity sows during gestation on fetal development and metabolism. For the first objective, pregnant females were ovariohysterectomized at day 95, fetal blood and muscle samples were collected and used to determine fetal metabolite concentrations and muscle fiber number and size, respectively. On day 95 of gestation, primary and secondary muscle fiber size of both loin and ham muscle samples were increased in fetuses of low placental efficiency compared to high placental efficiency fetuses. For the second objective, pregnant females farrowed naturally and pigs were caught, umbilical cords tagged and ears notched so placental efficiency could be determined following expulsion of placentae. Pigs were then fed to market weight (120 kg) and slaughtered. Muscle samples were collected following a 24 hour chill and used to determine muscle fiber number and size. Placental efficiency at birth decreased the secondary to primary ratio of muscle fibers in loin muscle samples in low placental efficiency pigs at market weight. Finally, in accordance with the third objective, second parity sows were exercised from day 44 to day 94 of gestation. On day 94, sows were ovariohysterectomized and euthanized. Fetal blood samples and muscle samples were collected to determine fetal metabolite concentrations and fetal muscle fiber number and size, respectively. Exercise during gestation decreased fetal body and muscle weights as well as increasing muscle fiber size and decreasing muscle fiber number in ham muscle samples. In conclusion, placental efficiency, and therefore placental function, plays an important role not only in the in utero development of muscle, but postnatal development, as well. Exercise during gestation negatively altered fetal development and potentially fetal metabolism, which could result in poor growth performance later in life. 


\section{TABLE OF CONTENTS}

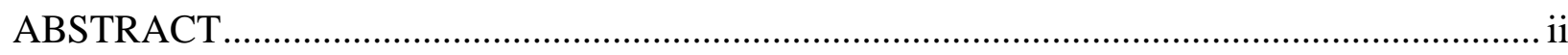

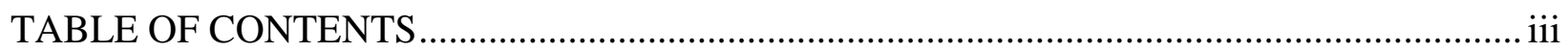

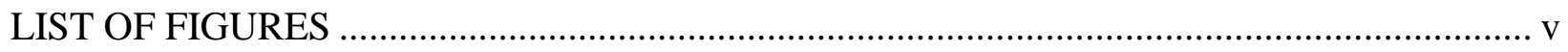

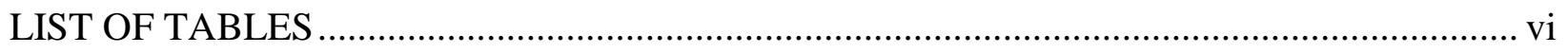

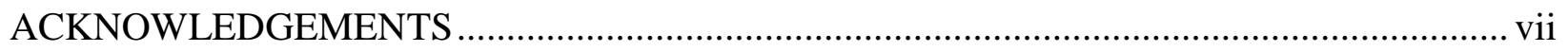

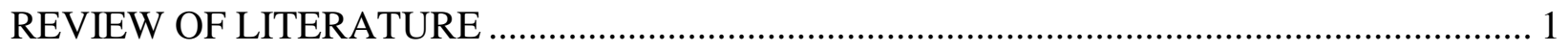

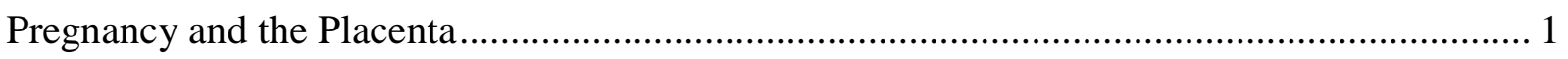

Placental Development and Attachment ……………........................................................ 2

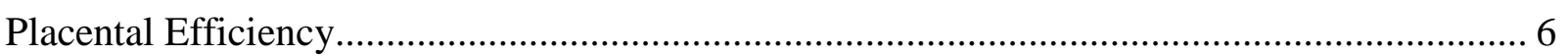

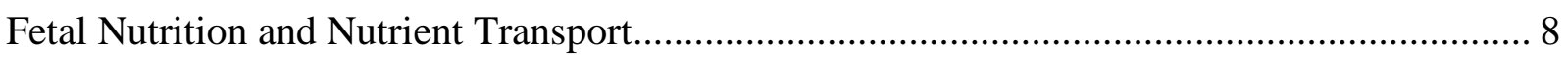

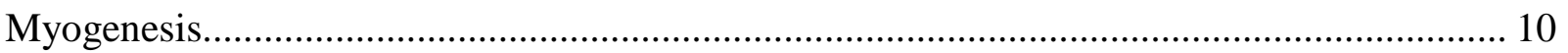

Fetal Muscle Growth and Development......................................................................... 12

Postnatal Growth and Development of Muscle................................................................... 14

Environmental Factors Affecting Postnatal Muscle Development ............................................. 15

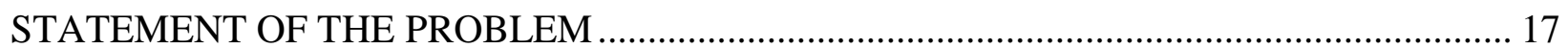

ALTERATIONS IN FETAL MUSCLE DEVELOPMENT IN HIGH AND LOW PLACENTAL

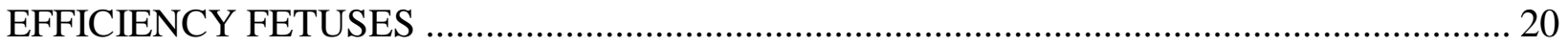

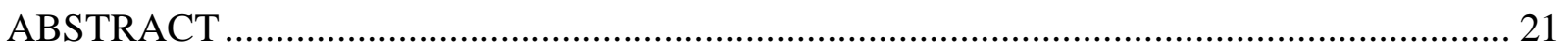

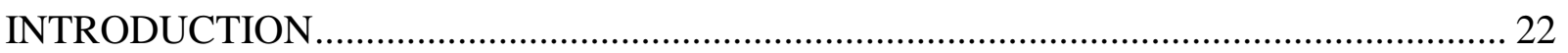

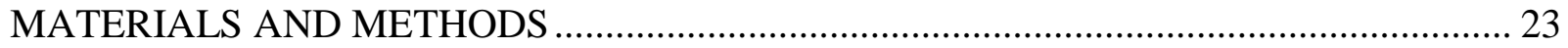

Animal Management ………………………………………………………………. 23

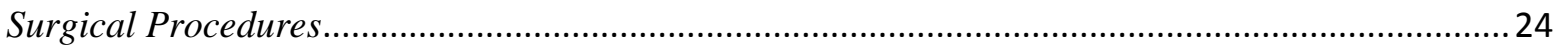

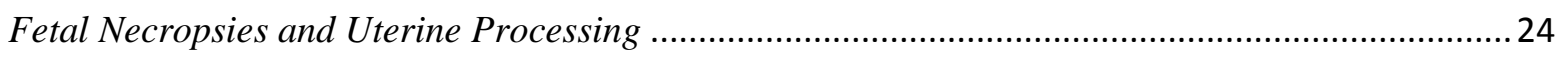

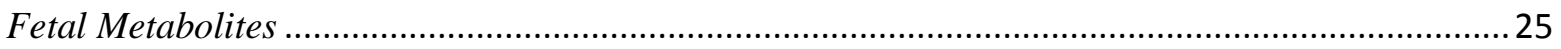

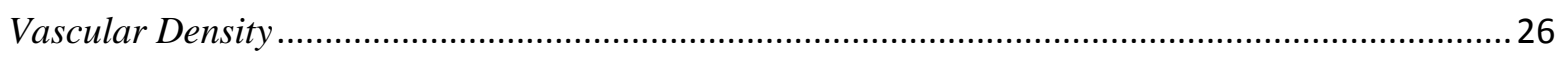

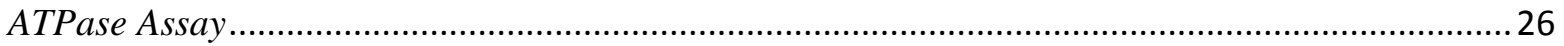

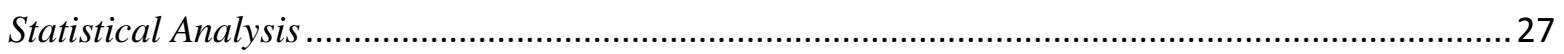

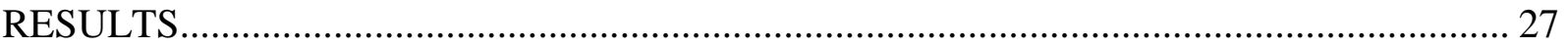

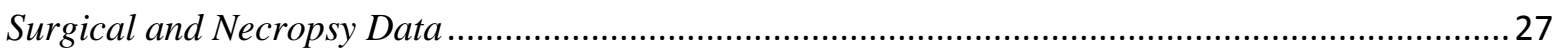

Fetal Metabolites and Vascular Density ............................................................................ 28

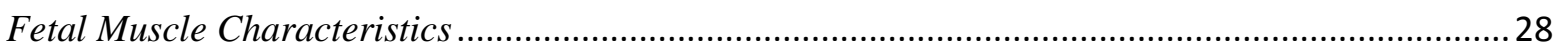

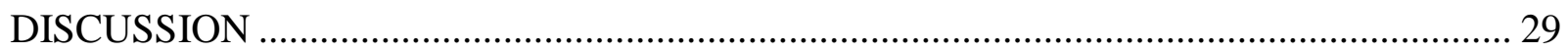

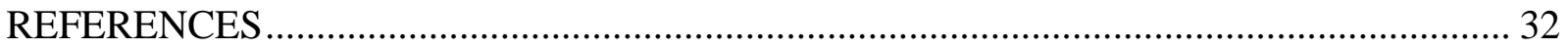




\section{PLACENTAL EFFICIENCY AT BIRTH ALTERS MUSCLE DEVELOPMENT}

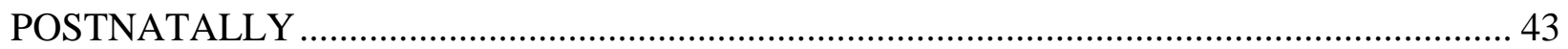

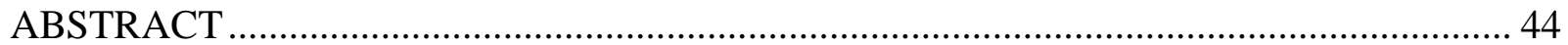

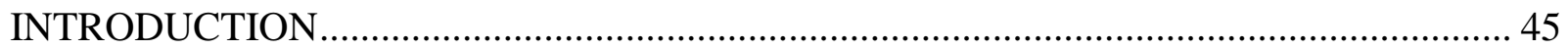

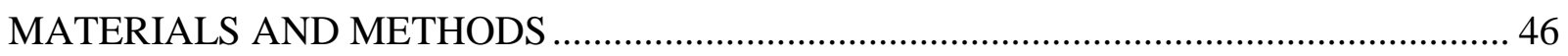

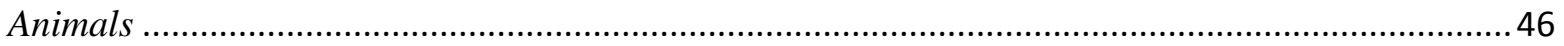

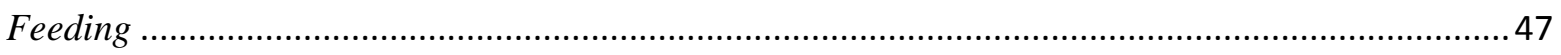

Harvest and Sample Collection.............................................................................................

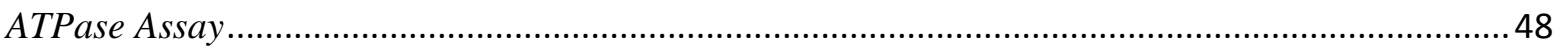

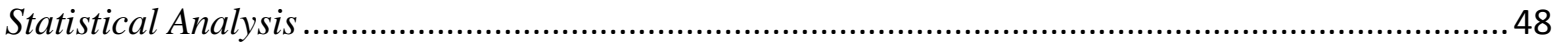

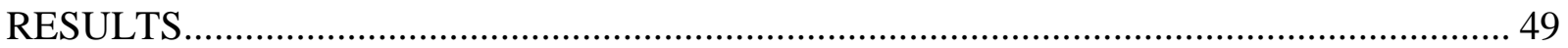

Neonatal and Placental Characteristics ................................................................................. 49

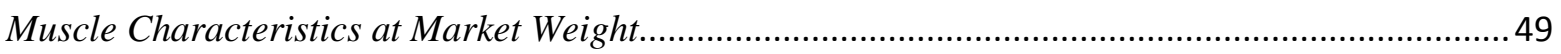

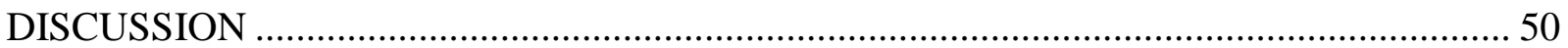

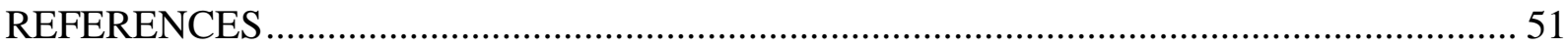

MATERNAL EXERCISE IN SECOND PARITY SOWS ALTERS FETAL GROWTH AND

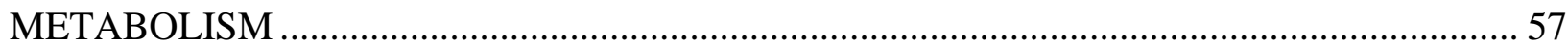

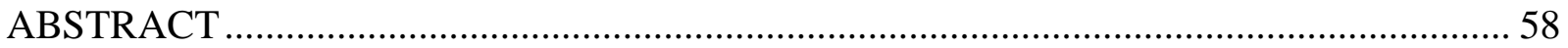

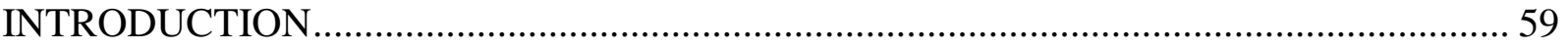

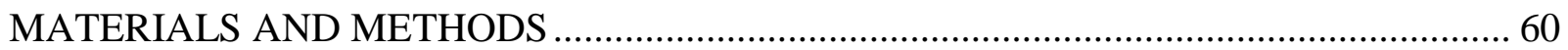

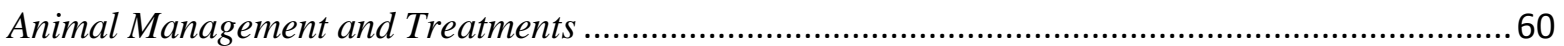

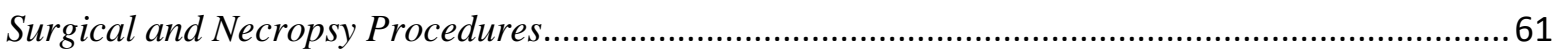

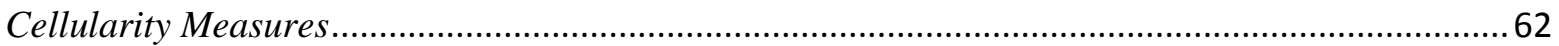

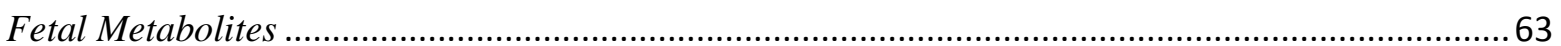

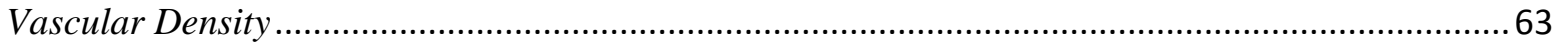

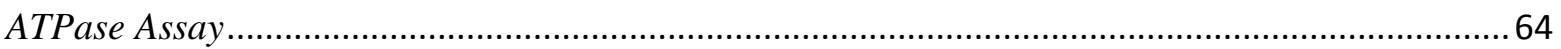

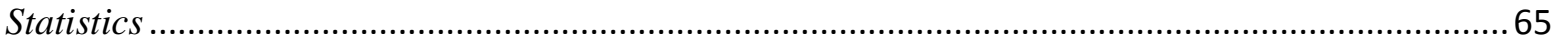

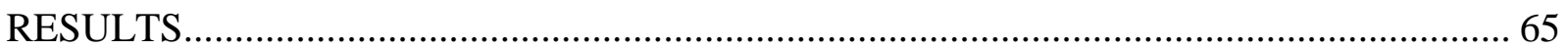

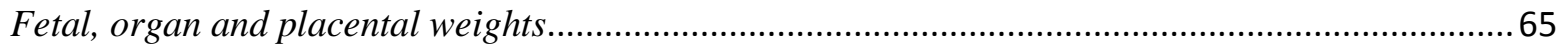

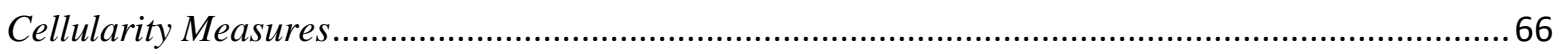

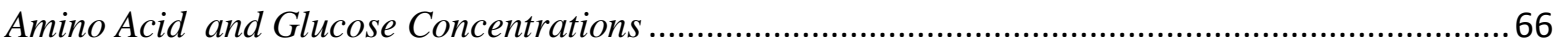

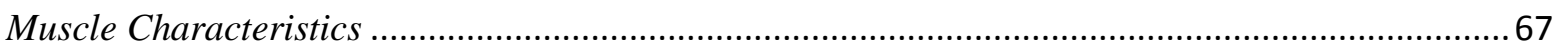

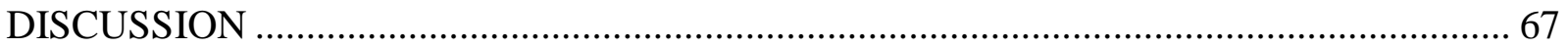

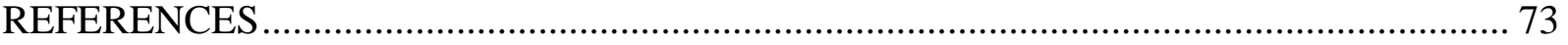

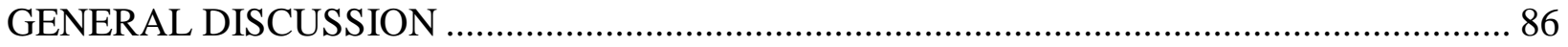

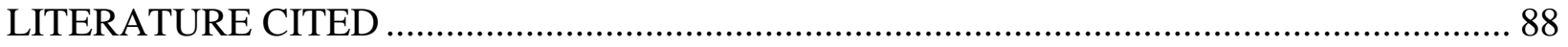




\section{LIST OF FIGURES}

Figure 1. Diagram of conceptus at the blastocyst stage. (Perry, 1981) ........................................ 2

Figure 2. Photograph representing population of porcine blastocysts at different stages of

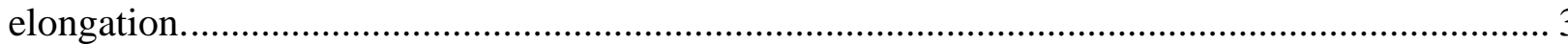
3

Figure 3. Figure representing blastocyst distribution throughout uterine horns prior to (a) and following (b) elongation. (Perry, 1981) ......................................................................................... 3

Figure 4. Diagram depicting formation of amnion and chorion.(Perry, 1981)............................... 4

Figure 5. Placental development by day 18 of gestation, note formation of allantois.................... 5

Figure 6. Placental development at day 21 of gestation, note formation of allanto-chorion.

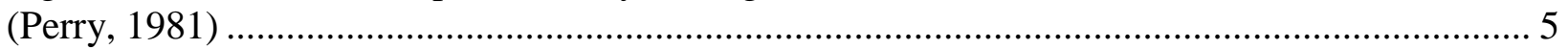

Figure 7. Figure representing neural tube and paraxial somites, arranged in pairs, along each side

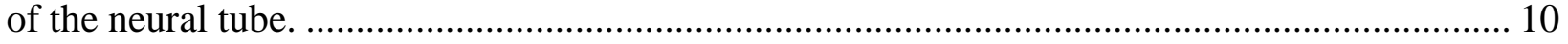

Figure 8. Figure representing development of muscle fibers (Rehfeldt et al., 2000). .................. 12

Figure 9. Placental weight (g) of high placental efficiency feto-placental units (open bars) and low placental efficiency feto-placental units (closed bars). Means \pm SEM, $\mathrm{P}<0.0001$.............. 34

Figure 10. Neonatal and placental weights for piglets assigned to high (open bars) or low (closed bars) placental efficiency groups. Means \pm SEM, $\mathrm{P}<0.05$........................................................... 53

Figure 11.Girth of neonatal pigs in high (open bars) and low (closed bars) placental efficiency

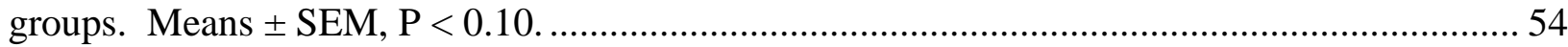

Figure 12. Ratio of secondary to primary muscle fibers in LD muscle from high (open bars) and low (closed bars) placental efficiency groups. Means \pm SEM, $\mathrm{P}<0.05$...................................... 55

Figure 13. Number of primary muscle fibers in SM and ST muscles of fetuses of EX dams (closed bars) compared to CON dams (open bars). Means \pm SEM, ** $\mathrm{P}<0.05$.

Figure 14.Number of secondary muscle fibers in SM and ST muscle from fetuses of EX dams (closed bars) and CON dams (open bars).Means \pm SEM, $* *$ P $<0.05$ by treatment. 85 


\section{LIST OF TABLES}

Table 1. Correlations between ST weight and fetal and placental characteristics..................... 35

Table 2. Vascular Density and Metabolite Concentrations .................................................. 36

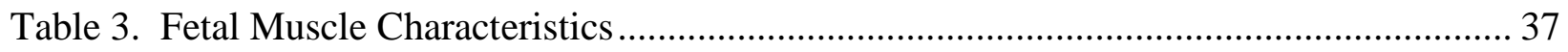

Table 4. Correlations between fetal weight and muscle fiber size ....................................... 38

Table 5. Correlations between placental weight and muscle characteristics ........................... 39

Table 6. Correlations between ST weight and ST muscle characteristics .............................. 40

Table 7. Correlations between vascular density and muscle characteristics .......................... 41

Table 8. Correlations between fetal metabolites and muscle characteristics.......................... 42

Table 9. Correlations between muscle characteristics .................................................... 56

Table 10. Fetal, Organ and Placental Weights............................................................... 76

Table 11. Cellularity Measures in Chorio-Allantoic Tissue ............................................... 77

Table 12. Concentrations of Essential Amino Acids in Fetal Plasma and Amniotic Fluid ......... 78

Table 13. Concentrations of Non - Essential Amino Acids in Fetal Plasma and Amniotic Fluid80

Table 14. Glucose Concentrations in Umbilical Plasma ....................................................... 83 


\section{ACKNOWLEDGEMENTS}

The opportunity to work with so many faculty, staff, graduate and undergraduate students has influenced me in a way that I cannot put into words and the experiences I have had with everyone while completing this and other degrees will be forever remembered. However, there are a few people who were crucial to this process.

I would like to start by thanking my committee members. My advisor, Matt Wilson, thank you for all the opportunities you have offered me over the years. I appreciate everything you have done for me and am really thankful that you walked into Dr. Lewis' office that day, oh so long ago. Realize that you have not only had an influence on the kind of scientist I will be one day, but also the person I hope to be one day. I will always remember to be prepared when opportunity knocks.

Dr. Blemings, I don’t know where to start, you have always pushed me to think outside the box and appreciate all the things around me. Thank you so much for all of the work you put into me over the past few years. Dr. Moritz, I want to thank you for serving on this committee even though the work we planned didn't work out. I also want to thank you for encouraging me to write the grant for my prelims. It was quite and experience and will be helpful in the future. Dr. Vonnahme, thank you for giving me the opportunity to work with you and come to North Dakota to work for a while. The experience you gave me really opened my eyes and I truly appreciate it. Thank you also for the collaboration and opportunity you offered me with the parity two exercise study. Dr. Yao, thank you so much for serving on this committee, I realize you stepped in later than the rest of the committee and I appreciate your efforts. You have all 
helped me immensely along the way and helped to shape the person that I am and for that I cannot say thank you enough.

Additionally, I would like to mention Dr. Bryon Wiegand at the University of Missouri and Dr. Bowdridge. Dr. Wiegand, thank you for your collaboration and work on the placental efficiency growth study. I enjoyed the time I spent in Missouri and learned a considerable amount each time. Next Midwest meeting, we should have a drink! Dr. Bowdridge, thank you for all of your help with the cryotome and the graduate student association.

Bill Miller, you have been a huge help with this and all the other work I have done here at WVU, as well as a pillar of support. I will miss our "barn talks" and, of course, the fireballs! I really enjoyed our time working together and made the animal work so much more fun!

I would like to thank all of the graduate students I have worked with for their support, friendship and camaraderie. Thank you to all of you who helped get the Animal and Nutritional Sciences Graduate Student Association off the ground and running. I really think that as it grows it will be a huge benefit to you and other graduate students. Steph, thank you for your friendship, support, comisery and of course your invaluable help with the pig surgeries. I really miss our Friday movie dates and think they would have been particularly helpful throughout this last semester! I don't know what I would have done without you. Siri, thank you for your help with the pig surgeries and for being a friend these last few years. I have enjoyed your friendship and working through this together. I would also like to give a congrats to the graduate students who joined the ISPPP, it will be a skill that will take you far in life, never forget!

Kristina, you are always wonderfully supportive and a fantastic friend. Mom and Dad, you guys have been so hugely supportive of this even when I didn't think I could possible do it 
anymore. Thank you for allowing me all the opportunities I had when growing up without them I would be here or the person I am today. 


\section{REVIEW OF LITERATURE}

\section{Pregnancy and the Placenta}

The placenta is an extraordinary organ which serves multiple functions during its brief lifespan, including shock absorption, protection from the maternal immune system as well as harmful chemicals or toxicants, hormone production and nutrient exchange. Summatively, the placenta ensures proper growth and development of the fetus.

The placenta is an embryonically derived tissue, meaning that the placenta of the fetus is unique to that fetus. The placenta consists of different membranes, including the amnion, the chorion, the allantois and the yolk sac. The amnion is the membrane in closest contact with the embryo and acts as a shock absorber in conjunction with the production of amniotic fluid which is produced by the amniotic epithelium (Greyling, 2004). The placenta is capable of producing hormones for the recognition and maintenance of pregnancy. In some species, such as the sheep, the placenta produces sufficient amounts of progesterone in late gestation to maintain pregnancy following ovariectomy (Flint, 1983). While this does not occur in the pig, the trophectoderm of the porcine blastocyst produces estradiol 17- $\beta$ that is the signal for maternal recognition of pregnancy and therefore contributes to the maintenance of pregnancy in early gestation (Bazer et al., 1986). Finally, the placenta is the only avenue the fetus has for exchanging nutrients and gases as well as removing wastes.

Placental structure varies greatly between species. In litter bearing animals, such as the pig, each fetus within the litter will develop its own placenta, independent and separate from the placentae of adjacent fetuses. Commonly, placentae are characterized by either the number of layers separating fetal and maternal circulatory systems or by the type of attachment that occurs between the placenta and the adjacent endometrium of the uterus. The placenta of the pig is described as epitheliochorial indicating that six layers of tissue separate fetal and maternal blood, which is the highest degree of separation. Of these six layers, three are maternal and three are fetal, and include maternal endothelium, maternal 
interstitium, maternal epithelium, fetal epithelium, fetal interstitium, fetal endothelium (Steven, 1975). The porcine placenta can also be described as diffuse which indicates that the entire surface area of the placenta is in contact with the entire surface area of the adjacent endometrium. This attachment is nearly uniform with the exception of the necrotic tips on either end of the placenta that prevent the sharing of vascular supply between the placentae of individual fetuses (Steven, 1975).

\section{Placental Development and Attachment}

The placenta is an embryonically derived tissue and its development occurs concomitantly with embryonic development. By approximately day 10 of gestation, myometrial contractions have evenly distributed porcine embryos throughout both uterine horns (Steven, 1975). When these contractions cease, the embryo will remain at its respective location and placental attachment will occur in this area. At this point, the embryo is a blastocyst and is more appropriately termed the conceptus consisting of both fetal and placental tissues (Figure 1).

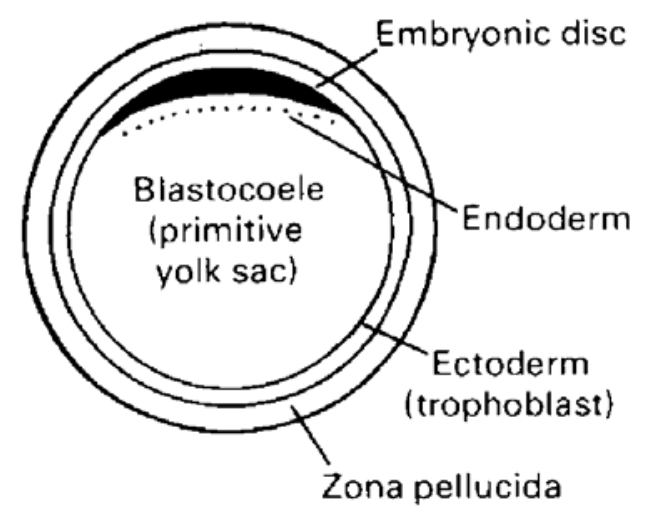

Figure 1. Diagram of conceptus at the blastocyst stage. (Perry, 1981)

Fetal tissues include the inner cell mass or embryonic disc, which will become the fetus; the placental tissues include the blastocoele, or the primitive yolk sac, and the trophectoderm, which will become the placenta. The placenta forms when these fetal tissues come into contact with maternal tissues (Perry, 1981). Over the next few days, the blastocyst will undergo dramatic morphological change. It will 
change from a sphere of about $6 \mathrm{~mm}$ in diameter to a long filamentous structure of up to one meter in length, the majority of which is trophectoderm (Perry, 1981; Figure 2).

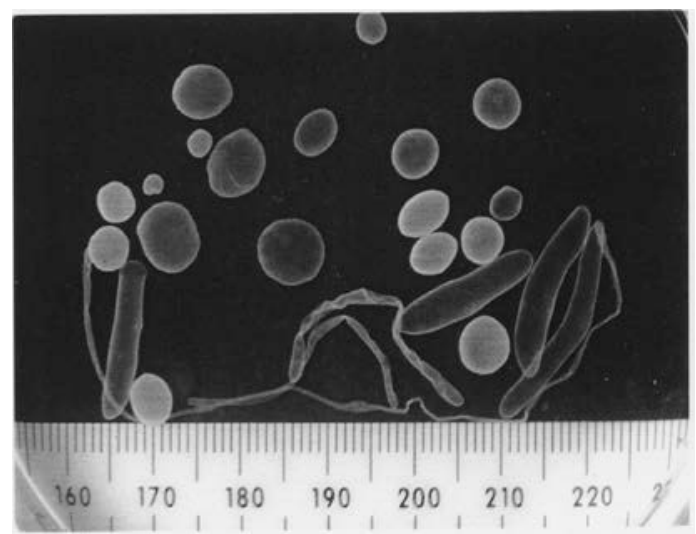

Figure 2. Photograph representing population of porcine blastocysts at different stages of elongation.

Following elongation, the conceptuses will grow to occupy the entirety of the uterine horns and until they come into contact with each other (Figure 3).
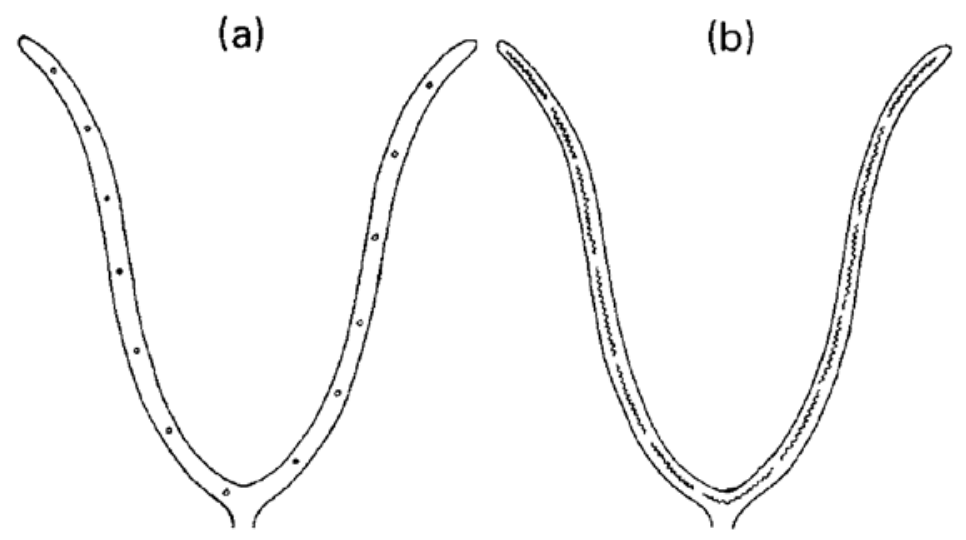

Figure 3. Figure representing blastocyst distribution throughout uterine horns prior to (a) and following (b) elongation. (Perry, 1981)

Beginning on day 13 of gestation, the ectoderm will begin to "bud" off forming a mesoderm layer between the embryonic disc and endoderm (Figure 4a). This mesoderm will split, resulting in two layers, one closely covering the endoderm and the other lying under the ectoderm, and forming a cavity called the exocoele (Figure 4b). The outer layer of the mesoderm and the ectoderm will begin to fold around the embryonic disc forming the amniotic fold (Figure 4c). This fold will grow to either side of the embryo 
and fuse above it, forming the amnion and separating it from the chorion, made up of the outer layer of mesoderm and the ectoderm (Figures $4 \mathrm{~d}$ and $4 \mathrm{e}$ ) by day 17 of gestation. The inner layer of mesoderm, which is closely covering the yolk sac, continues to be important as it contains blood islands which will develop into the first blood vessels.

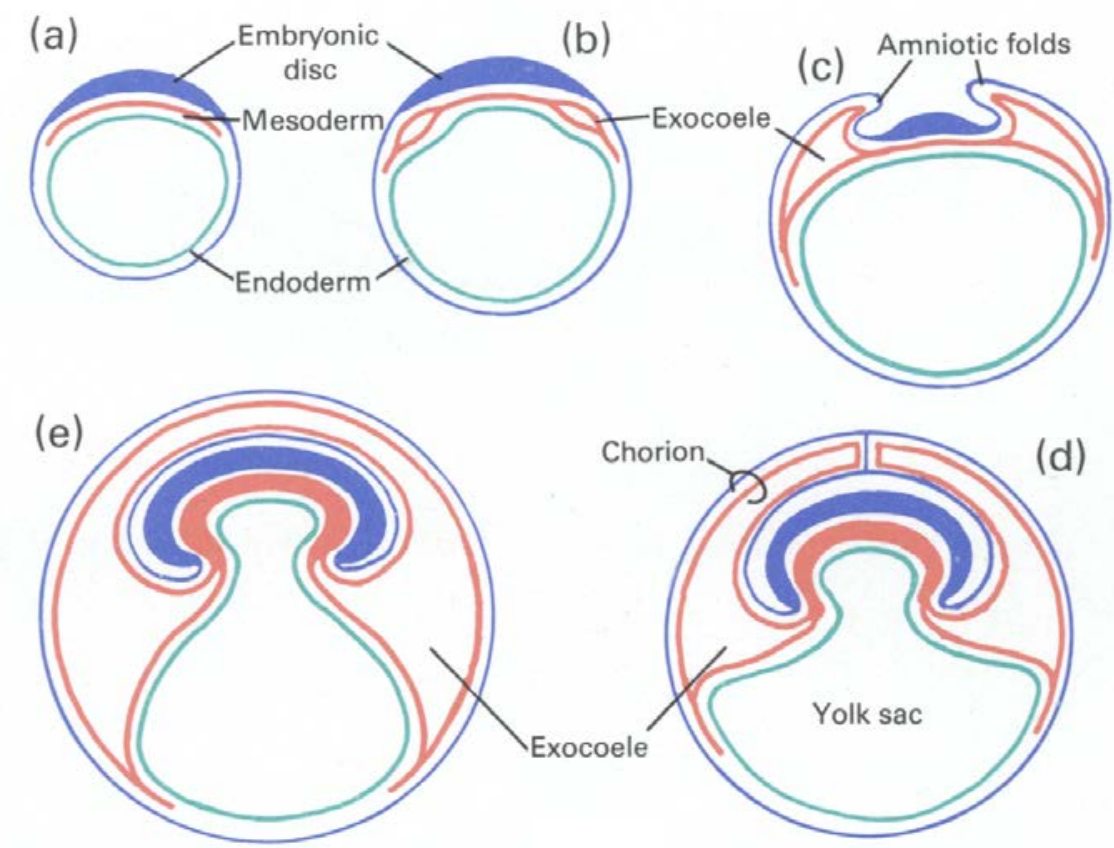

Figure 4. Diagram depicting formation of amnion and chorion.(Perry, 1981).

By day 18, the yolk sac has reached its maximum development and by day 20 will begin to shrink rapidly. The allantois, near the posterior end of the embryo, will begin to protrude. The allantois collects fetal urine and will become part of the urinary bladder (Perry, 1981; Figure 5). At this time, the placenta will begin to attach to the endometrium.

As gestation proceeds, the allantois will swell causing the shape of the conceptus to change. The allantois will fill the exocoele except where the amnion is fused to the chorion and results in the formation of the allanto-chorion (Perry, 1981; Figure 6). The allanto-chorion consists of the allantois, the mesodermal layer and the ectodermal layer. The mesoderm is where the blood vessels are located. The blood vessels occur over the entirety of the tissue with the exception of the extremities, or necrotic tips. 


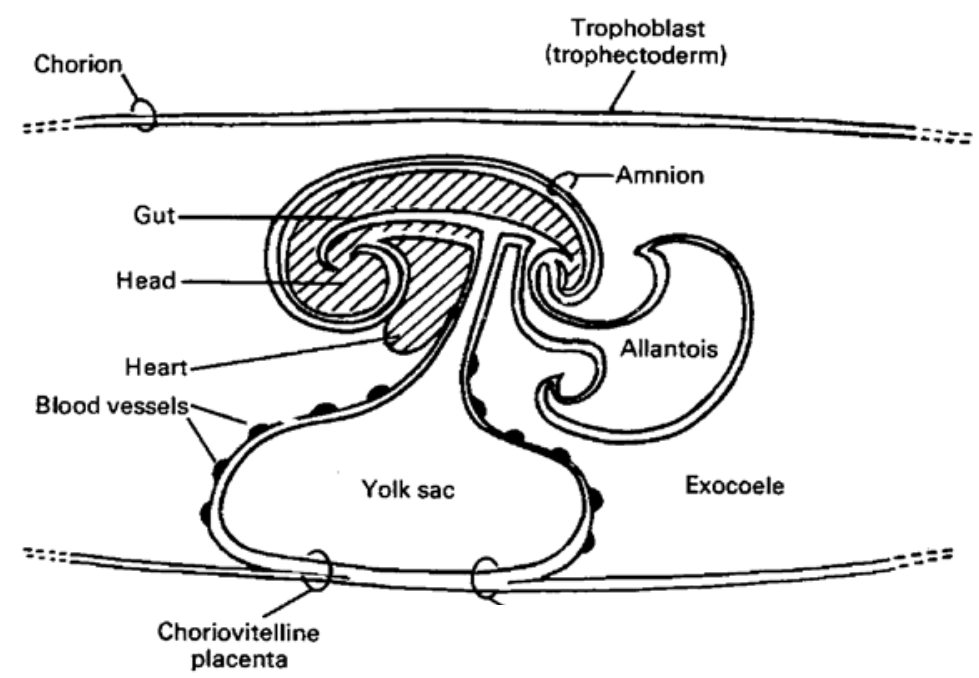

Figure 5. Placental development by day 18 of gestation, note formation of allantois.

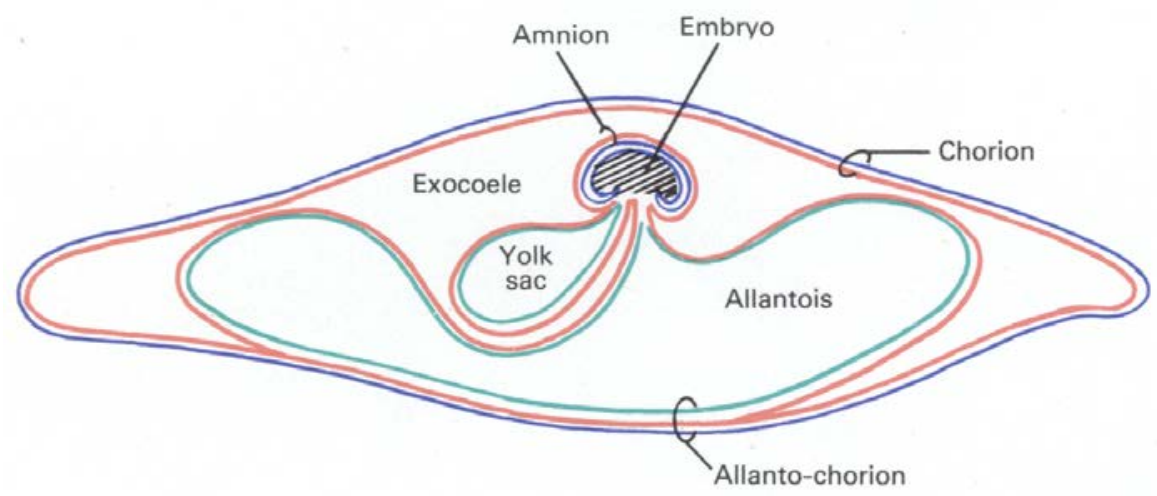

Figure 6. Placental development at day 21 of gestation, note formation of allanto-chorion. (Perry, 1981)

Placental attachment includes the formation of areolae around the openings of uterine glands (Friess et al., 1982). Around these areolae, the trophoblast cells are modified and the trophectoderm becomes folded forming regular areolae. However, if the maternal epithelial cells become modified, an irregular areola is formed. Including both regular and irregular areolae, as well as the microvillar attachments of the trophectoderm cells and uterine luminal epithelial cells, there are three different structural components in the placenta that allow for nutrient and gas exchange between the dam and fetus.

It is proposed that the areolae, since they cover the uterine gland openings, transfer secretions from these uterine glands to the fetus (Friess et al., 1982). The interaerolar attachment by the interlocking 
of microvilli offers gaseous, as well as nutrient exchange sites. This attachment allows the allanto-chorion and endometrium to stay connected throughout gestation so that fetal and maternal capillaries are in close proximity with each other to facilitate nutrient transfer. As the placenta and fetus grow, the allantochorion and endometrium will fold into each other forming rugae (primary and secondary) and corresponding troughs. This serves to increase surface area, and potentially the nutrient transport capacity, of the placenta. This folding begins to occur at about day 18-20 of gestation and increases in complexity throughout gestation (Friess et al., 1980, 1982). Friess et al. (1980) concluded that gaseous exchange occurs at the summit and lateral sides of the ridges where the capillaries are, while transport of less diffusible compounds occurred near or around the chorionic troughs. This was supported by the discovery of a high number of pinocytotic vesicles in the fetal epithelium of the chorionic troughs.

Friess et al. (1980) found that around day 30, the distance between maternal and fetal blood is approximately $40 \mu \mathrm{m}$. Throughout gestation, fetal capillaries grow and indent the epithelium on the sides and summits of the ridges, decreasing the cellular height of the epithelial layers and decreasing the distance between the maternal and fetal blood (Friess et al., 1980). Around day 60, the intercellular channels between cells of the maternal epithelium are distinct. By day 100, indentation of both fetal and maternal capillaries is increased, while the height of the cells making up the fetal and maternal epithelium has decreased. There is now a marked decrease in the distance between maternal and fetal blood with less than $2 \mu \mathrm{m}$ separating the structures (Friess et al., 1980). Though intercellular channels were observed in both fetal and maternal epithelium, Friess et al. (1980) did not notice any continuity between these layers after perfusion.

\section{Placental Efficiency}

In the 1980’s, the Chinese Meishan pig was imported in the United States. This breed of pig differed from domestic commercial Large White breeds in that litter size was approximately 40\% larger. The Meishan, however, exhibited similar ovulation and fertility rates as well as uterine size as Large 
White breeds. In addition to litter size, placental size was vastly different between the two breeds, the placentae of the Meishan was approximately $40 \%$ smaller than the placentae of Large White breeds (Wilson et al., 1998). The size difference was also accompanied by a difference in vascularity, with the Meishan having a placenta that is three times more vascular than a placenta of Large White breeds on day 110 of gestation (Biensen et al., 1998). These authors suggested that the efficiency of the placenta may be a factor in the differing litter sizes.

Placental efficiency is defined as fetal weight divided by placental weight. This ratio numerically represents the grams of fetus that can be produced per gram of placenta. Placental efficiency has been studied in marmoset monkeys (Rutherford and Tardif, 2008) and mice (Fowden et al., 2006, 2009, Coan et al,. 2008, Angiolini et al., 2006). Placental efficiency is not only variable among breeds or litters of pigs, but also within an individual litter. Placental efficiency can vary as much as five units within a litter (Wilmoth, 2009). Placental efficiency is largely dependent upon placental weight; therefore placental weight varies greatly within a litter as well. This variation can result in fetuses that are very similar in body weight (i.e., within $4 \%$ ) but with one fetus having a placenta that is $50 \%$ heavier than the other (Wilmoth, 2009). The ability of the smaller placenta to produce a similarly sized fetus as the larger placenta demonstrates the efficiency of function of that placenta. Appreciating the differences in function between high and low efficiency placentae may lead to the improvement of placental function of all fetoplacental units within a litter, potentially improving not only litter sizes, but fetal growth and development.

In 1999, Wilson and colleagues selected boars and gilts at birth based on their placental efficiency, either high or low. When selected animals reached maturity, high placental efficiency animals were bred to high placental efficiency animals and those with low placental efficiency were mated. Litter size was increased (40\%) in litters born to dams selected for high placental efficiency at birth. These litters were also associated with a decreased placental weight (30\%) and decreased fetal weight (20\%) compared to those born to dams selected for low placental efficiency. Though placental efficiency increased, the decrease in fetal weight is of concern. There is ample evidence of negative effects 
associated with low birth weight neonates (Milligan et al., 2002). The relationship between placental efficiency and piglet birth weight could be reliant on the nutrient transport capabilities of the placenta, particularly with the degree of vascularity of the uteroplacenta.

When Meishan and Yorkshire embryos were transferred into both Yorkshire and Meishan recipients, placental surface area of Yorkshire embryos increased throughout the last third of gestation. However, in Meishan conceptuses, placental surface area did not increase during the same gestational period, but placental vascular density increased, doubling from day 70 to day 110 of gestation (Biensen, 1998). This increase was the result of an increase in the number of blood vessels present as well as their diameter. Meishan embryos also exhibited an increase in endometrial vascular density as opposed to Yorkshire or Yorkshire x Meishan cross conceptuses (Biensen et al., 1999). This indicated that the Meishan embryo had increased vascularity going to it, potentially allowing for an increase in blood flow and nutrient exchange.

In 2003, Vonnahme and Ford selected pigs for increased placental efficiency. They found an increase in vascular density between days 70 and 90 of gestation in animals selected for high placental efficiency compared to the low placental efficiency and control groups. Vascular endothelial growth factor (VEGF) was also found to increase with increasing placental efficiency (Vonnahme et al., 2003).

\section{Fetal Nutrition and Nutrient Transport}

The placenta serves numerous functions in its very short lifetime; however the most vital of its functions is nutrient exchange to the fetus. Nutrients are transported out of the dam's blood vessels through the tissue layers separating maternal and fetal vascular systems and into the blood vessels of the fetus. As previously discussed, the porcine placenta is diffuse epitheliochorial meaning that six layers of tissue separate fetal and maternal vascular systems: maternal endothelium, maternal interstitium, maternal epithelium, fetal epithelium, fetal interstitium, and fetal endothelium. Therefore, two components of the uteroplacenta are vital for nutrient transport: 1) vascularity and 2) transport proteins. 
Uteroplacental vasculature is arranged differently for different placental types. These arrangements include concurrent, countercurrent and crosscurrent. In concurrent, the maternal and fetal blood vessels lie parallel to each other with the same direction of flow, allowing for approximately 50\% maximum exchange. Countercurrent exchange is similar to concurrent blood flow in that fetal and maternal blood vessels run next to each other, however with opposing blood flow. This arrangement allows for up to $100 \%$ exchange and is the most efficient, in that it best maintains concentration gradients of metabolites and waste products (Brocking and Harding, 2001). In crosscurrent exchange, fetal and maternal blood vessels lie perpendicular to each other with maternal blood flowing in one direction and fetal blood flowing in both directions. In the pig, the arrangement is cross-countercurrent; this type is a combination of cross and countercurrent arrangements (Leiser and Dantzer, 1988). Exchange capacity of the placenta increases in the last 30-40 days of gestation, consistent with the presence of both countercurrent and crosscurrent blood flow, the development of vasculature on both fetal and maternal sides and the rapid growth of the fetuses (Leiser and Dantzer, 1988).

The second component of nutrient transport is the abundance of transport proteins in the tissue layers separating fetal and maternal blood. Each metabolite transported out of the dam's circulatory system has to be transported with the use of these transporters across each of the six layers separating fetal and maternal blood in the pig placenta. Nutrients transported to the fetus include glucose, amino acids and fatty acids.

Glucose, the primary energy source for fetal use, is transported via hexose transporters, GLUT1 and GLUT3, down a concentration gradient (Robertson and Karp, 1976; Hay, Jr, 1995). The gradient is a result of a concentration of glucose in the fetus which is approximately $70 \%$ of the maternal glucose concentration (Smith and Moe, 1992).

Amino acids are precursors for proteins, neurotransmitters, hormones and nucleotides (Self et al., 2004). Amino acids are transported using a number of transport systems, which are organized into transporting amino acids similar in structure and charge. For example, cationic amino acids are transported via the $\mathrm{y}^{+}$and $\mathrm{b}^{0,+}$, with cationic amino acid transporters 1,2 and 3 (Gao et al., 2009). System 
X-AG transports anionic amino acids and is located in the basal layer of the rat placenta (Sibley et al, 1997).

To date, five fatty acid transport proteins have been discovered: plasma membrane fatty acid binding protein, caveolin, fatty acid translocase, fatty acid transport protein, and an unnamed $56 \mathrm{kD}$ protein (Hui and Bernlohr, 1997). Fatty acids are transferred through the placenta in the non-esterified fatty acid (NEFA) form (Leskanich and Noble, 1999).

In the uteroplacenta, the abundance of nutrient transporters, the density of vasculature and the degree of blood flow all influence nutrient delivery to the fetus. Impaired nutrient delivery and/or placental dysfunction result in disrupted fetal growth and development, potentially to the extent of low birth weight neonates.

\section{Myogenesis}

Muscle development occurs in utero, and while hypertrophy can occur postnatally, muscle fiber number and only slightly change. Along the neurotube of the embryo lies the paraxial mesoderm, which is divided into somites, a portion of which form the precursor to muscle tissue (Figure 1). There are three parts to the somite: sclerotome, dermatome and myotome. The sclerotome will become the vertebrae, the dermatome becomes the skin and the myotome gives rise to muscle. The myotome is further divided into two sections the epimere and hypomere, which consist of myoblasts, or progenitor muscle cells (Gilbert, 2000).

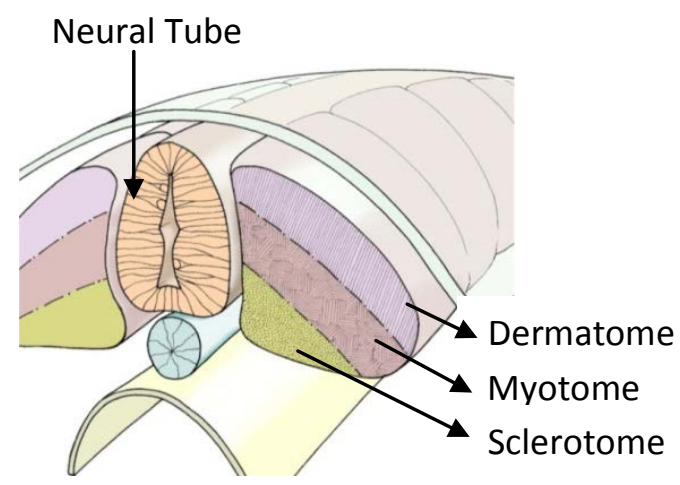

Figure 7. Figure representing neural tube and paraxial somites, arranged in pairs, along each side of the neural tube. 
The hypomere is the lateral portion of the myotome and forms the hypaxial muscles (e.g. every other muscle). The epimere is the medial section of the myotome, lying right against the neural tube and is the precursor for epaxial muscles (e.g. erector spinae muscles and intervertebral muscles).

Hypaxial muscle development, which is the concern of all meat scientists, involves myoblasts migrating out into the body. Muscle development is a biphasic event in both the fetal lamb and the fetal pig (Ashmore et al., 1972, Ashmore et al., 1973). Initially, a primary population of myoblasts will produce primary muscle fibers and the second population gives rise to secondary muscle fibers. Secondary fibers form around the primary fibers in clusters known as facicula. The primary fibers act as scaffolding for the secondary fibers to grow the length of the muscle. Initally development involves hyperplasia of the myoblasts, which is spurred by fibroblast growth factor (FGF). They will continue to proliferate until FGF is depleted and then they will begin to secrete fibronectin which is secreted onto the extracellular matrix (Gilbert, 2000). They also begin to express myogenic determination factor genes that attract other myoblasts. Myoblasts align and fuse together and the cell membranes of each individual myoblast dissolve (Figure 2, Mintz and Baker, 1967). When myoblasts fuse in this manner myotubes are formed.

The myotube is multinucleated due to all of the myoblasts, or cells, that it consists of. Myotube formation occurs in a biphasic fashion during muscle development. The first myotubes to develop form primary muscle fibers, while the second population of myotubes that arise, form secondary muscle fibers. However, not all myoblasts become myotubes. A proportion of myoblasts will remain close to secondary myofibers. These cells are termed satellite cells and have the ability to proliferate and serve as a new source of myonuclei during postnatal growth. They primarily are important for the growth of fibers and regeneration of muscle fibers during postnatal development (Rehfeldt et al., 2000). 


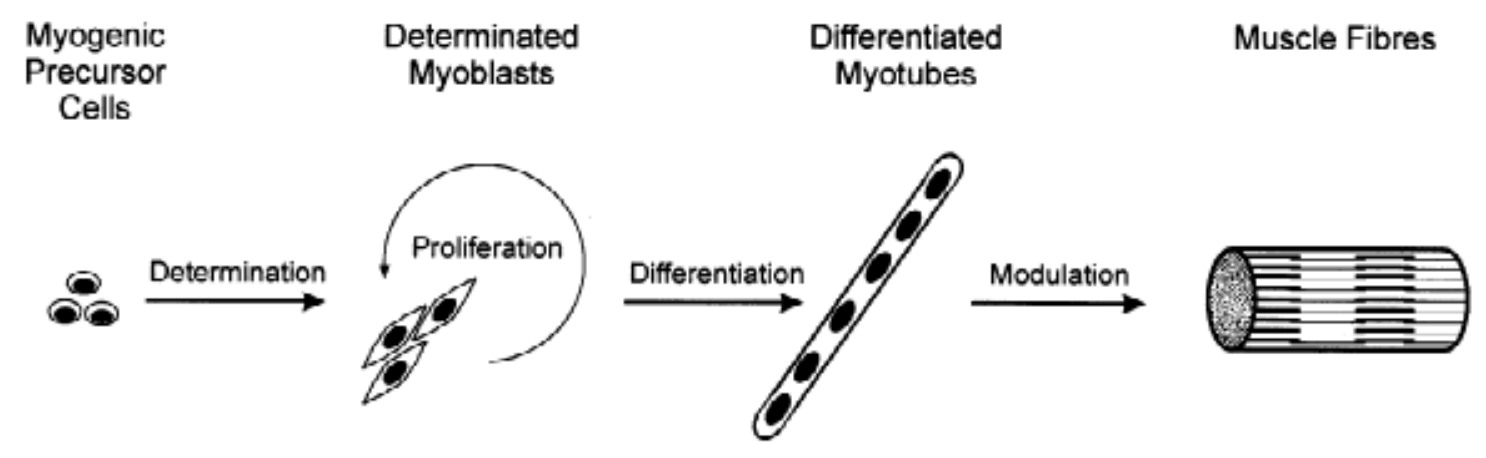

Figure 8. Figure representing development of muscle fibers (Rehfeldt et al., 2000).

\section{Fetal Muscle Growth and Development}

In the pig, muscle development begins by approximately day 35 of gestation with the first myotubes appearing by day 38 (Ashmore et al., 1973, Wigmore and Stickland, 1983). Ashmore and colleagues (1973) obtained fetal pigs on multiple days of gestation and enzymatically stained semitendonosus muscle for adenosine triphosphatase activity. On day 35, some multinucleated myotubes exist, however mononucleated cells are present as well. On day 50 of gestation, size of the myotubes have increased greatly from that seen on day 35. There is a vacuole in the center of each myotube, commonly containing glycogen, although the fibers are unable to utilize glycogen at this time. These myotubes are referred to as primary muscle fibers because they are part of the primary myotube population to form. At day 60 of gestation, the second population of myotubes is present and therefore the secondary muscle fibers are present. These secondary fibers form around the primary fibers, at this stage there are about eight secondary fibers surrounding each primary fiber. The primary fibers still contain a central vacuole though smaller than at day 50; however, very few secondary fibers contain central vacuoles. By day 75 of gestation, the primary and secondary muscle fibers can be differentiated based on the ATPase reaction. The size of the primary fibers has not increased since day 60 and the size of the central vacuole is continuing to decrease. Central vacuoles are absent from all secondary fibers and the number of secondary fibers has increased drastically since day 60. The size of the secondary fibers 
continues to increase, but not uniformly among all secondary fibers. By day 90 of gestation, no new myotubes are formed and muscle growth is reliant upon hypertrophy of secondary fibers only. Due to this, muscle fiber number and types at this stage of gestation are highly reflective of adult muscle fiber number and type (Ashmore et al., 1973). Enzymatic activity has changed by day 110, but no further changes in the primary myotubes and only growth in secondary myotube size has occurred.

The importance of muscle development during gestation is confirmed by evidence that following birth of the animal, the total number of fibers present in the muscle and the size of the primary fibers do not change (Ashmore et al., 1973). Muscle mass is determined by the total number of fibers in the muscle, while the quality of the muscle is determined by the ratio of secondary to primary (S:P) fibers, with particular regard to the number of secondary fibers. However, there is plenty of evidence to show that while the number and size of primary fibers are set during gestation that the size of the secondary fibers are able to change postnatally and can be altered by environmental factors (Maltin et al., 2001).

Litter size is important for litter bearing, meat producing animals, but there may be some concern that litter size is too large. Dziuk (1968) and others have reported that litter sizes greater than 14 lead to uterine crowding and fetuses that are susceptible to intrauterine growth retardation (IUGR; Dziuk, 1968; Town et al., 2004). The defining characteristic of IUGR fetuses is their low birth weight, which has been shown to affect the growth rate of these animals. Wigmore and Stickland (1983) selected the smallest and largest fetuses within a litter and compared the muscle development of the semitendonosus muscle. In the smallest fetuses, the weight of the muscle, the diameters of both primary and secondary fibers, total fiber number and S:P were less than those of the largest fetus. Furthermore, the larger fetuses always had more fibers during any point in gestation and they reached maximum fiber diameter nearly 20 days sooner than smaller fetuses. The results of this study make it possible for one to conclude not only that small fetusesare likely to have decreased muscle quality, but that they also may grow more slowly.

Town and colleagues (2004) also found that semitendonosus muscle weight and cross sectional area as well as the number of secondary fibers were decreased in fetuses in crowded uterine environments compared to those in roomy uterine environments. Dwyer and others (1994) investigated the effect of 
maternal nutrition on fetal muscle development as well as postnatal growth of the animal. The sows that were overfed during the period of fetal muscle development had fetuses with increased S:P compared to control sows, this increase was a result of increased secondary fibers formed. The postnatal growth rates of these animals were also increased compared to animals of control sows. The difference in the number of secondary fibers gives further evidence that they are more sensitive to environmental factors, such as crowded uterine environments and maternal nutrition, both of which could impact postnatal growth and development.

\section{Postnatal Growth and Development of Muscle}

During the postnatal growth of the animal, the muscle will increase in mass and functionality. This growth is the direct result of hypertrophy of muscle fibers (Rehfeldt et al., 2000; Maltin et al., 2001). Satellite cells also play a role in the increase in muscle mass because they are incorporated into existing fibers. However, the extent to which these muscle fibers can grow depends largely on the number of muscle fibers present. The more fibers there are, the less growth will occur; conversely, the fibers will be able to grow bigger if there are fewer fibers within the muscle (Fielder et al., 1997). The characteristics of postnatal muscle are more dependent upon neural and growth factor effects than the prenatal muscle, indicating that environmental conditions or stresses could impact their development (Maltin et al., 2001). However, in meat producing animals lean growth of the muscle, quality of the muscle post-harvest as well as how environmental stressors affect both lean muscle growth and meat quality are of interest.

Some report incidences of conversion of type II fibers into type I fibers occurring postnatally in humans and rats (Maltin et al., 2001). Swatland (1977) reported a growth related increase in the number of fibers with weak oxidative properties in pigs. However, this increase was only observed in the young animal and was complete when piglets reached weights greater than $50 \mathrm{~kg}$. Increases in the proportion of fibers with weak ATPase activity have also been observed in the longissimusdorsi muscle of pigs

(Davies, 1972; Suzuki and Cassens, 1980). Conversely, other reports have indicated that these changes in fiber types do not occur (Ashmore et al., 1972, 1973). 
Lean growth depends on the number of fibers determined prenatally and therefore the amount of hypertrophy that occurs postnatally (Rehfeldt et al., 2000). Henckel and others in 1997 found a positive correlation between muscle mass and both fiber number and type. Stickland and Goldspink (1975) indicated that pigs with more muscle fibers had less fat accumulation, this may be due to nutrient repartitioning following muscle growth. The growth of the fibers in animals with fewer muscle fibers reaches its maximum sooner than fibers in animals with more muscle fibers, nutrients following this plateau are then available for fat deposition within the muscle (Rehfeldt et al., 2000). Subsequently, when maximum fiber growth is reached, lean meat percentage is often compromised (Lengerken et al., 1997; Rehfeldt et al., 2000).

\section{Environmental Factors Affecting Postnatal Muscle Development}

The quality of the meat product from the animal is subject to development of fibers postnatally. This is due to the susceptibility of the type II muscle fibers to be influenced by environmental factors such as nutrition and stress. Stress immediately prior to slaughter causes an increase in the activity of glycolytic fibers of muscle, which rapidly decreases the $\mathrm{pH}$ of the muscle. This rapid decrease in $\mathrm{pH}$ increases the incidence of pale, soft and exudative pork. Additionally, higher counts of white fibers have been found to be correlated with low overall fiber numbers (Fielder et al., 1999).

Recently, a whole field of research based on the Barker hypothesis has been developed. The Barker hypothesis is based on the idea that the nutritional status of the dam during gestation can influence the postnatal development of the fetus, therefore influencing the growth and physiology during later life. Similarly, many have studied the effects of nutritional status of the sow or gilt on the muscle fiber development and meat quality of the piglets. Cerisuelo and colleagues (2009) over fed sows and gilts from day 45-85 of gestation. While they observed increases in average daily gain and gain to feed ratios in nursery piglets whose dams were overfed during midgestation, these observations were not present during the grower/finisher phase. Pigs whose dams were overfed had increased pH 24 hours post mortem, as well as decreased L* rating, which measures the lightness of the meat measured 24 hours post 
mortem. They also had a decreased number of type IIB fibers, however fiber diameter for type IIB fibers was increased. They had decreased total number of fibers, reflected by decreases in both the number of primary and secondary fiber types, consequently no differences in the S:P ratio were detected. Matlin and others (2001), however, report no effect on muscle development when dams are underfed.

In addition to nutrition, stress in the animal's environment can affect its prenatal, and therefore, postnatal growth. Currently, pigs are being housed in individual pens called gestation stalls, which allows for reduced fighting, individual feeding and better husbandry of the animal. However, the stalls measure 2.2 x $0.6 \mathrm{~m}$ (Lammers et al., 2007), so the sow or gilt has enough room to get up or lie down, but not turn around or move very much. The animals will also develop vices such as bar biting, learned helplessness and weaving, or shifting weight from side to side repetitively. Due to this, farrowing stalls are illegal in many states and many swine facilities are using group housing instead. In group housing, the animals are co-mingled in a larger pen. Unfortunately, this format allows for fighting among pen mates, feeding is more difficult as all animals have access to all feeders usually and individual care and husbandry is reduced. However, this format allows for social interaction and increased movement.

The benefits of exercise on maternal and fetal metabolism and fetal development have been reported in ewes (Chandler et al., 1985), rats (Mottola et al., 1983), mice (Rosa et al., 2011) and pigs (Hale et al., 1981). In the ewe, fetal glucose concentrations and uterine uptake of glucose increased during prolonged exercise, however insulin concentrations did not increase until after exercise was complete (Lotgering et al., 1985). Little has been done on the effects of maternal exercise on fetal muscle development; however Mottola and colleagues in 1983 found that maternal exercise in rats did not change the number of fibers or fiber types in rat pup diaphragm muscle. The effects of maternal exercise on the development of fetal pig skeletal muscle would have important implications on pork production. 


\section{STATEMENT OF THE PROBLEM}

Average litter size for domestic commercial breeds (e.g. large white breeds) is 10.3 pigs per litter (NASS, 2011). While litter size has increased from 9.3 in 2009 (NASS, 2009), the capacity for larger litter sizes has yet to be reached. The Chinese Meishan is known to have litters $40 \%$ larger than domestic breeds. This more prolific breed is associated with a placenta that is $40 \%$ smaller than the placentae associated with Large White breeds (Wilson, 1998). Each pig within a litter is associated with its own placenta, larger placentae will occupy more space within the uterus, which is the ultimate restriction to litter size. Importantly, these differences in litter and placental sizes do not only exist between breeds and dams but also exist within individual litters, such that two fetuses within the same litter can be within $4 \%$ body weight of each other, but one placenta is $50 \%$ heavier than the other (Wilmoth, 2009). The ability of the smaller placenta to produce the same size fetus indicates that the efficiency of that placenta to transfer nutrients and support fetal growth is greater than that of the larger placenta. Additionally the smaller placenta will occupy less space in the uterus making more space available for additional fetoplacental units, increasing litter size.

The placenta is an extraordinary organ that serves multiple functions: exchange of nutrients, gases and wastes between the dam and fetus; protection from the dam's immune system, as well as harmful toxicants and chemicals; shock absorber for the fetus; and production of hormones to maintain and regulate pregnancy (Maccani and Marsit, 2009). Relative to litter size and fetal development, the efficiency with which the placenta can transfer nutrients and support a fetus is of utmost importance. Placental efficiency is defined as fetal weight divided by placental weight. Placental weight is highly correlated to placental surface area and is therefore a good indication of general placental size (Biensen et al., 1998). Like placental size, placental efficiency is highly variable not only between breeds and dams, but also within individual litters. When pigs were selected for high placental efficiency, the result was increased litter size and decreased placental size (Wilson et al., 1999). Understanding placental function and nutrient exchange between the dam and the fetus could be of utmost importance when investigating 
the differences between high and low placental efficiency feto-placental units. However, with increased litter sizes and decreased placental weights, decreased fetal weights were also noted (Wilson et al., 1999).

The uterine environment is critical to the development of the offspring while in utero, but also postnatally, essentially setting the animal up for the rest of its life, its growth potential, the onset of adult diseases, and the lifespan of the animal. Importantly for the pork industry, the uterine environment can influence muscle development. The effects of placental efficiency on muscle development are not known, but selection for increased litter size, could be a result of decreased placental size and therefore an altered uterine environment. Town and colleagues (2004) found that when fetuses were exposed to a crowded uterine environment, semitendonosus muscle weight and cross sectional area were both decreased compared to fetuses from a roomy uterine environment. There was a tendency for a decrease in the number of primary muscle fibers and for an increase in the secondary muscle fiber cross sectional area in fetuses form the crowded uterine environment ( $P<0.10$, Town et al., 2004). It is known that increases in the number of secondary muscle fibers and their relative size has negative effects on pork quality (Henckel et al., 1997). Furthermore, it is well known that environmental factors are what influence the development of secondary muscle fibers.

Environmental factors include such things as stress, nutritional status and disease. Currently in the pork industry, gestation stalls are being utilized for pregnant gilts and sows. Gestation stalls have many positive assets including individualized feeding, handling and care, as well as reduced fighting and aggression among animals. However, some negative effects of gestation stalls include reduced ambulation and development of vices. Therefore, gestation stalls are a point of ethical concern and the industry is considering transitioning to group housing. In group housing, animals are housed together, they can be more ambulatory, but it is harder for individualized care and feeding and animals are in contact with each other leading to aggression. Several authors have reported the benefits of exercise during gestation in species such as the rat and sheep, however little is known about the effects of exercise in pregnant pigs, particularly how it affects the metabolism of the fetus and fetal development including muscle development. 
Placental efficiency is a heritable trait, ultimately influencing placental size which may affect fetal development and postnatal performance. Therefore, the objectives of the current work are to determine the nutrient exchange differences between high and low placental efficiency feto-placental units and how fetal muscle development is affected, investigate the effect of placental efficiency on postnatal growth performance and pork quality and, finally, to examine the effect of exercise on fetal metabolism and development. 


\title{
ALTERATIONS IN FETAL MUSCLE DEVELOPMENT IN HIGH AND LOW PLACENTAL EFFICIENCY FETUSES
}

\author{
T.A. Wilmoth and M.E. Wilson \\ Division of Animal and Nutritional Sciences, Davis College ofAgriculture, Natural Resources \\ and Design, West Virginia University Morgantown, West Virginia, USA
}

Address all correspondence and requests for reprints to: Matthew E. Wilson, Division of Animal and Nutritional Sciences, Davis College of Agriculture, Natural Resources and Design, West Virginia University, P.O. Box 6108, Room G038, Morgantown, West Virginia 26506. E-mail: Matt.Wilson@mail.wvu.edu. This work is published with the approval of the Director of West Virginia Agriculture and Forestry Experiment Station as scientific paper /. This project was supported by Hatch project 468 (NCERA 057).

Key Words:placental efficiency, pigs, gestation, muscle development 
ABSTRACT: Placental efficiency (fetal weight divided by placental weight) is known to be a measure of placental function. Placental function has been related to fetal development, including the development of muscle in utero. By day 100 of gestation, muscle development is complete in the pig. Muscle development occurs in two phases in which two populations of muscle fibers are formed, the first population forms primary muscle fibers and the second produces secondary muscle fibers. Once these fibers form, the number of those fibers does not change throughout the animal's postnatal life. Importantly, the ratio of secondary to primary muscle fibers, a measure of pork quality, does not change during postnatal development as growth of the muscle is mostly hypertrophic. Muscle development in utero is known to be related to both fetal and placental weights. Therefore, the objective of the current study was to determine the effects of placental efficiency at day 95 of gestation of the muscle development of the fetuses and also to determine any relationships that may exist between placental efficiency and fetal growth and development variables. Camborough 23 gilts $(\mathrm{n}=8)$ were bred and assigned to ovariohysterectomy on day 95 of gestation. At the time of surgery, fetuses were exteriorized from the uterus, umbilical blood samples taken and then removed and necropsied. Longissimusdorsi (LD) and semitendonosus (ST) muscle samples were collected and used to determine muscle fiber number and size. After hysterectomy, the uterus was processed and placentae removed and weighed for determination of placental efficiency. The three highest and three lowest placental efficiency feto-placental units were selected from each litter and effects were determined by ANOVA using the GLM procedures of SAS ( $n=48)$. Relationships among variables were determined by the correlation procedures of SAS among all fetuses of all litters $(n=86)$. No differences in fetal, organ or muscle weights, crown-rump length, girth or implantation site length were found between high and low placental efficiency fetuses. Placental 
weight was decreased in fetuses in the high placental efficiency group. Primary muscle fiber size was increased in both LD and ST muscles in the low placental efficiency group and secondary muscle fiber size in LD tended to be greater in these fetuses. Relationships existed between fetal and placental weights and muscle characteristics, indicating a role of sufficient placental function for in utero muscle development.

Key Words:placental efficiency, pigs, gestation, muscle development

\section{INTRODUCTION}

Placental efficiency, fetal weight divided by placental weight, has been used as a measure of placental function. Initially, placental efficiency was observed as a means to explain differences in litter size between domestic and foreign breeds of pigs. The discovery of smaller, more vascularized placenta in these more prolific pigs led to investigations of placental impact on fetal development. In 1999, Wilson and colleagues selected high and low placental efficiency fetuses at birth. Gilts were bred to boars of their respective placental efficiencygroup at maturity. The resulting litters were larger with smaller placenta as observed in the more prolific breeds, however neonatal size was reduced by approximately $22 \%$.

Several authors have reported on the negative effects associated with reduced weight at

birth. However, low birth weight neonates are defined as having a birth weight in the $10^{\text {th }}$ percentile, which is an approximately $40 \%$ reduction in birth weight compared to neonates of normal birth weight in the $90^{\text {th }}$ percentile (Wollmann, 1998). With only a $22 \%$ reduction in fetal size, these fetuses were not in danger of intrauterine growth restrticion, however the relative degree of fetal development due to uterine environment and placental function could be implicated. Low birth weight piglets have higher mortality rates and take longer to reach market 
weight than normal birth weight littermates (Finch et al, 2004, Wolter et al., 2002). In fact, Gondret and colleagues (2006) found that it took low birth weight piglets 12 additional days to reach market weight than normal birth weight counterparts.

Importantly, although controversial, low birth weight could negatively affect in utero muscle development and as a result meat quality (Gondret et al., 2004, Bee, 2004). Low birth weight pigs had increased back fat thickness, intramuscular adipocyte size and lipid content (Gondret et al., 2006). Low birth weight pigs also had decreased cross sectional area of muscle fibers in semitendonosus (ST) and longissimusdorsi (LD) muscles, as well as decreased ST weight and total number of fibers (Gondret et al., 2006).

The objective of the current work was to determine how placental efficiency affected in utero muscle development, fetal development and fetal metabolism and how these variables may be related to each other.

\section{MATERIALS AND METHODS}

All procedures were approved by the West Virginia University Animal Care and Use Committee (ACUC \# 10-0505).

\section{Animal Management}

Eight Camborough 23 gilts were bred by artificial insemination 12 and 24 hours following the onset of estrus with PIC 1025 maternal line semen (Birchwood Genetics, West Manchester, $\mathrm{OH})$. At the time of breeding, gilts were assigned to ovario-hysterectomy on day 95 of gestation. Gilts were group housed and managed similarly until the time of surgery. 


\section{Surgical Procedures}

Gilts were moved to the Food Animal Research Facility at the West Virginia University Animal Science Farm at least two days prior to surgery and were taken off feed 12 hours prior to surgery. Gilts were anesthetized using a ketamine (2 mg/kg) and xylazine (3 mg/kg) cocktail and anesthesia was maintained using inhalant isoflurane.

The gravid uterus was exposed via a mid ventral incision. Beginning with the left uterine horn, working from tip (closest to the ovary) to base (closest to cervix), umbilical vein and artery samples were collected and stored with EDTA (20 $\mu \mathrm{L} /$ tube) on ice until plasma could be collected. The umbilical cord was cut and umbilical clamps were placed on both the piglet and placenta with matching numbers. The piglet was then removed, weighed, measured for girth and crown-rump length and necropsied. This was done for each piglet in the litter.

Following removal of all fetuses, the uterus was removed via cervical transsection and placed aside for processing. The gilt was euthanized using sodium pentobarbital $(100 \mathrm{mg} / \mathrm{kg}$, Sigma Aldrich, St. Louis, MO).

\section{Fetal Necropsies and Uterine Processing}

Fetal heart, livers and brains were removed and weighed. Longissimus dorsi (LD) and semitendonosus muscle samples were taken and stored in O.C.T. medium (Tissue Tek, Sakura Finetek USA Inc., Torrance, CA) and frozen in liquid nitrogen chilled isopentane in Peel-A-Way disposable embedding molds (Thermo Fisher Scientific, Inc, Pittsburgh, PA) and stored at $-80^{\circ}$ C. The LD sample was taken near the last rib on the left side of the fetus. The entire ST muscle 
was removed from the left hindquarter and weighed. The ST muscle was bisected midmuscle and stored in O.C.T. medium, cut side down.

After the broad ligament was removed, the uterus was cut along the antimesometrial side and laid out flat. For each placenta, an approximately $5 \mathrm{~cm}^{2}$ uteroplacental cross section was taken, placed in histology cassettes and stored in $10 \%$ buffered formalin. Each chorio-allantois was then peeled away from the endometrium and weighed. Fetal weight was divided by placental weight to determine placental efficiency. The length of the implantation site was also recorded for each feto-placental unit.

\section{Fetal Metabolites}

Fetal blood samples were centrifuged at $1000 \mathrm{xg}$ for 20 minutes at $4^{\circ} \mathrm{C}$. Plasma was removed and frozen at $-20^{\circ} \mathrm{C}$ until assays could be performed. Fetal glucose concentrations were determined using a glucose assay kit from Cayman Chemical Company (Ann Arbor, MI). Assays were performed according to the manufacturer's directions and the absorbance determined using a spectrophotometer (SpectraMaxPlus 384, Molecular Devices, Sunnyvale, CA) at $515 \mathrm{~nm}$. Non-esterified fatty acid (NEFA) concentrations in fetal blood were determined using the NEFA-HR kit following the manufacturer's instructions (Wako Chemicals, Richmond, VA).

For both NEFA and glucose concentrations, the umbilical artery and venous concentrations were used to calculate the veno-arterial (VA) differences by subtracting the arterial concentrations from the venous concentrations. This was done as a way of determining net direction of the metabolite (i.e. towards the fetus or towards the uteroplacental unit). 


\section{Vascular Density}

Uteroplacental cross sections were fixed in 10\% buffered formalin, dehydrated with graded ethanol and xylenes and perfused with molten paraffin, similar to the procedure Koch et al., 2007 used. The cross sections were then formed in molds. Four $\mu \mathrm{m}$ sections were taken and fixed on charged glass microscope slides. Two sections of each cross section was stained using periodic acid (Sigma Aldrich, St. Louis, MO) and Schiff's reagent (Sigma Aldrich, St. Louis, MO). One image of each section was visualized by Nikon Eclipse TE2000-5 inverted microscope and captured by camera (Retiga 2000R, Q Imaging, Surrey, BC, Canada) and imaging software (Q Capture, Quantitative Imaging Corporation, v2.90.1, Surrey, BC, Canada). Images were analyzed by Northern Eclipse image analysis software (Empix, Inc., v6.0, North Tonawanda, NY). The chorio-allantois and endometrium were outlined using a drawing tool, one at a time. The program then measured the number of objects, total area and the area of the objects of the selected area only. Percentage of vasculature was determined by dividing the area of the vessels by the total selected area.

\section{ATPase Assay}

ST and LD muscles were sectioned into $10 \mu \mathrm{m}$ sections using Cryotome FSE (Thermo Scientific, Kalamazoo, MI). Sections were fixed onto glass slides and stored at $-80^{\circ} \mathrm{C}$. ATPase assay was performed utilizing an acid pre-incubation buffer (Ashmore et al., 1973). This resulted in the primary fibers staining black while the secondary fibers were grey in color. Two sections of each muscle were stained per fetus and one image of each section was visualized using a Nikon Eclipse TE2000-5 inverted microscope and captured by camera (Retiga 2000R, Q 
Imaging, Surrey, BC, Canada) and imaging software (Q Capture, Quantitative Imaging Corporation, v2.90.1, Surrey, BC, Canada). Images were then analyzed by Northern Eclipse (Empix, Inc., v6.0, North Tonawanda, NY). Numbers and diameters of primary and secondary fibers were measured in four images for each muscle type. Measurements were averaged across images for each muscle. The secondary to primary (S:P) ratio of fibers, as an indicator of meat quality, was also determined for each muscle type.

\section{Statistical Analysis}

The three highest $(n=24)$ and the three lowest $(n=24)$ placental efficiency feto-placental units were selected from each litter and used to make comparisons based on placental efficiencies. Runt piglets were excluded from the selection of the highest and lowest placental efficiency feto-placental units. The GLM procedures of SAS were used. Means were separated by an LSMeans statement and means \pm SEM are reported. Differences were significant when $P<$ 0.05 and were considered to be a trend when $P<0.10$. All feto-placental units from all litters $(\mathrm{n}=86)$ were used to determine associations between all variables by using the correlation procedures of SAS.

\section{RESULTS}

\section{Surgical and Necropsy Data}

Fetal weights were not different between high and low placental efficiency feto-placental units (853.63 \pm 56.21 vs $887.56 \pm 56.21, P<0.67$ ). Heart, liver, brain and semitendonosus weights, crown-rump length, girth and implantation site length were also not different based on 
placental efficiency $(P>0.40)$. Placental weight was decreased in fetuses of high placental efficiency compared to fetuses of low placental efficiency $(198.56 \pm 18.36$ vs $321.57 \pm 18.36, P$ $<0.0001$, Figure 9). Semitendonosus weight was positively correlated with fetal weight, placental weight and implantation site length (Table 1). Chorio-allantois vascular density was positively correlated with the size of secondary fibers in $\operatorname{LD}(P<0.05$, Table 7)

\section{Fetal Metabolites and Vascular Density}

No differences were detected based on placental efficiency for umbilical arterial, venous or VA differences of glucose and NEFA concentrations (Table 2). No differences were detected in vascular density for either chorio-allantois or endometrial tissue based on placental efficiency (Table 2).

\section{Fetal Muscle Characteristics}

For LD muscle, the diameter and area of primary fibers were increased in fetuses selected as low placental efficiency compared to high placental efficiency fetuses $(P<0.05$, Table 3$)$. The diameter and area of secondary fibers in LD tended $(P<0.10$, Table 3$)$ to be increased in low placental efficiency fetuses versus high placental efficiency fetuses.

In ST muscle, the diameter and area of primary muscle fibers was increased in low placental efficiency fetuses compared to high placental efficiency fetuses $(P<0.05$, Table 3$)$.

Fetal weight was positively correlated with LD primary and secondary fiber size and ST

secondary fiber size. Fetal weight was negatively correlated with the number of primary and secondary muscle fibers $(P<0.05$, Table 4$)$. 
Placental weight was positively correlated with LD primary and secondary fiber size, the LD S:P ratio, and area of secondary fibers in ST. Negative correlations were observed between the number of primary and secondary fibers in ST and placental weight $(P<0.05$, Table 5). A trend for a negative correlation was observed for ST secondary fiber diameter and placental weight $(P<0.10$, Table 5).

Semitendonosus weight was negatively correlated with ST secondary fiber size $(P<0.05$, Table 6), but positively correlated with ST primary and secondary fiber number $(P<0.05$, Table 6). Placental vascular density tended to be positively correlated with the size of secondary fibers in $\operatorname{LD}(P<0.10$, Table 7). The VA NEFA was negatively correlated with the number of primary fibers in LD, and tended to be correlated to the S:P ratio of LD and the area of secondary fibers in ST (Table 8). The VA difference in glucose was negatively correlated with the size of secondary fibers in ST and tended to be positively correlated with the number of primary fibers in ST (Table 8).

\section{DISCUSSION}

Fetal, organ and muscle weights, crown-rump length, girth and implantation site length were not affected by placental efficiency. The variation that exists within litter in placental efficiency is vast. In fact, piglets within $4 \%$ body weight of each other can be grown on placentae of very different sizes, with one placenta being 50\% heavier than the other (Wilmoth, 2009). The lack of effect of placental efficiency on fetal weight and growth variables could be explained by this. Placental weight was decreased in the high placental efficiency group as was expected (Wilson et al., 1999). 
The lack of change in vascular density and metabolite concentrations is of interest as a hallmark of high placental efficiency placentae is a smaller placental surface area with the capacity to transfer a similar amount of nutrients (Wilson et al., 1998, Biensen et al., 1998, 1999), potentially resulting in greater nutrient transfer per gram of placenta. Wilmoth (2009) found no difference in nutrient transporter mRNA expression in the placenta or endometrium. However, nutrient transporters and the amount of vascularity as well as blood flow to the placenta affect nutrient delivery to the fetus.

In both LD and ST muscles, primary fiber size was increased in low placental efficiency fetuses. There was a trend for an increase in the size of secondary muscle fibers in LD. These low placental efficiency feto-placental units could be setting up a mild nutrient restriction to the fetus and altering muscle development. Aberle (1984) reported that fetal growth retardation due to insufficient placental function resulted in a decrease of the number of secondary muscle fibers. While this was not observed here, it is known that in cases of reduced fiber number the fibers will undergo hypertrophy to compensate for the lack of muscle fibers. Additionally, both primary and secondary ST muscle fiber number, as well as the size of secondary fibers, was negatively correlated with placental weight.

The smallest fetus in the litter was found to have decreased size of both primary and secondary fibers, decreased total fiber number and decreased S:P ratio in the LD muscle (Wigmore and Strickland, 1983). Fetal weight was found to be negatively correlated with the number of secondary and primary fibers in ST muscle, indicating that smaller fetuses will develop more muscle fibers which could limit the size to which those fibers grow.

Reynolds and colleagues (2005) reported that placental vascularity is a better predictor of birth weight than placental weight, here we see that placental vascular density is positively 
correlated to secondary fiber size in LD, which is also positively related to fetal weight. Given this, placental vascularity may also be an indicator of muscle development.

In conclusion, differences in placental efficiency at day 95 of gestation influences fetal muscle development. Primary and secondary fiber sizes were increased in low placental efficiency fetuses, indicating a potential for a decreased meat quality at harvest. 


\section{REFERENCES}

Aberle, A. D. 1984. Myofiber differentiation in skeletal muscles of newborn runt and normal weight pigs. J. Anim. Sci. 59:1651-1656.

Ashmore, C.R., P.B. Addis and L. Doerr. 1973. Development of muscle fibers in the fetal pig. J. Anim. Sci. 36(6):1088-1093.

Bee, G. 2004.Effect of early gestation feeding, brith weight, and gender of progeny on muscle fiber characteristics of pigs at slaughter. J. Anim. Sci. 82:826-836.

Biensen, N.J., M.E. Wilson and S.P. Ford. 1998. The impact of either a Meishan or Yorkshire uterus on Meishan or Yorkshire fetal and placental development to days 70, 90, and 110 of gestation. J. Anim. Sci. 76:2169-2176.

Biensen, N.J., M.E. Wilson and S.P. Ford. 1999. The impacts of uterine environment and fetal genotype on conceptus size and placental vascularity during late gestation in pigs. J. Anim. Sci. 77:954-959.

Finch, A.M., L.G. Yang, M.O. Nwagwu, K.R. Page, H.J. McArdle and C.J. Ashworth. 2004. Placental transport of leucine in a porcine model of low birth weight. Reprod. 128:229-235.

Gondret, F., L. Lefaucheur, H. Juin, I. Louveau and B. Lebret. 2006. Low birth weight is associated with enlarged muscle fiber area and impaired meat tenderness of the longissimus muscle in pigs. J. Anim. Sci. 84:93-103.

Koch, J. M., J. S. Moritz, D. C. Lay, Jr. and M. E. Wilson. 2007. Effect of melengestrol acetate as an alternative to induce molting in hens on the expression of yolk proteins and turnover of oviductal epithelium. Anim. Reprod. Sci. 102:14-23. 
Reynolds, L. P., P. P. Borowicz, K. A. Vonnahme, M. L. Johnson, A. T. Grazul-Bilska, J. M. Wallace, J. S. Caton and D. A. Redmer. 2005. Animal models of placental angiogenesis. Placenta. 26:689-708.

Wigmore, P.M.C. and N.C. Stickland. 1983. Muscle development in large and small pig fetuses. J. Anat. 137(2):235-245.

Wilmoth, T. (2009). Variation in, and contributing factors of placental efficiency in swine.(Master’s thesis).Retrieved from ProQuestDisserations and Theses. West Virginia University, 2009. 1471825.

Wilson, M.E., N.J. Biensen, C.R. Youngs and S.P. Ford. 1998. Development of Meishan and Yorkshire littermate conceptuses in either a Meishan or Yorkshire uterine environment to day 90 of gestation and to term. Biol. Reprod. 58:905-910.

Wilson, M.E., N.J. Biensen and S.P. Ford. 1999. Novel insight into the control of litter size in pigs, using placental efficiency as a selection tool. J.Anim.Sci. 77:1654-1658.

Wollmann, H. A. 1998. Intrauterine growth restriction: definition and etiology. Horm. Res. 49:16.

Wolter, B. F., M. Ellis, B. P. Corrigan and J. M. DeDecker. 2002. The effect of birth weight and feeding of supplemental milk replacer to piglets during lactation on pre-weaning and post-weaning growth performance and carcass characteristics. J. Anim. Sci. 80:301-308. 


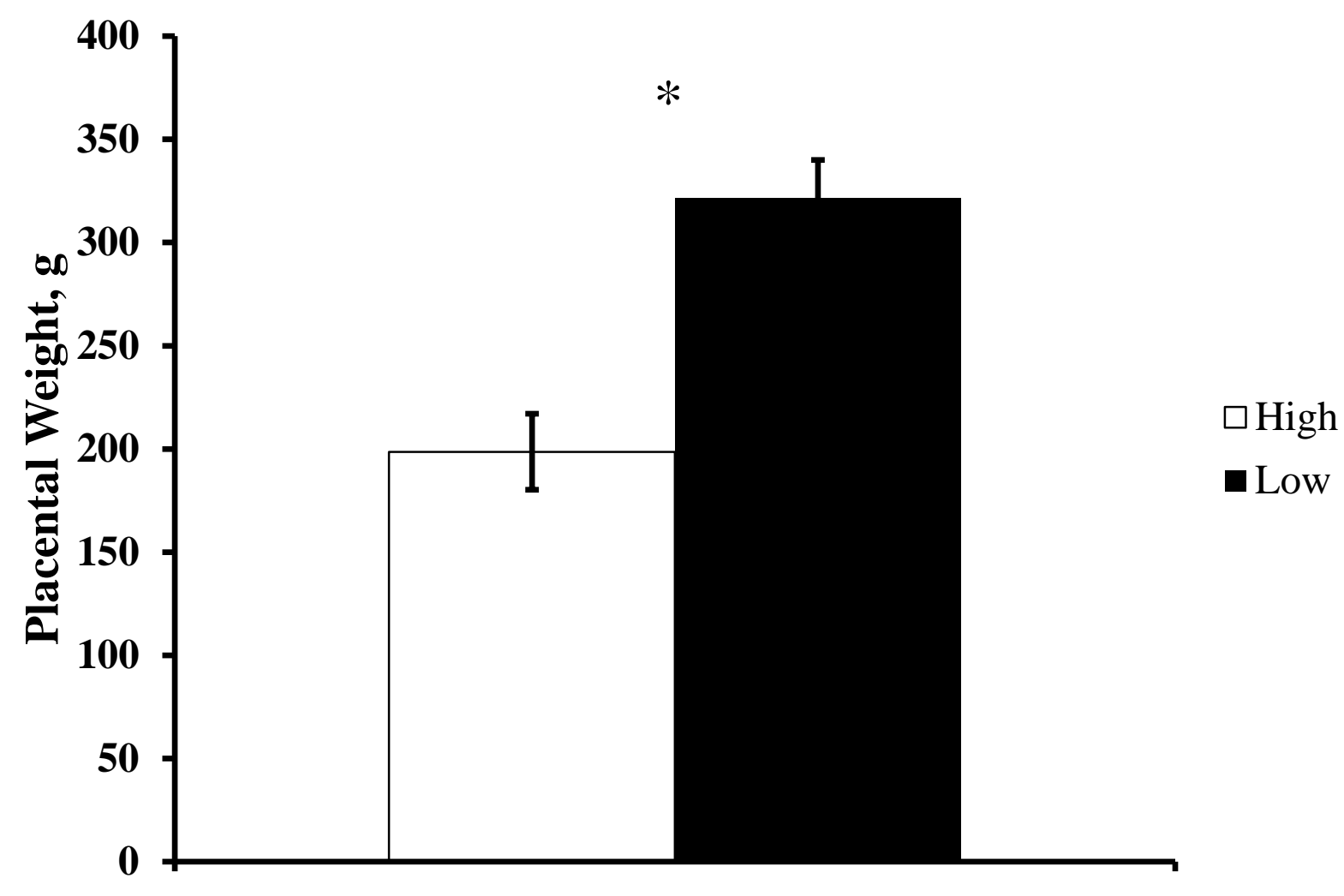

Figure 9. Placental weight (g) of high placental efficiency feto-placental units (open bars) and low placental efficiency feto-placental units (closed bars). Means \pm SEM, $\mathrm{P}<0.0001$. 
Table 1. Correlations between ST weight and fetal and placental characteristics

\begin{tabular}{lcc}
\hline \hline \multicolumn{1}{c}{ Variables } & r & P - value \\
\hline ST Weight (g) and Fetal Weight (g) & 0.9 & $<0.001$ \\
ST Weight (g) and Placental Weight (g) & 0.62 & $<0.001$ \\
ST Weight (g) and Implantation Length (cm) & 0.46 & 0.002 \\
\hline
\end{tabular}


Table 2. Vascular Density and Metabolite Concentrations

\begin{tabular}{lccc}
\hline \hline \multirow{2}{*}{\multicolumn{1}{c}{ Variable }} & \multicolumn{2}{c}{ Group } & \\
\cline { 2 - 3 } & & High & $\boldsymbol{P}$ - value \\
\hline Vascular Density, \% & $5.50 \pm 0.82$ & $7.33 \pm 0.83$ & 0.13 \\
Chorio-Allantois VD & $5.48 \pm 0.82$ & $6.54 \pm 0.84$ & 0.37 \\
Endometrial VD & $29.33 \pm 2.24$ & $31.77 \pm 2.24$ & 0.45 \\
Metabolite Concentrations, & mmol & & \\
Umbilical Artery Glucose & $33.15 \pm 1.56$ & $33.19 \pm 1.56$ & 0.52 \\
Umbilical Vein Glucose & $3.83 \pm 1.16$ & $1.42 \pm 1.16$ & 0.15 \\
VA Glucose & $0.07 \pm 0.001$ & $0.069 \pm 0.001$ & 0.42 \\
Umbilical Artery NEFA & $0.072 \pm 0.001$ & $0.073 \pm 0.001$ & 0.55 \\
Umbilical Vein NEFA & $0.0027 \pm 0.001$ & $0.0039 \pm 0.001$ & 0.59 \\
VA NEFA & &
\end{tabular}


Table 3. Fetal Muscle Characteristics

\begin{tabular}{lccc}
\hline \multirow{2}{*}{\multicolumn{1}{c}{ Variable }} & \multicolumn{2}{c}{ Treatment } & \\
\cline { 2 - 3 } & High & Low & P - value \\
\hline LD Primary Fiber Number & $19.8 \pm 1.85$ & $16.9 \pm 1.85$ & 0.27 \\
LD Primary Diameter, $\mu \mathrm{m}$ & $13.2 \pm 0.4$ & $14.7 \pm 0.4^{\mathrm{a}}$ & 0.01 \\
LD Primary Area, $\mu \mathrm{m}^{2}$ & $139.3 \pm 9.8$ & $173.8 \pm 9.8^{\mathrm{a}}$ & 0.02 \\
LD Secondary Fiber Number & $461.7 \pm 21.8$ & $502.1 \pm 21.8$ & 0.20 \\
LD Secondary Diameter, $\mu \mathrm{m}$ & $10.0 \pm 0.3$ & $10.7 \pm 0.3$ & 0.09 \\
LD Secondary Area, $\mu m^{2}$ & $80.0 \pm 4.8$ & $92.3 \pm 4.8$ & 0.08 \\
ST Primary Fiber Number & $15.4 \pm 1.2$ & $14.9 \pm 1.2$ & 0.75 \\
ST Primary Diameter, $\mu \mathrm{m}$ & $16.5 \pm 0.6$ & $18.1 \pm 0.6^{\mathrm{a}}$ & 0.05 \\
ST Primary Area, $\mu m^{2}$ & $214.8 \pm 17.1$ & $265.5 \pm 17.1^{\mathrm{a}}$ & 0.04 \\
ST Secondary Fiber Number & $461.1 \pm 25.9$ & $458.6 \pm 25.9$ & 0.94 \\
ST Secondary Diameter, $\mu \mathrm{m}$ & $11.4 \pm 0.4$ & $11.7 \pm 0.4$ & 0.55 \\
ST Secondary Area, $\mu m^{2}$ & $103.6 \pm 7.3$ & $110.1 \pm 7.3$ & 0.53 \\
\hline
\end{tabular}

${ }^{\mathrm{a}}$ Means within a row differ, $P<0.05$. 
Table 4. Correlations between fetal weight and muscle fiber size

\begin{tabular}{lcc}
\hline \hline \multicolumn{1}{c}{ Variables } & r & P - value \\
\hline Fetal Weight $(\mathrm{g})$ and LD Primary Fiber Number & -0.11 & 0.46 \\
Fetal Weight $(\mathrm{g})$ and LD Primary Diameter $(\mu \mathrm{m})$ & 0.48 & $<0.001$ \\
Fetal Weight (g) and LD Primary Area $\left(\mu \mathrm{m}^{2}\right)$ & 0.47 & 0.001 \\
Fetal Weight (g) and LD Secondary Fiber Number & -0.07 & 0.66 \\
Fetal Weight (g) and LD Secondary Diameter $(\mu \mathrm{m})$ & 0.54 & $<0.001$ \\
Fetal Weight (g) and LD Secondary Area $\left(\mu \mathrm{m}^{2}\right)$ & 0.52 & 0.0002 \\
Fetal Weight (g) and ST Primary Fiber Number & -0.44 & 0.002 \\
Fetal Weight (g) and ST Primary Diameter $(\mu \mathrm{m})$ & 0.10 & 0.53 \\
Fetal Weight (g) and ST Primary Area $\left(\mu \mathrm{m}^{2}\right)$ & 0.11 & 0.45 \\
Fetal Weight (g) and ST Secondary Fiber Number & -0.46 & 0.002 \\
Fetal Weight (g) and ST Secondary Diameter $(\mu \mathrm{m})$ & 0.29 & 0.05 \\
Fetal Weight (g) and ST Secondary Area $\left(\mu \mathrm{m}^{2}\right)$ & 0.28 & 0.06 \\
\hline
\end{tabular}


Table 5. Correlations between placental weight and muscle characteristics

\begin{tabular}{|c|c|c|}
\hline Variables & $\mathbf{r}$ & $P$ - value \\
\hline Placental Weight (g) and LD Primary Fiber Number & -0.17 & 0.25 \\
\hline Placental Weight (g) and LD Primary Diameter $(\mu \mathrm{m})$ & 0.54 & 0.0001 \\
\hline Placental Weight (g) and LD Primary Area $\left(\mu \mathrm{m}^{2}\right)$ & 0.54 & 0.0001 \\
\hline Placental Weight (g) and LD Secondary Fiber Number & 0.15 & 0.30 \\
\hline Placental Weight (g) and LD Secondary Diameter $(\mu \mathrm{m})$ & 0.49 & 0.0006 \\
\hline Placental Weight (g) and LD Secondary Area $\left(\mu \mathrm{m}^{2}\right)$ & 0.48 & 0.0007 \\
\hline Placental Weight (g) and LD S:P Ratio & 0.3 & 0.04 \\
\hline Placental Weight (g) and ST Primary Fiber Number & -0.41 & 0.005 \\
\hline Placental Weight (g) and ST Primary Diameter $(\mu \mathrm{m})$ & 0.14 & 0.35 \\
\hline Placental Weight (g) and ST Primary Area $\left(\mu \mathrm{m}^{2}\right)$ & 0.18 & 0.24 \\
\hline Placental Weight (g) and ST Secondary Fiber Number & -0.40 & 0.006 \\
\hline Placental Weight (g) and ST Secondary Diameter ( $\mu \mathrm{m})$ & -0.25 & 0.09 \\
\hline Placental Weight (g) and ST Secondary Area $\left(\mu \mathrm{m}^{2}\right)$ & 0.24 & 0.10 \\
\hline Placental Weight (g) and ST S:P Ratio & 0.18 & 0.22 \\
\hline
\end{tabular}


Table 6. Correlations between ST weight and ST muscle characteristics

\begin{tabular}{lcc}
\hline \hline \multicolumn{1}{c}{ Variables } & r & $\boldsymbol{P}$ - value \\
\hline ST Weight $(\mathrm{g})$ and ST Primary Fiber Number & 0.43 & 0.005 \\
ST Weight $(\mathrm{g})$ and ST Primary Diameter $(\mu \mathrm{m})$ & 0.04 & 0.79 \\
ST Weight $(\mathrm{g})$ and ST Primary Area $\left(\mu \mathrm{m}^{2}\right)$ & 0.05 & 0.78 \\
ST Weight $(\mathrm{g})$ and ST Secondary Fiber Number & 0.42 & 0.005 \\
ST Weight (g) and ST Secondary Diameter $(\mu \mathrm{m})$ & -0.38 & 0.01 \\
ST Weight $(\mathrm{g})$ and ST Secondary Area $\left(\mu \mathrm{m}^{2}\right)$ & -0.52 & 0.0004 \\
\hline
\end{tabular}


Table 7. Correlations between vascular density and muscle characteristics

\begin{tabular}{lcc}
\hline \multicolumn{1}{c}{ Variables } & r & P - value \\
\hline Chorio-Allantois Vascular Density (\%) and LD Primary Fiber Number & -0.01 & 0.93 \\
Chorio-Allantois Vascular Density (\%) and LD Primary Diameter $(\mu \mathrm{m})$ & 0.18 & 0.26 \\
Chorio-Allantois Vascular Density (\%) and LD Primary Area $\left(\mu \mathrm{m}^{2}\right)$ & 0.17 & 0.28 \\
Chorio-Allantois Vascular Density (\%) and LD Secondary Fiber Number & 0.18 & 0.25 \\
Chorio-Allantois Vascular Density (\%) and LD Secondary Diameter $(\mu \mathrm{m})$ & 0.25 & 0.10 \\
Chorio-Allantois Vascular Density (\%) and LD Secondary Area $\left(\mu \mathrm{m}^{2}\right)$ & 0.26 & 0.09 \\
Chorio-Allantois Vascular Density (\%) and LD S:P Ratio & -0.06 & 0.70 \\
Chorio-Allantois Vascular Density (\%) and STPrimary Fiber Number & 0.02 & 0.90 \\
Chorio-Allantois Vascular Density (\%) and STPrimary Diameter $(\mu \mathrm{m})$ & -0.04 & 0.81 \\
Chorio-Allantois Vascular Density (\%) and STPrimary Area $\left(\mu \mathrm{m}^{2}\right)$ & -0.004 & 0.98 \\
Chorio-Allantois Vascular Density (\%) and ST Secondary Fiber Number & -0.18 & 0.25 \\
Chorio-Allantois Vascular Density (\%) and ST Secondary Diameter $(\mu \mathrm{m})$ & 0.05 & 0.76 \\
Chorio-Allantois Vascular Density (\%) and ST Secondary Area $\left(\mu \mathrm{m}^{2}\right)$ & 0.04 & 0.79 \\
Chorio-Allantois Vascular Density (\%) and STS:P Ratio & -0.18 & 0.25 \\
\hline
\end{tabular}


Table 8. Correlations between fetal metabolites and muscle characteristics

\begin{tabular}{lcc}
\hline \multicolumn{1}{c}{ Variables } & r & P - value \\
\hline \hline VA Glucose (mmol) and LD Primary Fiber Number & 0.10 & 0.53 \\
VA Glucose (mmol) and LD Primary Fiber Diameter $(\mu \mathrm{m})$ & -0.32 & 0.04 \\
VA Glucose (mmol) and LD Primary Fiber Area $\left(\mu \mathrm{m}^{2}\right)$ & -0.33 & 0.03 \\
VA Glucose (mmol) and LD Secondary Fiber Number & -0.14 & 0.37 \\
VA Glucose (mmol) and LD Secondary Diameter $(\mu \mathrm{m})$ & -0.25 & 0.09 \\
VA Glucose (mmol) and LD Secondary Area $\left(\mu \mathrm{m}^{2}\right)$ & -0.27 & 0.07 \\
VA Glucose (mmol) and LD S:P Ratio & -0.10 & 0.54 \\
VA Glucose (mmol) and ST Primary Fiber Number & 0.25 & 0.10 \\
VA Glucose (mmol) and ST Primary Fiber Diameter $(\mu \mathrm{m})$ & -0.09 & 0.57 \\
VA Glucose (mmol) and ST Primary Fiber Area $\left(\mu \mathrm{m}^{2}\right)$ & -0.09 & 0.58 \\
VA Glucose (mmol) and ST Secondary Fiber Number & 0.18 & 0.23 \\
VA Glucose (mmol) and ST Secondary Diameter $(\mu \mathrm{m})$ & -0.29 & 0.05 \\
VA Glucose (mmol) and ST Secondary Area $\left(\mu \mathrm{m}^{2}\right)$ & -0.27 & 0.08 \\
VA Glucose (mmol) and ST S:P Ratio & -0.10 & 0.52 \\
VA NEFA (mmol) and LD Primary Fiber Number & -0.42 & 0.004 \\
VA NEFA (mmol) and LD Primary Fiber Diameter $(\mu \mathrm{m})$ & 0.06 & 0.69 \\
VA NEFA (mmol) and LD Primary Fiber Area $\left(\mu \mathrm{m}^{2}\right)$ & 0.08 & 0.59 \\
VA NEFA (mmol) and LD Secondary Fiber Number & 0.02 & 0.92 \\
VA NEFA (mmol) and LD Secondary Diameter $(\mu \mathrm{m})$ & 0.09 & 0.57 \\
VA NEFA (mmol) and LD Secondary Area $\left(\mu \mathrm{m}^{2}\right)$ & 0.09 & 0.54 \\
VA NEFA (mmol) and LD S:P Ratio & 0.27 & 0.07 \\
VA NEFA (mmol) and ST Primary Fiber Number & -0.09 & 0.55 \\
VA NEFA (mmol) and ST Primary Fiber Diameter $(\mu \mathrm{m})$ & -0.24 & 0.11 \\
VA NEFA (mmol) and ST Primary Fiber Area $\left(\mu \mathrm{m}^{2}\right)$ & -0.23 & 0.13 \\
VA NEFA (mmol) and ST Secondary Fiber Number & -0.17 & 0.27 \\
VA NEFA (mmol) and ST Secondary Diameter $(\mu \mathrm{m})$ & -0.25 & 0.16 \\
VA NEFA (mmol) and ST Secondary Area $(\mu \mathrm{m} 2)$ & -0.02 & 0.10 \\
VA NEFA (mmol) and ST S:P Ratio & & 0.89 \\
\hline & & \\
\hline
\end{tabular}




\title{
PLACENTAL EFFICIENCY AT BIRTH ALTERS MUSCLE DEVELOPMENT POSTNATALLY
}

\author{
T.A. Wilmoth ${ }^{1}$, C. S. Perkins ${ }^{2}$, Z.E. Kerley ${ }^{2}$, Z.D. Callahan ${ }^{2}$, B. R. Wiegand ${ }^{2}$, M.E. Wilson ${ }^{1}$ \\ ${ }^{1}$ Division of Animal and Nutritional Sciences, Davis College ofAgriculture, Natural Resources \\ and Design, West Virginia University, Morgantown, West Virginia, USA \\ ${ }^{2}$ Division of Animal Sciences, College of Agriculture, Food and Natural Resources, University \\ of Missouri, Columbia, Missouri, USA
}

Address all correspondence and requests for reprints to: Matthew E. Wilson, Division of Animal and Nutritional Sciences, Davis College of Agriculture, Natural Resources and Design, West Virginia University, P.O. Box 6108, Room G038, Morgantown, West Virginia 26506. E-mail: mwilso25@wvu.edu This work is published with the approval of the Director of West Virginia Agriculture and Forestry Experiment Station as scientific paper /. This project was supported by Hatch project 468 (NCERA 057).

Key Words:placental efficiency, pigs, postnatal development, muscle development 
ABSTRACT: By d100 of gestation the populations of primary and secondary muscle fibers have formed. While fiber number remains relatively similar after birth, the size of muscle fibers can change, influencing pork quality. Placental efficiency (fetal weight divided by placental weight) is often employed as a measure of placental function and may impact muscle development during gestation and assumedly at slaughter. The objective of this work was to determine the relationship of placental efficiency to muscle development of the market weight hog. Placental efficiency was determined for each piglet at birth. At two months of age, barrows $(\mathrm{n}=19)$ were individually housed, fed to a final weight of $121 \mathrm{~kg}$ and slaughtered. Following a $24 \mathrm{hr}$ chill, a $2.5 \mathrm{~cm}^{2}$ sample of longissimusdorsi (LD) at the $10^{\text {th }}$ rib and semitendonosus (ST) from the middle of the muscle were collected and frozen. Two sections were taken of each muscle type and two images of each section were captured. The number and diameter of primary and secondary fiber types were determined by ATPase assay using acid preincubation. From each image, 15 primary fibers and 20 secondary fibers were measured for diameter. The GLM procedures of SAS were used to determine Pearson correlation coefficients between variables. The diameter of primary and secondary muscle fibers in LD were positively related $(P<0.0001, \mathrm{r}=0.80)$. The diameter of primary muscle fibers was negatively correlated to the number of secondary muscle fibers in the $\operatorname{LD}(P<0.05, r=-0.42)$. The number of secondary muscle fibers in LD were negatively correlated to the diameter of secondary muscle fibers in LD $(P<0.05, r=-0.40)$. In ST, the secondary to primary fiber ratio was found to be positively correlated to the diameter of primary fibers $(r=0.39, P<0.05)$. Placental efficiency, determined at birth, influences the ratio of muscle fibers determined at harvest, potentially altering meat quality.

Keywords: placental efficiency, pigs, postnatal development, muscle development 


\section{INTRODUCTION}

Placental efficiency (fetal weight divided by placental weight) is a measure of placental function. Fetal development is dependent on sufficient placental function. The placenta is responsible for nutrient and gas exchange, waste removal, hormone production to maintain pregnancy, protection from the dam's immune system and other harmful toxicants or chemicals (Maccani and Marsit, 2009). If the placenta is insufficient at proper nutrient exchange it could lead to fetal growth retardation which negatively impacts the number of muscle fibers developed in utero (Maltin et al., 2001).

Selection for placental efficiency has been found to be effective, increasing placental efficiency and litter size and decreasing placental weight, but while reducing fetal weight by 22\% (Wilson et al., 1999). According to Wollmann (1998) this 22\% reduction is not of sufficient magnitude to put the fetus in danger of severe growth restriction; however, this does imply that fetal development could be altered. The potential for fetal, and therefore muscle, development to be affected by low birth weight is great (Wigmore and Strickland, 1983, Tilley et al., 2007). Furthermore, low birth weight impacts the growth potential and postnatal development of the animal (Rehfeldt and Kuhn, 2006). Gondret and colleagues (2006) found that low birth weight fetuses had increased muscle fiber area and decreased meat tenderness of the longissimusdorsi (LD)muscle and that those animals took 12 days longer to reach market weight compared to their normal weight counterparts.

In the pig, fetal muscle development begins around day 30 of gestation and is complete by approximately day 100 of gestation (Ashmore et al., 1973). Muscle development occurs in two phases, the first phase produces a population of muscle fibers referred to as primary fibers 
and the second phase results in secondary fibers. Following development of both populations of muscle fibers, no new muscle fiber formation will occur and from here, the growth of the muscle is highly hypertrophic (Ashmore et al., 1973). As a result, the number of muscle fibers the animal is born with is highly reflective of the number of muscle fibers the animal will have at maturity, or in the case of meat animals at market weight.

The objective of the current work was to determine if placental efficiency at birth affects postnatal muscle development and ultimately pork quality as determined by muscle fiber number and size in muscles of the loin (LD) and ham (semitendonosus, ST).

\section{MATERIALS AND METHODS}

All procedures were approved by the University of Missouri Animal Care and Use Committee.

\section{Animals}

Pregnant sows $(\mathrm{N}=15)$ of similar genetics were monitored continuously throughout parturition. Near the vulva, piglets were caught prior to the umbilical cord breaking and the umbilical cord was tagged with a corresponding number to the piglets ear notch so that the piglet's placenta could be identified. Piglet birth weight was immediately recorded. This was repeated for each piglet within the litter. Placentae were collected, weighed and recorded. Placental efficiency (fetal weight divided by placental weight) was calculated for each piglet within the litter. By $24 \mathrm{~h}$ of age, piglet girth and crown-rump length were recorded. 


\section{Feeding}

Piglets were allowed to nurse from their dams and were weaned at 21 days. Following weaning, piglets were moved to the nursery and remained there until approximately 60 days of age, at which time, barrows $(n=19)$ were selected and moved to the feed out facility. Barrows were fed until they reached market weight at $120 \mathrm{~kg}$.

\section{Harvest and Sample Collection}

At market weight, barrows were stunned by electrocution and then exsanguinated. Hair was removed from carcasses followed by removal of the head and viscera. Carcasses were then halved and placed in a cooler overnight.

Following a 24 hour chill, carcasses were processed. A piece of the LD muscle was removed cranial to the $10^{\text {th }}$ rib for analysis. The sample was cut into a $2.5 \mathrm{~cm}^{2}$ section, covered in O.C.T. medium (Tissue Tek, Sakura Finetek USA Inc., Torrance, CA), frozen in liquid nitrogen chilled isopentane in Peel-A-Way disposable embedding molds (Thermo Fisher Scientific, Inc, Pittsburgh, PA), and stored at $-80^{\circ} \mathrm{C}$. Similarly, a muscle sample from the ham was taken from the center of the muscle and processed in the same manner as the LD muscle. From both muscle samples, muscle fibers were oriented in such a way that transverse sections could be taken and cross sections of fibers could be visualized. 


\section{ATPase Assay}

Muscle samples were sectioned into $10 \mu \mathrm{m}$ sections using Cryotome FSE (Thermo Scientific, Kalamazoo, MI). Sections were fixed onto glass slides and stored at $-80^{\circ} \mathrm{C}$. ATPase assay was performed utilizing an acid pre-incubation buffer (Ashmore et al., 1973). This resulted in the primary fibers staining black while the secondary fibers were grey in color. Two sections of each muscle were stained per fetus and one image of each section was visualized using a Nikon Eclipse TE2000-5 inverted microscope and captured by camera (Retiga 2000R, Q Imaging, Surrey, BC, Canada) and imaging software (Q Capture, Quantitative Imaging Corporation, v2.90.1, Surrey, BC, Canada). Images were then analyzed by Northern Eclipse (Empix, Inc., v6.0, North Tonawanda, NY). Of the two images taken for each muscle sample, all primary and secondary muscle fibers were counted. For determination of fiber diameter, 20 primary and 40 secondary muscle fibers were analyzed per image. Measurements were averaged among tissue type and one mean value was reported for each muscle type for each fetus. The secondary to primary (S:P) ratio of fibers was also determined for each muscle type.

\section{Statistical Analysis}

Relationships among variables were determined by the correlation procedures of SAS. Pigs were placed into high and low placental efficiency groups based on their placental efficiency at birth, pigs with placental efficiency values above the average were placed in the high placental efficiency group and below the average were placed in the low placental efficiency group. The GLM procedures of SAS were used to determine differences in variables according to high or low placental efficiency. Means were separated by the LSMeans statement 
and reported here as the mean \pm SEM. Differences were significant when $P<0.05$ and were considered to be a trend when $P<0.10$.

\section{RESULTS}

\section{Neonatal and Placental Characteristics}

Neonatal weight tended to be lower in the low placental efficiency group $(P<0.10$, Figure 10). Neonatal girth also tended to be less for piglets of the low placental efficiency group $(P<0.10$, Figure 11). Placental weight was greater in the low placental efficiency group ( $P<$ 0.05, Figure 10).

\section{Muscle Characteristics at Market Weight}

There were no differences detected between high and low placental efficiency animals at birth for primary or secondary fiber number, diameter or area for either muscle sample. However, there was a decrease in the S:P ratio of the LD muscle in animals of low placental efficiency at birth $(P<0.05$, Figure 12).

The diameter of primary muscle fibers in LD was negatively related to the diameter of secondary muscle fibers in $\mathrm{LD}(P<0.05$, Table 9$)$ and tended to be negatively related to the number of secondary fibers present in LD muscle $(P<0.05$, Table 9$)$. The diameter of secondary muscle fibers in LD had a tendency to be negatively related to the number of secondary muscle fibers in LD ( $P<0.08$, Table 9). There was a trend for the number of primary fibers in the ham muscle sample to be positively related to the diameter of those fibers $(P<0.10$, Table 9$)$. 


\section{DISCUSSION}

Neonatal weight and girth had a tendency to be reduced in fetuses of the low placental efficiency group. As opposed to other studies, where runt or low birth weight piglets could be excluded from the selection of low and high placental efficiency feto-placental units, due to the manner in which placental efficiency data were obtained, these animals were not excluded and could be contributing to this decrease in fetal weight and girth. Fetal growth measurements such as girth and crown-rump length are highly correlated to fetal weight and would explain that as well. As expected, in the low placental efficiency group, placental weight was increased.

Muscle fiber number and size at market weight were unaffected by placental efficiency at birth, with the exception of the S:P ratio in the LD muscle, which was decreased in fetuses in the low placental efficiency group. The ratio of secondary to primary muscle fibers is used as a measure of meat quality. Increased S:P ratio is indicative of increased number of secondary fibers, which are more susceptible to environmental changes than primary fibers, therefore a lower S:P ratio is desired for improved meat quality (Fielder et al., 1999). In the LD muscle of these pigs, as the number of primary muscle fibers increased, the number of secondary decreased and the size of the secondary increased. This is similar to other reports of postnatal muscle development (Rehfeldt et al., 2000).

In conclusion, placental efficiency at birth had no effect on muscle fiber size at market weight but did alter the ratio of muscle fibers in LD muscle of pigs born with a low placental efficiency. 


\section{REFERENCES}

Ashmore, C.R., P.B. Addis and L. Doerr. 1973. Development of muscle fibers in the fetal pig. J. Anim. Sci. 36(6):1088-1093.

Fielder, I., K. Ender, M. Wicke, S. Maak, G. von Lengerken and W. Meyer. 1999. STructureal characteristics of muscle fibers in pigs with different malignant hyperthermia susceptibility and different meat quality. Meat Sci. 53:9-15

Gondret, F., L. Lefaucheur, H. Juin, I. Louveau and B. Lebret. 2006. Low birth weight is associated with enlarged muscle fiber area and impaired meat tenderness of the longissimus muscle in pigs. J. Anim. Sci. 84:93-103.

Maccani, M. and C. Marsit. 2009. Epigenetics in the placenta. Am. J. Reprod. Immunol. 62(2):78-92.

Maltin, C.A., M.I. Delday, K.D. Sinclair, J. Steven and A.A. Sneddon. 2001. Impact of manipulations of myogenesisin utero on the performance of adult skeletal muscle. Reprod 122:359-374.

Rehfeldt, C. and G. Kuhn. 2006. Consequences of birth weight for postnatal growth performance and carcass quality in pigs as related to myogenesis. J. Anim. Sci. 84:E113-123.

Rehfeldt, C., I, Fielder, G. Dietl and K. Ender. 2000. Myogenesis and postnatal skeletal muscle cell growth as influenced by selection. Liv Prod Sci 66:177-188.

Tilley, R. E., C. J. McNeil, C. J. Ashworth, K. R. Page and H. J. McArdle. 2007. Altered muscle development and expression of the insulin-like growth factor system in growth retarded fetal pigs. Dom. Anim. Endocrinol. 32:167-177.

Town, S.C., C.T. Putnam, N.J. Turchinsky, W.T. Dixon and G.R. Foxcroft. 2004. Number of conceptusesin utero affects porcine fetal muscle development. Reprod. 128:443-454. 
Wigmore, P.M.C. and N.C. Stickland. 1983. Muscle development in large and small pig fetuses. J. Anat. 137(2):235-245.

Wilson, M. E., N. J. Biensen and S. P. Ford. 1999. Novel insight into the control of litter size in pigs, using placental efficiency as a selection tool. J. Anim. Sci. 77:1654-1658. 


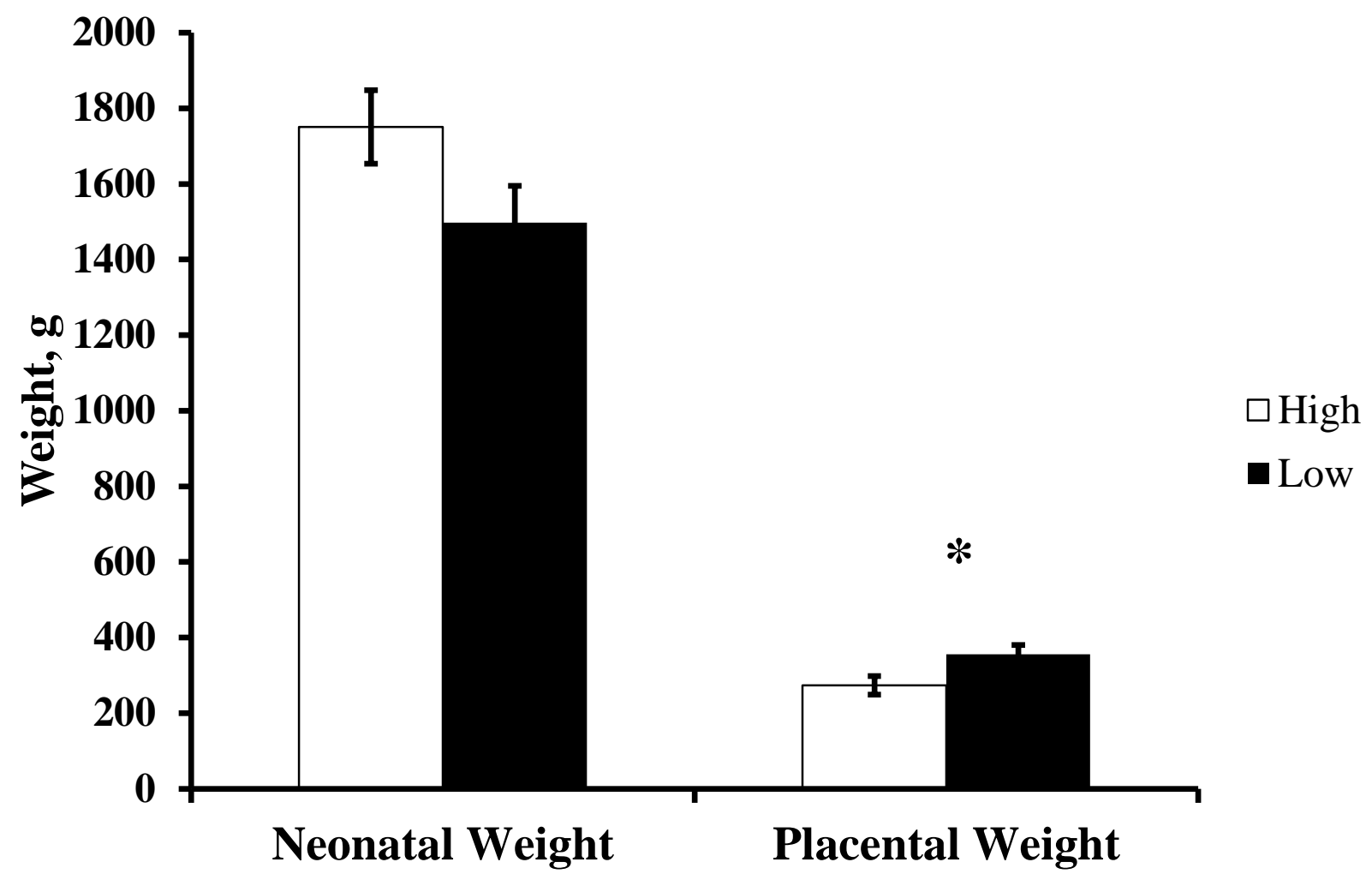

Figure 10. Neonatal and placental weights for piglets assigned to high (open bars) or low (closed bars) placental efficiency groups. Means \pm SEM, $\mathrm{P}<0.05$. 


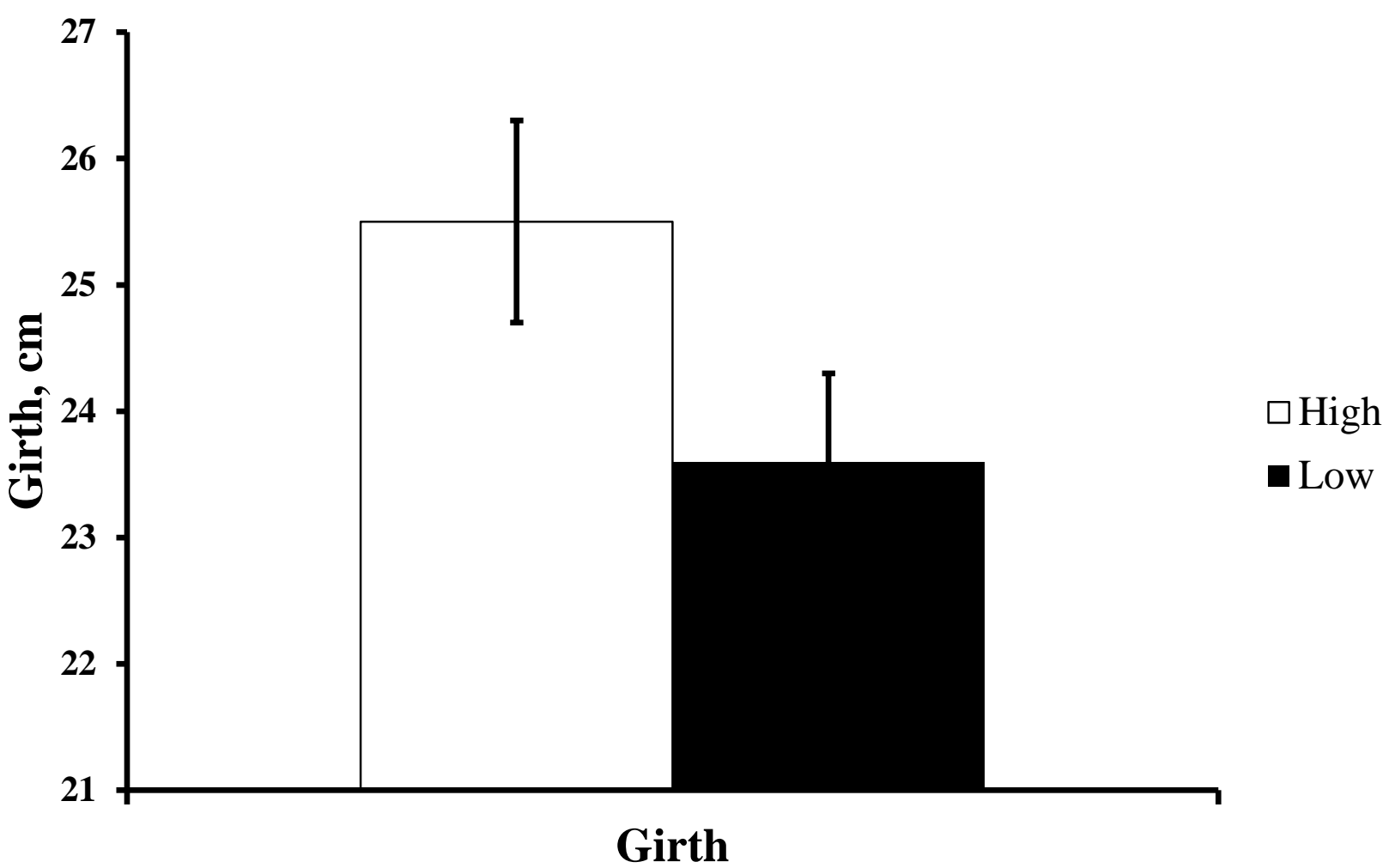

Figure 11.Girth of neonatal pigs in high (open bars) and low (closed bars) placental efficiency groups. Means \pm SEM, $\mathrm{P}<0.10$. 


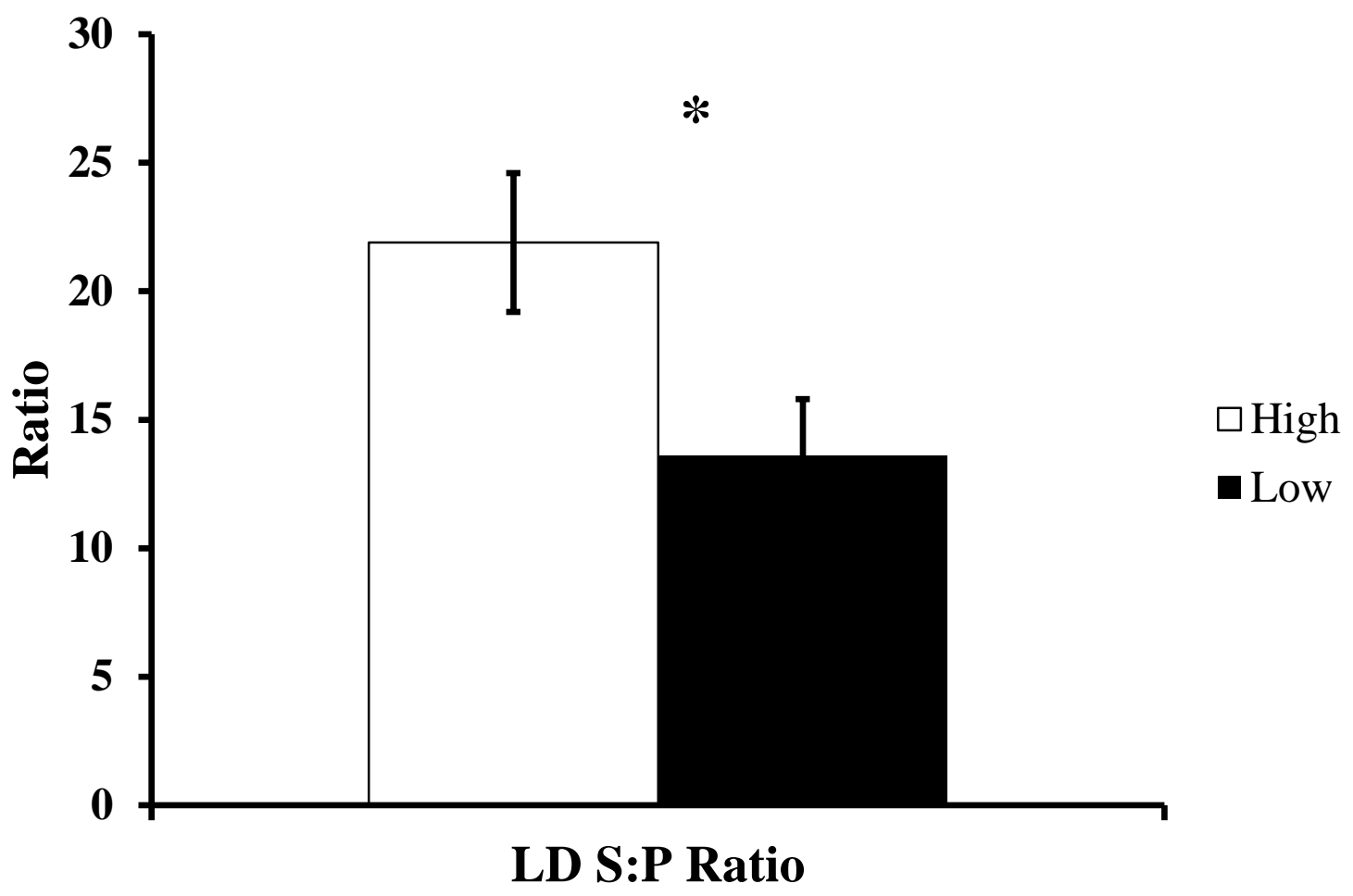

Figure 12. Ratio of secondary to primary muscle fibers in LD muscle from high (open bars) and low (closed bars) placental efficiency groups. Means \pm SEM, $\mathrm{P}<0.05$. 
Table 9. Correlations between muscle characteristics

\begin{tabular}{lcc}
\hline \hline \multicolumn{1}{c}{ Variables } & $\mathbf{r}$ & $\boldsymbol{P}$ - value \\
LD Primary Diameter $(\mu \mathrm{m})$ and LD Secondary Fiber Number & -0.25 & 0.10 \\
LD Primary Diameter $(\mu \mathrm{m})$ and LD Secondary Diameter $(\mu \mathrm{m})$ & -0.29 & 0.05 \\
LD Secondary Fiber Number and LD Secondary Diameter $(\mu \mathrm{m})$ & -0.27 & 0.08 \\
ST Primary Diameter $(\mu \mathrm{m})$ and ST Primary Fiber Number & 0.25 & 0.10 \\
\hline
\end{tabular}




\title{
MATERNAL EXERCISE IN SECOND PARITY SOWS ALTERS FETAL GROWTH AND METABOLISM
}

\author{
T.A. Wilmoth ${ }^{1}$, E.K. Harris ${ }^{2}$, T.L. Neville ${ }^{2}$, E.P. Berg ${ }^{2}$, M.E. Wilson ${ }^{1}$ and K.A. Vonnahme ${ }^{2}$ \\ ${ }^{1}$ Division of Animal and Nutritional Sciences, Davis College ofAgriculture, Natural Resources \\ and Design, West Virginia University Morgantown, West Virginia, USA \\ ${ }^{2}$ Department of Animal Sciences, Nutrition and Pregnancy, North Dakota State University, \\ Fargo, ND, USA
}

Address all correspondence and requests for reprints to: Kimberly A. Vonnahme, Department of Animal Sciences, Nutrition and Pregnancy, North Dakota State University, 181 Hultz Hall, Fargo, ND 58105. E-mail: kim.vonnahme@ndsu.edu. This work is published with the approval of the Director of West Virginia Agriculture and Forestry Experiment Station as scientific paper /. This project was supported by Hatch project 468 (NCERA 057).

Key Words: maternal exercise, pigs, gestation, fetal development 
ABSTRACT: Currently the swine industry is shifting housing of swine from housing in gestation stalls to group housing arrangements. The most notable benefit of this shift is the increased movement available to gestating sows and gilts. Benefits of exercise during gestation are contradictory, but include improved fetal weight and growth and improved fetal metabolism. However, while the effects of exercise have been studied in the rat, human and sheep, very little is known about the implications maternal exercise will have on swine. The objective of this work was to exercise second parity sows, which were also exercised during their first parity, and determine the effects on fetal development and metabolism, particularly with respect to fetal muscle development. Six Yorkshire sows were assigned to the same treatment group as their first parity, either exercise (EX; $n=3$ ) or control (CON; $n=3)$. Beginning on day 40 of gestation, sows were acclimated to exercise. Beginning day 44 of gestation, sows were exercised for 30 minutes three times per week until day 94 of gestation when sows were euthanized and fetuses necropsied. Fetal, placental, organ and muscle weights were recorded. Protein, RNA and DNA content were determined for placental and endometrial tissues, as well as fetal livers. Blood samples were collected and used to determine glucose, non-esterified fatty acid and amino acid concentrations. Fetal muscle samples were collected and used to determine primary and secondary muscle fiber number and size as well as secondary to primary fiber ratio. The effects of treatment and sows were determined by ANCOVA using the GLM procedures of SAS. Fetal, placental, organ and muscle weights were decreased in fetuses of EX dams. Placental RNA and DNA concentrations were increased in fetuses of EX dams. Fetal concentrations of amino acids and glucose were largely variable and dependent on source and individual metabolite. Primary and secondary muscle fibers were decreased and secondary muscle fiber size was increased in 
EX fetuses. This study shows that exercise during gestation could negatively impact fetal growth and metabolism at day 94 of gestation.

Keywords: maternal exercise, pigs, gestation, fetal development

\section{INTRODUCTION}

Gestation stalls comprise a vast majority of gilt and sow housing systems in the United States. Gestation stalls offer monitored feed intake, more personalized attention to health and pregnancy status, decreased injuries due to fighting and maximum stocking density. However, due to the concern for the well-being of the animal including lameness due to a lack of ability to move around, development of vices (i.e. bar biting, tongue rolling, head weaving and learned helplessness), the swine industry is moving towards group housing of females. Group housing allows for increased mobility and social interactions but tends to leadto increased incidences of fighting and less individualized care of animals.

Maternal and fetal responses to exercise during gestation have been investigated in many species (Lotgering et al., 1985). Decreases in uterine blood flow (Chandler et al., 1985) and increases in blood glucose concentrations have been reported in sheep exercised during gestation (Chandler and Bell, 1981). In human pregnancies, glucose concentrations in response to exercise were reviewed by Lotgering et al. (1981) and were reported as having increased, decreased or remained constant. Sows and gilts exercised during gestation farrowed and weaned heavier pigs than sows and gilts not receiving exercise during gestation (Hale et al., 1981). Fetal weight was increased in rats exercised during gestation depending on type of exercise as well as position in uterine horn (Rosa et al., 2011). Fetal crown to rump length was also increased in fetuses of exercised dams and was related to position in uterine horn (Rosa et al., 2011). The mid-uterine 
horn fetuses and fetuses closest to the cervix were heavier and longer than those at the ovarian end of the uterine horns. Harris (2010) showed that when gilts were exercised for 30 minutes three times weekly from day 40 to 104 of gestation that umbilical blood flow of fetuses of exercised dams was greater than the umbilical blood flow of fetuses of control dams. The objective of the current study was to determine the effects of exercise in second parity sows during gestation on fetal metabolism and growth.

\section{MATERIALS AND METHODS}

All procedures were approved by the North Dakota State University Animal Care and Use Committee.

\section{Animal Management and Treatments}

Yorkshire sows $(n=6)$ were bred to a common boar at the onset of estrus $(d=0)$. Pregnancy was confirmed on day 28 of gestation by ultrasound (Aloka 500 SSD Ultrasound, Corometrics Medical Systems, Inc., Wallingford, CT). Sows were individually housed in gestation stalls $(57 \mathrm{~cm} \mathrm{x} 176.5 \mathrm{~cm})$. Sows were assigned to the same treatment groups based on the treatment groups assigned to them in a previous study (Harris, 2010). Briefly, as gilts, one animal in a littermate pair was randomly assigned to either the control ( $n=3$; CON) or exercise $(n=3 ; E X)$ group. The current study utilized the same littermate pairs in the same treatment

groups as the previous study (Harris et al., 2011). The CON group remained in the gestation stall for the duration of gestation, while the EX group, following acclimation to exercise, were exercised for 30 minutes, three times weekly. 
Beginning on day 40 of gestation, sows in the EX group were acclimated to exercise. On days 40 and 41, sows were exercised for 10 minutes each day. On days 42 and 43, exercise occurred for 20 minutes each day. On day 44, 30 minutes of exercise, three times weekly began and continued throughout day 94 of gestation. Exercise consisted of walking through an enclosed hallway, accompanied by two trained handlers, one behind and one in front of the sow. Exercise occurred between 0830 and 1130 each day. Exercise was timed using a stopwatch and began when the sow had left the stall (i.e. all four hooves outside of the stall). Time was stopped if the sows stopped to urinate or defecate; therefore a consistent time of 30 minutes of movement was achieved. Sows were encouraged to keep moving forward by light taps, soft vocal cues and a shuttle board.

\section{Surgical and Necropsy Procedures}

On day 94 of gestation, sows were anesthetized using ketamine $(2 \mathrm{mg} / \mathrm{kg}$ ) and xylazine (3 $\mathrm{mg} / \mathrm{kg}$ ) cocktail and anesthesia was maintained using inhalant isoflurane. Gravid uteri were exposed through a midventral incision. Fetuses were selected from the tip (T), mid (M) and base (B) of each uterine horn and exteriorized through antimesometrial incisions. Blood samples were collected from the umbilical vein and artery of each of these fetuses with a $25 \mathrm{~g}$ needles and 5 cc syringes. Blood was placed on ice until centrifugation. Following blood collection, dams were euthanized, ovariohysterectomized and necropsies of fetuses were performed.

Uterine horns were opened along the antimesometrial side. Uteroplacental cross sections were taken for fetuses in the T, M, B positions along each uterine horn and preserved in formalin for later determination of vascular density. Placenta were then detached from the endometrium and samples of placenta and endometrium from T, M, B fetuses were snap frozen and stored at - 
$80^{\circ} \mathrm{C}$ for later determination of cellularity measures. Implantation site length measurements were also taken at this time.

In addition to T, M, B fetuses, the lightest and heaviest male and female (LM, HM, LF, HF, respectively) fetuses were also selected and used for the following measurements: fetal weights, placental weights, crown rump lengths, heart girth, heart weight, liver weight, muscle weights and placental efficiency (fetal weight divided by placental weight) were recorded at the time of necropsy. Fetal livers were snap frozen for later determination of cellularity measures. Semitendonosus (ST) and semimembranosus (SM) muscles were frozen in O.C.T. medium (Tissue Tek, Sakura Finetek USA Inc., Torrance, CA) in liquid nitrogen chilled isopentane in Peel-A-Way disposable embedding molds (Thermo Fisher Scientific, Inc, Pittsburgh, PA) and stored at $-80^{\circ} \mathrm{C}$.

\section{Cellularity Measures}

Placental, endometrial and liver samples were used to determine protein, RNA and DNA content as previously described (Lekatz et al., 2010). Briefly, samples were homogenized using a Polytron homogenizer with PT-10s probe (Brinkmann, Westbury, NY) in 10X TNE buffer. The DNA and RNA assays were done using the diphenylamine and orcinol procedures, respectively (Lekatz et al., 2010). Protein was determined using the Bradford assay with Coomassie brilliant blue (Lekatz et al., 2010). Concentrations were determined using a spectrophotometer (Beckman DU 640, Beckman Coulter Inc., Fullerton, CA). DNA concentrations were used as a measure of cell number. RNA and protein concentrations were used to determine protein:DNA and RNA:DNA ratios as measures of cell size and proteinsynthetic activity, respectively. 


\section{Fetal Metabolites}

Blood samples were centrifuged and plasma retained and frozen at $-20^{\circ} \mathrm{C}$ for determination of amino acid, glucose and non-esterified fatty acid (NEFA) concentrations. Additionally, amniotic fluid samples were collected, centrifuged and stored at $-20^{\circ} \mathrm{C}$ for determination of amino acid concentrations. Amino acid concentrations were determined by the University of Missouri Experiment Station Chemical Laboratories by cation-exchange chromatography coupled with post-column ninhydrinderivitization and quantitation.

Glucose concentrations were determined by a glucose assay kit (Cayman Chemical Company, Ann Arbor, MI). Kits were used according to manufacturer's instructions and the absorbance read at $514 \mathrm{~nm}$. NEFA concentrations were determined by NEFA-HR kit following the manufacturer's instructions (Wako Chemicals, Richmond, VA). For all metabolites, venoarterial (VA) differences were calculated by subtracting arterial concentrations from venous concentrations to determine fetal usage.

\section{Vascular Density}

Uteroplacental cross sections were fixed in formalin and embedded in paraffin as previously described (Koch et al. 2007). Paraffin blocks were sectioned on a microtome at $4 \mu \mathrm{m}$ and fixed to charged slides (Probe On Plus, Thermo Fisher Scientific, Pittsburgh, PA). Sections were stained using the periodic acid Schiff's reagent staining procedure. Two microscopic fields for each fetus were visualized via Nikon Eclipse TE2000-5 inverted microscope and captured by camera (Retiga 2000R, Q Imaging, Surrey, BC, Canada) and imaging software (Q Capture, 
Quantitative Imaging Corporation, v2.90.1, Surrey, BC, Canada). Images were then analyzed by Northern Eclipse image analysis software (Empix, Inc., v6.0, North Tonawanda, NY). A drawing tool was used to outline the placental and endometrial portions of the image one at a time. The image was then thresholded so that all vasculature appeared white and the program measured the number of objects, total area and the area of the vessels of the selected area only. Percentage of vasculature was determined by dividing the total selected area by the area of the objects.

\section{ATPase Assay}

Semitendonosus and SM muscles were sectioned into $10 \mu \mathrm{m}$ sections using Cryotome FSE (Thermo Scientific, Kalamazoo, MI). Sections were fixed onto glass slides and stored at $80^{\circ} \mathrm{C}$. ATPase assay was performed utilizing an acid pre-incubation buffer (Ashmore et al., 1973). The $\mathrm{pH}$ of this buffer activates the myosin-ATPase enzyme which is bound to calcium. Following incubation with ATP at $37^{\circ} \mathrm{C}$ for $20 \mathrm{~min}$, the calcium is replaced with cobalt. The cobalt is then precipitated as a black compound by ammonium sulfide. The fibers containing this black compound are primary fibers, while fibers lacking this compound are secondary muscle fibers.

Two sections of each muscle were stained per fetus and one image of each section was visualized using a Nikon Eclipse TE2000-5 inverted microscope and captured by camera (Retiga 2000R, Q Imaging, Surrey, BC, Canada) and imaging software (Q Capture, Quantitative Imaging Corporation, v2.90.1, Surrey, BC, Canada). Images were then analyzed by Northern Eclipse (Empix, Inc., v6.0, North Tonawanda, NY). Numbers of primary and secondary fibers as well as diameters of both fiber types were measured four images of each muscle type. Measurements 
were averaged among the images and one mean value was reported for each muscle type for each fetus. The secondary to primary (S:P) ratio of fibers was also determined for each muscle type.

\section{Statistics}

Data were analyzed using the GLM procedures of SAS using ANCOVA. Covariates were treatment group (e.g. EX or CON) and sow. Sows were littermate pairs, with one of the pair in each of the treatment groups. Means were separated by the LSMeans statement and are represented at mean \pm SEM. Means with $P<0.05$ were considered to be significant and with $P<0.10$ were considered to be a trend.

\section{RESULTS}

\section{Fetal, organ and placental weights}

A trend for an decrease in fetal weight of fetuses of EX dams was observed $(P<0.10$, Table 10). Crown-rump length (CRL) was decreased as a result of treatment $(P<0.05$, Table 10). Organ weights varied in response to treatment. A tendency for brain weight to be decreased in response to treatment was observed $(P<0.10$, Table 10). Liver weight was decreased in fetuses of EX dams compared to fetuses of CON dams $(P<0.05$, Table 10). ST muscle weight was decreased in fetuses from exercised fetuses $(P<0.05$, Table 10). Placental weight was increased in control sows $(P<0.05$, Table 10). Placental efficiency (fetal weight divided by placental weight) was not affected by exercise $(P=0.75$, Table 10$)$. 


\section{Cellularity Measures}

Trends for differences in placental DNA and RNA concentrations were observed in response to treatment. There was a trend for an increase in placental DNA content in placenta associated with fetuses of EX dams $(P<0.08$, Table 11). There was an increase in placental RNA content in placenta associated with fetuses of EX dams $(P<0.08$, Table 11). No other differences were observed for treatment for DNA, RNA or protein content in endometrial tissue or fetal livers.

\section{Amino Acid and Glucose Concentrations}

Amino acid concentrations generally decreased in amniotic fluid samples in response to treatment. Proline decreased in amniotic fluid in response to exercise $(P=0.04$, Table 13). Threonine hydroxyproline, glutamine and 1-methyl-histidine tended to be reduced in the amniotic fluid of fetuses of exercised dams compared to fetuses of control dams (Tables 12 and 13). Cysteine, however, was increased in amniotic fluid samples in fetuses of EX dams compared to fetuses of CON dams ( $P=0.02$, Table 13).

Arterial concentrations of urea, glycine, $\beta$-alanine and 1- and 3-methyl-histidine were decreased by treatment (Table 13). Arterial concentrations of methionine and histidine were increased in fetuses of EX dams compared to fetuses of CON dams (Table 12). Venous concentrations of glutamate, glycine, citrulline, $\beta$-alanine and 1-methyl-histidine were decreased by exercise (Table 13). Venous concentrations of asparagine, glutamine, alanine, methionine, phenylalanine, histidine and leucine were increased in fetuses of EX dams (Tables 12 and 13). VA differences were increased in fetuses of EX dams for urea, glutamine, alanine, methionine, 
isoleucine, leucine and hydroxylysine, and, with the exception of urea, were in the direction of the placenta (Tables 12 and 13). VA differences were decreased in fetuses of EX dams for citrulline and glutamate (Table 13). Glutamate was in the direction of the fetus, while the net flux of citrulline was in the direction of the placenta. VA difference for glucose tended to be greater in fetuses of EX dams when $(P=0.09$, Table 14 . No differences were detected in the amount of vasculature occurring in either the chorio-allantois or endometrium of uteroplacental cross sections (data not shown).

\section{Muscle Characteristics}

The number of primary fibers in SM muscle tended to be less in fetuses of EX dams $(P<$ 0.10, Figure 13). Similarly, the number of secondary fibers of the SM muscle was decreased in fetuses of EX dams $(P<0.01$, Figure 14). The number of primary fibers in ST muscle was decreased in fetuses of EX dams ( $P<0.05$, Figure 13). Secondary fiber number in ST muscle tended to be less in fetuses from EX dams as well $(P<0.10$, Figure 14).

\section{DISCUSSION}

Fetal weights were found to be less when sows were exercised from d40 to d94 of gestation, however several authors have found conflicting results. When gilts and sows were exercised from d7 to d107 of gestation, fetuses were approximately $5 \%$ heavier at birth (Hale et al., 1981). Garris et al. (1985) found that rat pups were heavier when dams were exercised from d12 to d22 of gestation. Mottola et al. (1983) found no difference in fetal weights when dams were exercised throughout gestation, however these rats were acclimated to exercise prior to 
breeding. Fetal crown rump length was decreased in response to exercise. Rosa et al. (2011) found that fetal crown rump length increased with gestational exercise in rats. Additionally, Rosa et al. (2011) found that placental weight increased as a result of exercise in rats.

The time period in which exercise occurs during gestation and the intensity of the exercise is likely to influence effects on fetal weight. Different exercise types in rats caused differing results in fetal weight (Rosa et al., 2011). Furthermore, in women, when exercise was begun in early gestation birth weight, placental weight and fetal length were increased, but when the same exercise was begun in late gestation, placental weight and fetal length were reduced (Clapp et al., 2000, Clapp et al., 2002).

Fetal brain, liver, ST and SM weights were all decreased in response to exercise during gestation, which likely accounts for the reduced weight of these fetuses. Fetal development can be affected by the number of pigs in the litter and nutritional status of the dam, however for this study the number of pigs per litter was not different between EX and CON dams and dams were fed the same amount $(1.8 \mathrm{~kg})$ of the same feed daily.

Both placental RNA and DNA were increased in response to exercise during gestation. This indicates increased cellularity of the placenta associated with fetuses of EX dams. This could be a result of increased proliferation of placental cells or high cellular turnover rates.

Taking amino acid concentrations from multiple sources in this study resulted in an emerging pattern. The main players for all sources (e.g. amniotic fluid, umbilical artery, umbilical vein, and VA difference) were urea, glutamine, glutamate, citrulline, ornithine, arginine, alanine, lysine, hydroxylysine, $\alpha$-aminoadipic acid, methionine, 1-methyl-histidine, 3methyl histidine, histidine, $\beta$-alanine and leucine. Groupwise, these are members of the urea 
cycle, first and second limiting amino acids in the pig and their degradation products, and amino acids related to muscle protein metabolism.

The amniotic fluid serves two main functions for the fetus. Primarily, it acts as a shock absorber to protect the fetus from insults while the dam is in motion (Maccani and Marsit, 2009). Secondly, it serves as a source of nutritional energy for the fetus. Fetal swallowing of amniotic fluid during gestation accounts for 10-14\% of the fetal nutrient requirement (Underwood and Sherman, 2006). Additionally, the swallowing of this fluid enhances gastrointestinal development due to the protein and amino acid composition; glutamine supports gastrointestinal growth and function and cellular differentiation and proliferation, particularly prior to day 45 of gestation (Underwood and Sherman, 2006; Wu et al. 1995). However, glutamine decreases in concentration after day 45 of gestation, with alanine being the predominant amino acid by day 110 of gestation (Wu et al., 1995). Furthermore, concentrations of amino acids in amniotic fluid are controversial as fetuses not only swallow it, but additional contributions to amino acid composition are fetal excreta and the high rates of cellular turnover.

Fetal serum concentrations of amino acids are reflective of maternal serum concentration of amino acids as well as placentally derived amino acids and their metabolites. The placenta converts acidic amino acids into aspartate and glutamine, branched chain amino acids (e.g., leucine, isoleucine and valine) to glutamine and serine to glycine for transport to the fetus (Vaughn et al. 1995,McNanley and Woods, 2008). The placenta metabolizes a large portion (approximately 80\%) of glutamine (Vaughn et al., 1995). The fetal liver has contrary functions compared to the placenta and will convert glutamineback into glutamate and acidic and branched chain amino acids into their keto acids with the release of ammonia (Vaughn et al., 1995). This 
conversion releases ammonia which the fetus can then use to produce amino acids by de novo synthesis in the liver (McNanley and Woods, 2008).

Beginning with intermediates of the urea cycle, glutamate was increased in umbilical venous blood, but overall less glutamate was delivered to the fetus of EX dams compared to CON dams. This could be the result of decreased amino acid supply from the dam or placental derivation of glutamine (Vaughn et al., 1995). Glutamine and alanine concentrations were also decreased in fetal umbilical venous blood of EX sows and the fetus returned less glutamine to the placenta than fetuses of CON sows. The role of glutamine and alanine in the blood is to safely transport nitrogen, in the form of ammonia, to the liver for the urea cycle, so decreased glutamine in fetal circulation could indicate decreased need for fetal transport of nitrogen. The citrulline concentration in EX fetus umbilical venous blood was increased, but the EX fetuses were receiving less maternal and placental derived citrulline than CON fetuses. Citrulline is the precursor for arginine which is important in blood flow potentially indicating an alteration in the vascular development of EX fetuses (Wu et al., 1995). Urea was also increased in EX fetus umbilical venous blood, but these fetuses also had a positive VA difference (i.e. net flow of urea to the fetus) compared to CON fetuses, which had a negative VA difference for urea (i.e. net flow of urea to the placenta). Taken together, this indicates a potential for increased urea cycle activity, however urea is not produced at a greater rate in EX fetuses compared to CON fetuses.

Additionally, an increase in the concentration of alanine, with less being sent to the placenta in EX fetuses coincides with a decreased VA difference (less being sent to the placenta) of glucose in EX fetuses. This could indicate an increase in the Cori cycle in the skeletal muscle of fetuses. Alanine can also be produced from branch chained amino acids in the muscle and indeed, the VA differences for both leucine and isoleucine indicate a reduced net flow to the 
placenta. The umbilical venous concentration of leucine in EX fetuses was increased but this could be due to altered placental derivation of the branched chain amino acids.

Uterine environment can influence muscle development. Town and colleagues (2004) unilaterally ligated the oviduct and observed an increase in fetal weight, number of primary and secondary fibers, S:P muscle ratio and ST muscle weight in the "roomy” uterine environment. The number of primary and secondary fibers for both SM and ST muscles were decreased in EX fetuses, likely explaining the decrease in weight for both of these muscles. Additionally, the S:P ratio of SM muscle was increased, while the S:P ratio of ST was decreased. This could be explained by differential nutrient partitioning to the EX fetuses. Dwyer and others (1994) found that increasing maternal nutrition increased fiber number and S:P ratio in fetuses. In that study, the sows of both groups were fed equally, the amount of exercise was not accounted for in the amount of feed each animal got. The EX sows, due to the increased nutritional demand of exercise, could be supplying less nutrients to the uterus, potentially setting up the fetuses for intrauterine growth restriction or the need for alternative fuel sources (e.g. catabolization of muscle protein).

In SM muscle, secondary muscle fiber diameter and area were increased. Fielder and others (1997) determined that muscle fiber hyperplasia and hypertrophy are inversely related. This supports the finding of a decreased number of secondary muscle fibers, but increased size of these fibers in EX fetuses. The growth of the fibers in animals with fewer muscle fibers reaches its maximum sooner than fibers in animals with more muscle fibers (Rehfeldt et al., 2000).

In conclusion, the EX fetuses could be experiencing nutrient restriction causing decreases in fetal and organ weights concomitantly with increased placental weight. This could also explain the decrease in muscle weight, primary and secondary fiber number and increases in secondary fiber size in these fetuses. The altered metabolism observed in these fetuses (e.g. 
increased muscle protein breakdown) could be the result of fetal nutrient restriction at this stage of gestation. 


\section{REFERENCES}

Ashmore, C.R., P.B. Addis and L. Doerr. 1973. Development of muscle fibers in the fetal pig. J. Anim. Sci. 36(6):1088-1093.

Chandler, K. D. and A. W. Bell. 1981. Effects of maternal exercise on fetal and maternal respiration and nutrient metabolism in the pregnant ewe. J. Dev. Physiol. 3:161-176.

Chandler, K. D., B. J. Leury, A. R. Bird and A. W. Bell. 1985. Effects of undernutrition and exercise during late pregnancy on uterine, fetal and uteroplacental metabolism in the ewe. Brit. J. Nut. 53:625-635.

Clapp, J. F., H. Kim, B. Burciu and B. Lopez. 2000. Beginning regular exercise in early pregnancy: Effect on fetoplacental growth. Am. J. Obstet. Gynecol. 183:1484-1488.

Clapp, J. F., H. Kim, B. Burciu, S. Schmidt, K. Petry and B. Lopez. 2002. Continuing regular exercise during pregnancy: Effect of exercise volume on fetoplacental growth. Am. J. Obstet. Gynecol. 186:142-147.

Dwyer, C. M., N. C. Stickland and J. M. Fletcher. 1994. The influence of maternal nutrition on muscle fiber number development in the porcine fetus and on subsequent postnatal growth. J. Anim. Sci. 72:911-917.

Fielder, I., C. Rehfeldt, K. Ender and M. Henning. 1997. Phenotypic and genetic parameters of muscle fiber number and size. J. Anim. Sci. 75 (Suppl. 1):165.

Garris, D.R., G. J. Kasperek, S. V. Overton and G. R. Alligood, Jr. 1985. Effects of exercise on fetal-placental growth and uteroplacental blood flow in the rat. Biol. Neonate. 47:223229. 
Hale, O. M., C. V. Booram and W. C. McCormack. 1981. Effects of forced exercise during gestation on farrowing and weaning performance of swine. J. Anim. Sci. 52(6):12401243.

Harris, E.K. (2010). Maternal exercise during gestation and impacts on offspring development in pigs. (Master’s thesis). North Dakota State University, 2010.

Koch, J. M., J. S. Moritz, D. C. Lay, Jr. and M. E. Wilson. 2007. Effect of melengestrol acetate as an alternative to induce molting in hens on the expression of yolk proteins and turnover of oviductal epithelium. Anim. Reprod. Sci. 102:14-23.

Lekatz, L. A., J. S. Caton, J. B. Taylor, L. P. Reynolds, D. A. Redmer and K. A. Vonnahme. 2010. Maternal selenium supplementation and timing of nutrient restriction in pregnant sheep: Effects on maternal endocrine status and placental characteristics. J. Anim. Sci. 88:955-971.

Lotgering, F. K., R. D. Gilbert and L. D. Longo. 1985. Maternal and fetal responses to exercise during pregnancy. Physiol. Rev. 65(1): 1-36.

McNanley, T. and J. Woods. 2008. Placental Pathology, Placental development and pathology. Glob.Libr. Women’s Med. ISSN 1756-2228.

Maccani, M. and C. Marsit. 2009. Epigenetics in the placenta. Am. J. Reprod. Immunol. 62(2):78-92.

Mottola, M., K. M. Bagnall and K. D. McFadden. 1983. The effects of maternal exercise on developing rat fetuses. Brit. J. Sports Med. 17(2):117-121.

Rehfeldt, C., I, Fielder, G. Dietl and K. Ender. 2000. Myogenesis and postnatal skeletal muscle cell growth as influenced by selection. Liv Prod Sci 66:177-188. 
Rosa, B. V., E. C. Firth, H. T. Blair, M. H. Vickers and P. C. H. Morel. 2011. Voluntary exercise in pregnant rats positively influences fetal growth without initiating a maternal physiological stress response. Am. J. Physiol. Regul. Integr. Comp. Physiol. 300:R1134R1141.

Underwood, M.A. and M.P. Sherman. 2006. Nutritional characteristics of amniotic fluid. NewReviews 7:e310-316.

Vaughn, P. R., C. Lobo, F. C. Battaglia, P. V. Fennessey, P. R. Wilkening and G. Meschia. 1995. Glutamine - glutamate exchange between placental and fetal liver. Am. J. Physiol. 268(4):E705-711.

Wu, G., F.W. Bazer and W. Tou. 1995. Developmental changes of free amino acid concentrations in fetal fluids of pigs. J. Nutr. 125:2859-2868. 
Table 10. Fetal, Organ and Placental Weights

\begin{tabular}{lccc}
\hline \hline \multirow{1}{*}{\multicolumn{1}{c}{ Variable }} & \multicolumn{2}{c}{ Treatment } & \\
\cline { 2 - 3 } \multicolumn{1}{c}{ Control } & Exercise & P - value \\
\hline Fetal Weight, g & $743.3 \pm 31.1$ & $662.6 \pm 30.4$ & 0.07 \\
Crown-Rump Length, cm & $26.0 \pm 0.40$ & $24.9 \pm 0.39^{\mathrm{x}}$ & 0.05 \\
Brain Weight, g & $17.0 \pm 0.35$ & $16.1 \pm 0.33$ & 0.06 \\
Heart Weight, g & $4.6 \pm 0.2$ & $4.4 \pm 0.2$ & 0.44 \\
Liver Weight, g & $16.6 \pm 0.7$ & $14.3 \pm 0.7^{\mathrm{x}}$ & 0.02 \\
ST Weight, g & $1.87 \pm 0.17$ & $1.54 \pm 0.11^{\mathrm{x}}$ & 0.05 \\
SM Weight, g & $4.75 \pm 0.22$ & $3.77 \pm 0.22^{\mathrm{x}}$ & 0.03 \\
Placental Weight, g & $256.9 \pm 14.8$ & $210.5 \pm 14.1^{\mathrm{x}}$ & 0.03 \\
Placental Efficiency & $3.06 \pm 0.12$ & $3.11 \pm 0.11$ & 0.75 \\
\hline
\end{tabular}

${ }^{\mathrm{x}}$ Means within a row different by treatment $(\mathrm{P} \leq 0.05)$ 
Table 11. Cellularity Measures in Chorio-Allantoic Tissue

\section{Treatment}

\begin{tabular}{cccc}
\cline { 2 - 3 } Variable & Control & Exercise & P - value \\
\hline RNA, mg RNA g tissue $^{-1}$ & $1.65 \pm 0.16$ & $1.71 \pm 0.15$ & 0.8 \\
DNA, mg DNA g tissue $^{-1}$ & $0.20 \pm 0.03$ & $0.21 \pm 0.02$ & 0.8 \\
\hline
\end{tabular}


Table 12. Concentrations of Essential Amino Acids in Fetal Plasma and Amniotic Fluid

\begin{tabular}{|c|c|c|c|}
\hline \multirow{2}{*}{$\begin{array}{c}\text { Variable } \\
\mu \mathrm{M} \\
\end{array}$} & \multicolumn{2}{|c|}{ Treatment } & \multirow[b]{2}{*}{$P$ - value } \\
\hline & Control & Exercise & \\
\hline \multicolumn{4}{|l|}{ Asparagine } \\
\hline Umbilical Artery & $79.30 \pm 3.94$ & $79.04 \pm 4.07$ & 0.96 \\
\hline Umbilical Vein & $56.69 \pm 3.17$ & $66.13 \pm 3.27^{x}$ & 0.05 \\
\hline Veno-Arterial Difference & $-22.61 \pm 4.66$ & $-12.92 \pm 4.80$ & 0.16 \\
\hline Amniotic Fluid & $51.42 \pm 9.87$ & $40.23 \pm 9.00$ & 0.41 \\
\hline \multicolumn{4}{|l|}{ Histidine } \\
\hline Umbilical Artery & $59.6 \pm 2.3$ & $67.7 \pm 2.3^{x}$ & 0.02 \\
\hline Umbilical Vein & $57.2 \pm 2.0$ & $67.1 \pm 2.1^{\mathrm{x}}$ & 0.002 \\
\hline Veno-Arterial Difference & $-2.35 \pm 0.87$ & $-0.61 \pm 0.90$ & 0.18 \\
\hline Amniotic Fluid & $66.35 \pm 12.90$ & $46.36 \pm 11.77$ & 0.26 \\
\hline \multicolumn{4}{|l|}{ Isoleucine } \\
\hline Umbilical Artery & $50.17 \pm 4.01$ & $53.65 \pm 4.14$ & 0.55 \\
\hline Umbilical Vein & $46.23 \pm 4.34$ & $53.30 \pm 4.47$ & 0.27 \\
\hline Veno-Arterial Difference & $-4.0 \pm 1.5$ & $-0.40 \pm 1.5$ & 0.10 \\
\hline Amniotic Fluid & $17.78 \pm 1.47$ & $14.99 \pm 1.34$ & 0.17 \\
\hline \multicolumn{4}{|l|}{ Leucine } \\
\hline Umbilical Artery & $98.62 \pm 7.61$ & $115.82 \pm 7.85$ & 0.13 \\
\hline Umbilical Vein & $89.5 \pm 8.3$ & $114.3 \pm 8.5^{\mathrm{x}}$ & 0.04 \\
\hline Veno-Arterial Difference & $-9.1 \pm 3.0$ & $-1.5 \pm 3.0$ & 0.08 \\
\hline Amniotic Fluid & $35.52 \pm 2.35$ & $37.15 \pm 2.14$ & 0.62 \\
\hline \multicolumn{4}{|l|}{ Lysine } \\
\hline Umbilical Artery & $231.00 \pm 11.54$ & $232.80 \pm 11.89$ & 0.91 \\
\hline Umbilical Vein & $222.62 \pm 12.42$ & $228.38 \pm 12.80$ & 0.75 \\
\hline Veno-Arterial Difference & $-8.37 \pm 4.92$ & $-4.42 \pm 5.07$ & 0.58 \\
\hline Amniotic Fluid & $305.09 \pm 74.89$ & $154.36 \pm 68.33$ & 0.15 \\
\hline \multicolumn{4}{|l|}{ Methionine } \\
\hline Umbilical Artery & $20.2 \pm 1.8$ & $27.5 \pm 1.9^{x}$ & $<0.01$ \\
\hline Umbilical Vein & $18.6 \pm 1.5$ & $27.4 \pm 1.6^{\mathrm{x}}$ & $<0.001$ \\
\hline Veno-Arterial Difference & $-1.57 \pm 0.57$ & $-0.09 \pm 0.59$ & 0.08 \\
\hline Amniotic Fluid & $7.21 \pm 1.96$ & $10.40 \pm 1.79$ & 0.24 \\
\hline
\end{tabular}


Table 12. (Continued) Concentrations of Essential Amino Acids in Fetal Plasma and Amniotic Fluid

\begin{tabular}{|c|c|c|c|}
\hline \multirow{2}{*}{$\begin{array}{c}\text { Variable } \\
\mu \mathrm{M}\end{array}$} & \multicolumn{2}{|c|}{ Treatment } & \multirow[b]{2}{*}{$P$ - value } \\
\hline & Control & Exercise & \\
\hline \multicolumn{4}{|l|}{ Phenylalanine } \\
\hline Umbilical Artery & $27.21 \pm 2.86$ & $32.33 \pm 2.95$ & 0.22 \\
\hline Umbilical Vein & $24.23 \pm 3.08$ & $31.97 \pm 3.17$ & 0.09 \\
\hline Veno-Arterial Difference & $-2.98 \pm 1.17$ & $-0.35 \pm 1.20$ & 0.13 \\
\hline Amniotic Fluid & $10.30 \pm 1.00$ & $10.21 \pm 0.92$ & 0.95 \\
\hline \multicolumn{4}{|l|}{ Threonine } \\
\hline Umbilical Artery & $310.41 \pm 11.98$ & $287.41 \pm 12.35$ & 0.19 \\
\hline Umbilical Vein & $303.98 \pm 12.25$ & $282.36 \pm 12.63$ & 0.23 \\
\hline Veno-Arterial Difference & $-6.44 \pm 2.58$ & $-5.06 \pm 2.66$ & 0.71 \\
\hline Amniotic Fluid & $276.05 \pm 32.34$ & $199.88 \pm 29.50$ & 0.09 \\
\hline \multicolumn{4}{|l|}{ Tryptophan } \\
\hline Umbilical Artery & $22.5 \pm 1.1$ & $22.0 \pm 1.1$ & 0.72 \\
\hline Umbilical Vein & $21.57 \pm 1.09$ & $22.14 \pm 1.12$ & 0.72 \\
\hline Veno-Arterial Difference & $-0.94 \pm 0.49$ & $0.19 \pm 0.51$ & 0.12 \\
\hline Amniotic Fluid & $16.67 \pm 2.11$ & $13.61 \pm 1.93$ & 0.29 \\
\hline \multicolumn{4}{|l|}{ Valine } \\
\hline Umbilical Artery & $182.18 \pm 8.63$ & $190.22 \pm 8.90$ & 0.52 \\
\hline Umbilical Vein & $176.33 \pm 8.95$ & $187.62 \pm 9.22$ & 0.39 \\
\hline Veno-Arterial Difference & $-5.85 \pm 2.56$ & $-2.60 \pm 2.64$ & 0.38 \\
\hline Amniotic Fluid & $102.20 \pm 8.26$ & $89.34 \pm 7.54$ & 0.11 \\
\hline
\end{tabular}

${ }^{\mathrm{x}}$ Means within a row different by treatment $(\mathrm{P} \leq 0.05)$ 
Table 13. Concentrations of Non - Essential Amino Acids in Fetal Plasma and Amniotic Fluid

\begin{tabular}{|c|c|c|c|}
\hline \multirow{2}{*}{$\begin{array}{c}\text { Variable } \\
\boldsymbol{\mu M}\end{array}$} & \multicolumn{2}{|c|}{ Treatment } & \multirow[b]{2}{*}{$P$ - value } \\
\hline & Control & Exercise & \\
\hline \multicolumn{4}{|l|}{ 1-methyl-Histidine } \\
\hline Umbilical Artery & $9.17 \pm 0.56$ & $5.75 \pm 0.58^{x}$ & 0.0002 \\
\hline Umbilical Vein & $9.4 \pm 0.6$ & $6.4 \pm 0.7^{\mathrm{x}}$ & 0.002 \\
\hline Veno-Arterial Difference & $0.21 \pm 0.37$ & $0.61 \pm 0.38$ & 0.45 \\
\hline Amniotic Fluid & $28.27 \pm 9.31$ & $7.15 \pm 8.50$ & 0.11 \\
\hline \multicolumn{4}{|l|}{ 3-methyl-Histidine } \\
\hline Umbilical Artery & $14.5 \pm 1.2$ & $11.4 \pm 1.2$ & 0.08 \\
\hline Umbilical Vein & $14.73 \pm 1.30$ & $12.12 \pm 1.34$ & 0.17 \\
\hline Veno-Arterial Difference & $0.20 \pm 0.47$ & $0.74 \pm 0.49$ & 0.43 \\
\hline Amniotic Fluid & $23.85 \pm 5.60$ & $11.82 \pm 5.11$ & 0.12 \\
\hline \multicolumn{4}{|l|}{$\beta$-Alanine } \\
\hline Umbilical Artery & $25.8 \pm 0.7$ & $22.3 \pm 0.8^{\mathrm{x}}$ & 0.003 \\
\hline Umbilical Vein & $26.8 \pm 0.7$ & $22.7 \pm 0.7^{\mathrm{x}}$ & 0.0002 \\
\hline Veno-Arterial Difference & $1.04 \pm 0.63$ & $0.41 \pm 0.65$ & 0.49 \\
\hline Amniotic Fluid & $18.41 \pm 2.49$ & $13.48 \pm 2.27$ & 0.15 \\
\hline \multicolumn{4}{|l|}{ Alanine } \\
\hline Umbilical Artery & $528.59 \pm 18.17$ & $550.39 \pm 18.73$ & 0.41 \\
\hline Umbilical Vein & $499.2 \pm 16.0$ & $542.8 \pm 16.5$ & 0.07 \\
\hline Veno-Arterial Difference & $-29.4 \pm 7.9$ & $-7.6 \pm 8.1$ & 0.06 \\
\hline Amniotic Fluid & $515.93 \pm 29.88$ & $478.80 \pm 27.26$ & 0.37 \\
\hline \multicolumn{4}{|l|}{ Arginine } \\
\hline Umbilical Artery & $125.58 \pm 6.31$ & $132.55 \pm 6.50$ & 0.45 \\
\hline Umbilical Vein & $119.31 \pm 6.65$ & $131.76 \pm 6.86$ & 0.20 \\
\hline Veno-Arterial Difference & $-6.27 \pm 2.44$ & $-0.79 \pm 2.52$ & 0.13 \\
\hline Amniotic Fluid & $135.44 \pm 37.10$ & $67.97 \pm 33.85$ & 0.19 \\
\hline \multicolumn{4}{|l|}{ Aspartate } \\
\hline Umbilical Artery & $6.79 \pm 1.16$ & $6.18 \pm 1.20$ & 0.72 \\
\hline Umbilical Vein & $13.88 \pm 1.64$ & $11.19 \pm 1.69$ & 0.26 \\
\hline Veno-Arterial Difference & $7.09 \pm 1.81$ & $5.01 \pm 1.87$ & 0.43 \\
\hline Amniotic Fluid & $24.72 \pm 8.22$ & $8.84 \pm 7.50$ & 0.17 \\
\hline
\end{tabular}


Table 13. (Continued) Concentrations of Non - Essential Amino Acids in Fetal Plasma and Amniotic Fluid

\begin{tabular}{|c|c|c|c|}
\hline \multirow{2}{*}{$\begin{array}{c}\text { Variable } \\
\boldsymbol{\mu M}\end{array}$} & \multicolumn{2}{|c|}{ Treatment } & \multirow[b]{2}{*}{$P$ - value } \\
\hline & Control & Exercise & \\
\hline \multicolumn{4}{|l|}{ Citrulline } \\
\hline Umbilical Artery & $117.90 \pm 3.92$ & $110.62 \pm 4.04$ & 0.21 \\
\hline Umbilical Vein & $122.4 \pm 3.9$ & $110.3 \pm 4.0^{\mathrm{x}}$ & 0.04 \\
\hline Veno-Arterial Difference & $4.5 \pm 1.5$ & $-0.34 \pm 1.5^{x}$ & 0.03 \\
\hline Amniotic Fluid & $126.90 \pm 14.83$ & $96.46 \pm 13.53$ & 0.14 \\
\hline \multicolumn{4}{|l|}{ Cysteine } \\
\hline Umbilical Artery & $13.22 \pm 0.78$ & $12.36 \pm 0.81$ & 0.44 \\
\hline Umbilical Vein & $12.71 \pm 0.74$ & $12.07 \pm 0.76$ & 0.56 \\
\hline Veno-Arterial Difference & $-0.52 \pm 0.32$ & $-0.28 \pm 0.33$ & 0.60 \\
\hline Amniotic Fluid & $11.81 \pm 0.79$ & $14.41 \pm 0.72^{\mathrm{x}}$ & 0.02 \\
\hline \multicolumn{4}{|l|}{ Glutamate } \\
\hline Umbilical Artery & $74.99 \pm 22.87$ & $101.68 \pm 23.58$ & 0.42 \\
\hline Umbilical Vein & $318.81 \pm 22.07$ & $182.87 \pm 22.75^{\mathrm{x}}$ & 0.0002 \\
\hline Veno-Arterial Difference & $243.8 \pm 35.4$ & $81.2 \pm 36.5^{x}$ & 0.003 \\
\hline Amniotic Fluid & $356.35 \pm 101.16$ & $92.82 \pm 92.29$ & 0.06 \\
\hline \multicolumn{4}{|l|}{ Glutamine } \\
\hline Umbilical Artery & $850.94 \pm 18.25$ & $831.67 \pm 18.82$ & 0.47 \\
\hline Umbilical Vein & $701.6 \pm 24.4$ & $779.2 \pm 25.2^{\mathrm{x}}$ & 0.03 \\
\hline Veno-Arterial Difference & $-136.3 \pm 22.7$ & $-52.2 \pm 23.4^{x}$ & 0.02 \\
\hline Amniotic Fluid & $413.24 \pm 34.94$ & $378.30 \pm 31.88$ & 0.47 \\
\hline \multicolumn{4}{|l|}{ Glycine } \\
\hline Umbilical Artery & $497.8 \pm 13.3$ & $444.5 \pm 13.7^{\mathrm{x}}$ & $<0.01$ \\
\hline Umbilical Vein & $501.7 \pm 12.5$ & $449.7 \pm 12.9^{x}$ & $<0.01$ \\
\hline Veno-Arterial Difference & $3.89 \pm 4.10$ & $4.62 \pm 4.22$ & 0.90 \\
\hline Amniotic Fluid & $947.08 \pm 247.90$ & $400.27 \pm 226.18$ & 0.11 \\
\hline \multicolumn{4}{|l|}{ Hydroxylysine } \\
\hline Umbilical Artery & $3.76 \pm 0.25$ & $3.76 \pm 0.26$ & 0.99 \\
\hline Umbilical Vein & $3.54 \pm 0.22$ & $3.70 \pm 0.23$ & 0.62 \\
\hline Veno-Arterial Difference & $-0.23 \pm 0.06$ & $-0.06 \pm 0.07$ & 0.09 \\
\hline Amniotic Fluid & $28.46 \pm 12.05$ & $4.74 \pm 11.00$ & 0.16 \\
\hline
\end{tabular}


Table 13. (Continued) Concentrations of Non - Essential Amino Acids in Fetal Plasma and Amniotic Fluid

\begin{tabular}{|c|c|c|c|}
\hline \multirow{2}{*}{$\begin{array}{c}\text { Variable } \\
\boldsymbol{\mu M}\end{array}$} & \multicolumn{2}{|c|}{ Treatment } & \multirow[b]{2}{*}{$P$ - value } \\
\hline & Control & Exercise & \\
\hline \multicolumn{4}{|l|}{ Proline } \\
\hline Umbilical Artery & $179.68 \pm 4.91$ & $175.00 \pm 5.06$ & 0.51 \\
\hline Umbilical Vein & $179.05 \pm 4.90$ & $175.18 \pm 5.05$ & 0.59 \\
\hline Veno-Arterial Difference & $-0.63 \pm 2.11$ & $0.17 \pm 2.17$ & 0.79 \\
\hline Amniotic Fluid & $145.43 \pm 5.39$ & $129.89 \pm 4.92^{\mathrm{x}}$ & 0.04 \\
\hline \multicolumn{4}{|l|}{ Serine } \\
\hline Umbilical Artery & $227.74 \pm 8.03$ & $211.95 \pm 8.27$ & 0.18 \\
\hline Umbilical Vein & $224.20 \pm 8.68$ & $210.77 \pm 8.95$ & 0.29 \\
\hline Veno-Arterial Difference & $-3.54 \pm 3.79$ & $-1.19 \pm 3.91$ & 0.67 \\
\hline Amniotic Fluid & $216.29 \pm 47.38$ & $114.43 \pm 43.23$ & 0.13 \\
\hline \multicolumn{4}{|l|}{ Tyrosine } \\
\hline Umbilical Artery & $49.82 \pm 2.89$ & $52.08 \pm 2.98$ & 0.59 \\
\hline Umbilical Vein & $48.66 \pm 3.05$ & $52.04 \pm 3.15$ & 0.45 \\
\hline Veno-Arterial Difference & $-1.17 \pm 1.09$ & $-0.04 \pm 1.12$ & 0.48 \\
\hline Amniotic Fluid & $49.56 \pm 12.70$ & $24.56 \pm 11.59$ & 0.16 \\
\hline \multicolumn{4}{|l|}{ Urea } \\
\hline Umbilical Artery & $2561.1 \pm 280.4$ & $1822.0 \pm 289.1$ & 0.08 \\
\hline Umbilical Vein & $2016.2 \pm 205.9$ & $2130.5 \pm 212.2$ & 0.70 \\
\hline Veno-Arterial Difference & $-544.9 \pm 299.6$ & $308.5 \pm 308.8^{x}$ & 0.05 \\
\hline Amniotic Fluid & $7565.45 \pm 2282.94$ & $2502.28 \pm 2082.90$ & 0.11 \\
\hline
\end{tabular}

${ }^{\mathrm{x}}$ Means within a row different by treatment $(\mathrm{P} \leq 0.05)$ 
Table 14. Glucose Concentrations in Umbilical Plasma

\begin{tabular}{lrccc}
\hline \hline \multirow{2}{*}{ Glucose } & Variable & \multicolumn{2}{c}{ Treatment } & \\
& $\mathbf{m M}$ & Control & Exercise & P - value \\
& Umbilical Artery & $3.27 \pm 0.27$ & $2.94 \pm 0.27$ & 0.41 \\
& Umbilical Vein & $2.58 \pm 0.27$ & $2.90 \pm 0.27$ & 0.4 \\
\multirow{2}{*}{ NEFA } & Veno-Arterial Difference & $-0.69 \pm 0.26$ & $-0.05 \pm 0.27$ & 0.09 \\
& Umbilical Artery & $0.34 \pm 0.01$ & $0.34 \pm 0.01$ & 0.68 \\
& Umbilical Vein & $0.31 \pm 0.01$ & $0.32 \pm 0.01$ & 0.4 \\
& Veno-Arterial Difference & $-0.30 \pm 0.01$ & $-0.02 \pm 0.01$ & 0.46 \\
\hline
\end{tabular}

${ }^{\mathrm{x}}$ Means within a row different by treatment $(\mathrm{P} \leq 0.05)$ 


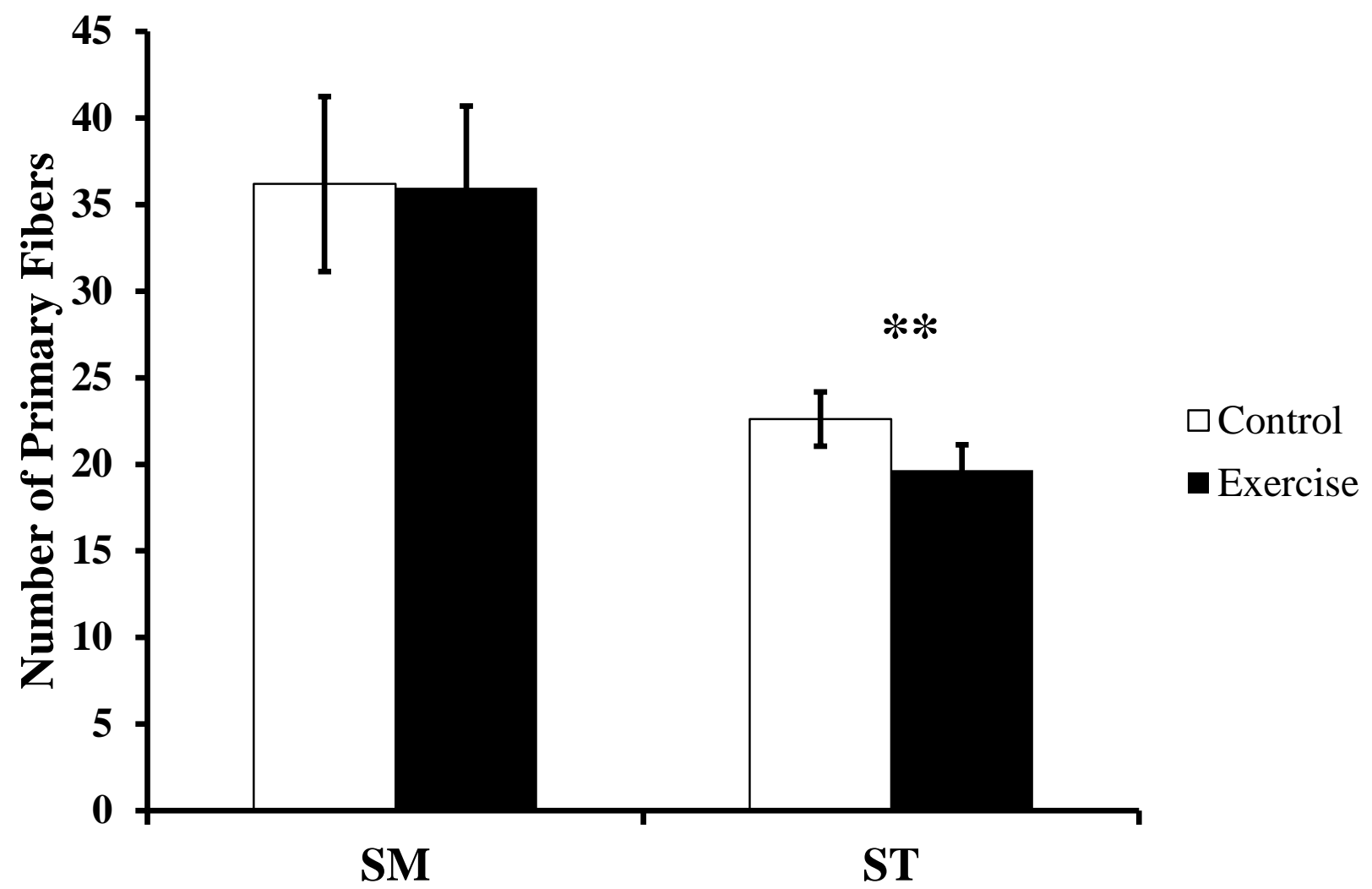

Figure 13. Number of primary muscle fibers in SM and ST muscles of fetuses of EX dams (closed bars) compared to CON dams (open bars). Means \pm SEM, ${ }^{* *} \mathrm{P}<0.05$. 


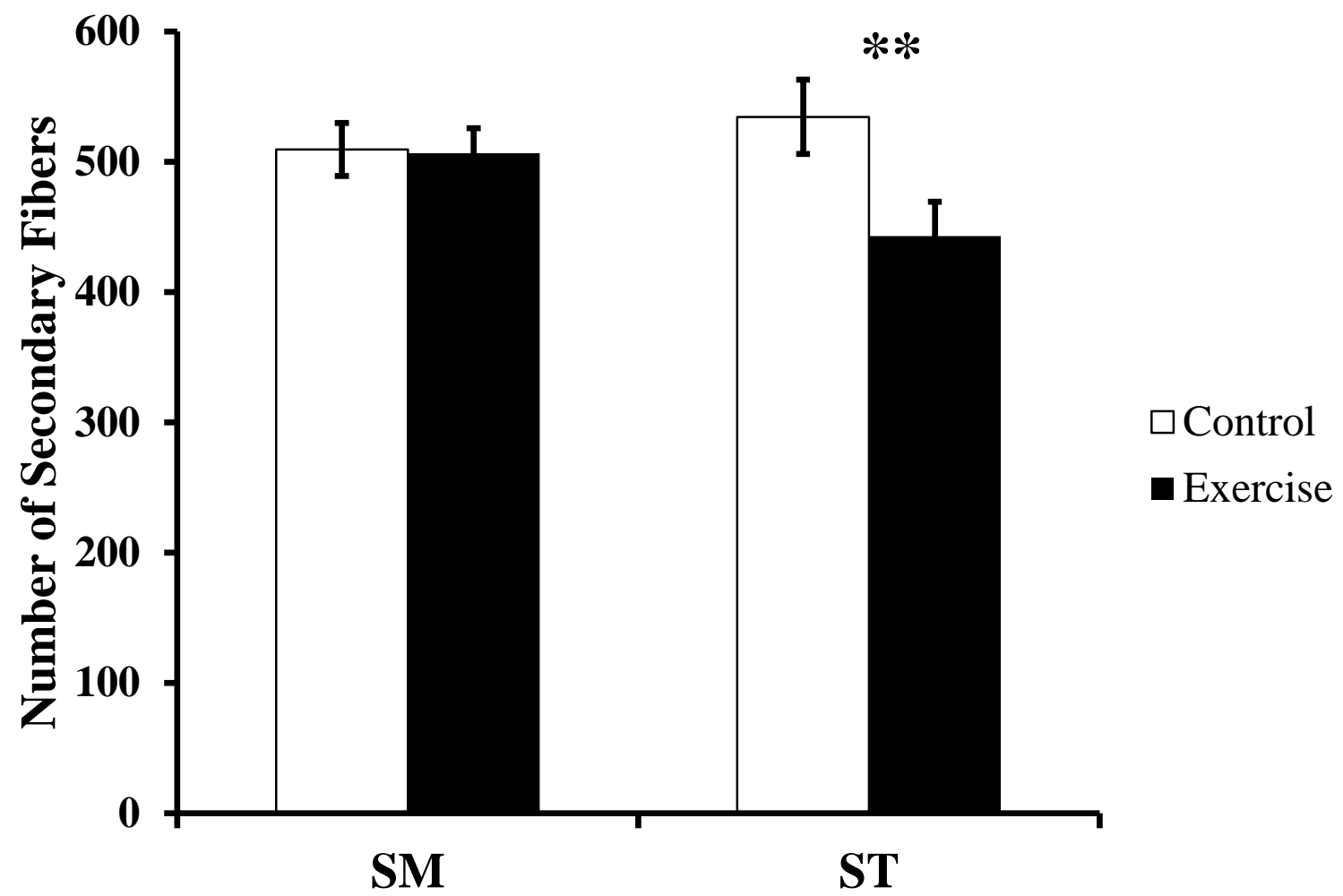

Figure 14.Number of secondary muscle fibers in SM and ST muscle from fetuses of EX dams (closed bars) and CON dams (open bars). Means \pm SEM, ** $\mathrm{P}<0.05$ by treatment. 


\section{GENERAL DISCUSSION}

The efficiency of pork production is dependent on two things: 1) litter size, and 2) developmental competence. Litter size of commercial domestic breeds is approximately 10 pigs per litter (NASS, 2011). While this number has improved from the late 1990's when it was approximately eight pigs per litter, it still falls short of more prolific breeds. The litters of these breeds are associated with placentae that are smaller and more vascularized than the placenta of commercial breeds. Investigators began studying the ratio of fetal weight to placental weight as a measure of the efficiency of the placenta to produce a piglet.

Due to the litter bearing nature (i.e. the vast number of piglets occupying a single uterus at one time), placental function is crucial for the developmental competence of the offspring. The ability of the placenta to function at a level where maximum number of fetuses can occupy the uterus without negatively affecting development is crucial to the successful production of the meat animal. Placental efficiency can be used as a tool to do just this.

Placental efficiency is incredibly variable not only between litters, but within a single litter. Two fetuses of the same size can be grown on two very differently sized placentae, with one being up to $50 \%$ heavier than the other. The increased mass of this placenta takes up additional space in the uterus, allowing less room for additional feto-placental units. However, to ensure that each of those placentae are functioning at the same level, fetal development across the litter must be studied. We know that the gestational development of an organism sets it up for the rest of the life and any shortcomings there can lead to morbidity and mortality.

Muscle development occurs in utero, in the pig, beginning around day 30 of gestation and continuing through day 100. The number of fibers that are formed during this time does not change postnatally, therefore any stressors encountered during gestation could affect not only the 
development of the muscle in utero, but postnatal growth and development as well. Postnatal muscle growth is only hypertrophic in nature and the size to which these muscle fibers grow has a significant impact on pork quality as the animal reaches market weight.

Here we have demonstrated that placental efficiency influences both in utero and postnatal muscle development by altering the number and size of fibers as well as the secondary to primary ratio of fibers that is an important measure of pork quality. However, more work will need to be done to clearly discern the exact effect placental efficiency has on pork quality.

Additionally, the swine industry is shifting from the use of gestation stalls to group housing for pregnant gilts and sows. The major benefit group housing offers is increased ambulation. Many have reported on the effects of exercise during gestation in rats, sheep and humans, however the results are often inconclusive and controversial. Often results vary based on the timing of exercise during gestation, the intensity of the exercise and the type of exercise that is performed. Furthermore, little is known about the effects exercise will have on swine.

In the second parity exercise study carried out in North Dakota, we found that fetal, organ and muscle weights were reduced as a result of exercise. Furthermore, fetal concentrations of metabolites suggest altered protein metabolism and breakdown of muscle proteins. Still, fetal muscle development was affected, with different muscles responding differently to exercise. We concluded here that exercise during gestation, for the second parity, had negative effects on fetal development and metabolism. 


\section{LITERATURE CITED}

Aberle, A. D. 1984. Myofiber differentiation in skeletal muscles of newborn runt and normal weight pigs. J. Anim. Sci. 59:1651-1656.

Angiolini, E., A. Fowden, P. Coan, I. Sandovici, P. Smith, W. Dean, G. Burton, B. Tycko, W. Reik, C. Sibley and M. Constância. 2006. Regulation of placental efficiency for nutrient transport by imprinted genes. Placenta 27 (Supp. A):S100-102.

Ashmore, C.R., D.W. Robinson, P. Rattray and L. Doerr. 1972. Biphasic development of muscle fibers in the fetal lamb. Exp. Neurol. 37(2):241-255.

Ashmore, C.R., P.B. Addis and L. Doerr. 1973. Development of muscle fibers in the fetal pig. J. Anim. Sci. 36(6):1088-1093.

Bazer, F.W., J.L. Vallet, R.M. Roberts, D.C. Sharp and W.W. Thatcher. 1986. Role of conceptus secretory products in establishment of pregnancy. J. Reprod. Fert. 76:841-850.

Bee, G. 2004.Effect of early gestation feeding, birth weight, and gender of progeny on muscle fiber characteristics of pigs at slaughter. J. Anim. Sci. 82:826-836.

Biensen, N.J., M.E. Wilson and S.P. Ford. 1998. The impact of either a Meishan or Yorkshire uterus on Meishan or Yorkshire fetal and placental development to days 70, 90, and 110 of gestation. J. Anim. Sci. 76:2169-2176.

Biensen, N.J., M.E. Wilson and S.P. Ford. 1999. The impacts of uterine environment and fetal genotype on conceptus size and placental vascularity during late gestation in pigs. J. Anim. Sci. 77:954-959.

Brocking, A. D. and R. Harding. 2001. Development and function of the placenta. In Fetal Growth and Development, pp. 17-43.[A.D. Brocking and R. Harding, editors]. Cambridge, United Kingdom: Cambridge University Press. 
Cerisuelo, A., M.D. Baucells, J. Gasa, J. Coma, D. Carrion, N. Chapinal and R. Sala. 2009. Increased sow nutrition during midgestation affects muscle fiber development and meat quality, with no consequences on growth performance. J. Anim. Sci. 87:729-739.

Chandler, E.K., B.J. Leury, A.R. Bird and A.W. Bell. 1985. Effects of undernutrition and exercise during late pregnancy on uterine, fetal and uteroplacental metabolism in the ewe. Brit. J. Nutr. 53:625-635.

Chandler, K. D. and A. W. Bell. 1981. Effects of maternal exercise on fetal and maternal respiration and nutrient metabolism in the pregnant ewe. J. Dev. Physiol. 3:161-176.

Chandler, K. D., B. J. Leury, A. R. Bird and A. W. Bell. 1985. Effects of undernutrition and exercise during late pregnancy on uterine, fetal and uteroplacental metabolism in the ewe. Brit. J. Nut. 53:625-635.

Clapp, J. F., H. Kim, B. Burciu and B. Lopez. 2000. Beginning regular exercise in early pregnancy: Effect on fetoplacental growth. Am. J. Obstet. Gynecol. 183:1484-1488.

Clapp, J. F., H. Kim, B. Burciu, S. Schmidt, K. Petry and B. Lopez. 2002. Continuing regular exercise during pregnancy: Effect of exercise volume on fetoplacental growth. Am. J. Obstet. Gynecol. 186:142-147.

Coan, P.M., E. Angiolini, I Sandovici, G.J. Burton, M. Constância and A.L. Fowden. 2008. Adaptations in placental nutrient transfer capacity to meet fetal growth demands depend on placental size in mice. J. Physiol. 586(18):4567-4576.

Davies, A.S. 1972. Postnatal changes in the histochemical fibre types of porcine skeletal muscle. J. Anat. 113:213-240. 
Dwyer, C. M., N.C. Stickland, and J.M. Fletcher. 1994. The influence of maternal nutrition on muscle fiber number development in the porcine fetus and on subsequent postnatal growth. J. Anim. Sci. 72:911-917.

Dziuk, P.J. 1968. Effect of number of embryos and uterine space on embryo survival in the pig. J. Anim. Sci. 27:673-376.

Fielder, I., C. Rehfeldt, K. Ender and M. Henning. 1997. Phenotypic and genetic parameters of muscle fiber number and size. J. Anim. Sci. 75 (Suppl. 1):165.

Fielder, I., K. Ender, M. Wicke, S. Maak, G. von Lengerken and W. Meyer. 1999. Structural characteristics of muscle fibers in pigs with different malignant hyperthermia susceptibility and different meat quality. Meat Sci. 53:9-15

Finch, A. M., L. G. Yang, M. O. Nwagwu, K. R. Page, H. J. McArdle and C. J. Ashworth. 2004. Placental transport of leucine in a porcine model of low birth weight. Reprod. 128:229235.

Flint, APF. 1983. Factors controlling placental endocrine function in domestic animals. Exp. Endocrinol. 5:75-95.

Fowden,A.L., J. W. Ward, F. P. B. Wooding, A. J. Forhead and M. Constância. 2006. Programming placental nutrient transport capacity. J. Physiol 572(1):5-15.

Fowden, A. L., A. N. Sferruzzi-Perri, P. M. Coan, M. Constância and G. J. Burton. 2009. Placental efficiency and adaptation: endocrine regulation. J. Physiol. 587(14):3459-3472.

Friess, A.E., F. Sinowatz, R. Skolek-Winnisch and W. Träutner. 1980. The Placenta of the Pig I. Finestructural changes of the placental barrier during pregnancy. Anat. Embryol. 158:179-191. 
Friess, A.E., F. Sinowatz, R. Skolek-Winnisch and W. Träutner. 1982. Structure of the epitheliochorial porcine placenta. Biblthca anat. 22:140-143.

Gao, H., G. Wu, T.E. Spencer, G.A. Johnson and F.W. Bazer. 2009. Select nutrients in the ovine uterine lumen. III. Cationic amino acid transporters in the ovine uterus and peri-implantation conceptuses. Biol. Reprod. 80: 602-609.

Garris, D. R., G. J. Kasperek, S. V. Overton and G. R. Alligood, Jr. 1985. Effects of exercise on fetal-placental growth and uteroplacental blood flow in the rat. Biol Neonate. 47:223-339.

Gilbert, S.F. $6^{\text {th }}$ ed. 2000.Myogenesis: The Development of Muscle. Developmental Biology. Sinauer Associates, Sunderland, MA.

Gondret, F., L. Lefaucheur, H. Juin, I. Louveau and B. Lebret. 2006. Low birth weight is associated with enlarged muscle fiber area and impaired meat tenderness of the longissimus muscle in pigs. J. Anim. Sci. 84:93-103.

Greyling, L. 2004. The placenta and amniotic fluid. Maternal and Newborn Care: A Complete Guide for Midwives and Other Health Professionals. Juta and Company, Ltd. Christa van der Walt and Joanita de Kock. Ch 7 pgs 7-1 to 7-11

Hale, O.M., C.V. Booram and W.C. McCormick. 1981. Effects of forced exercise during gestation on farrowing and weaning performance of swine. J. Anim. Sci. 52(6):12401244.

Harris, E.K. (2010). Maternal exercise during gestation and impacts on offspring development in pigs. (Master’s thesis). North Dakota State University, 2010.

Hay, Jr, William. 1995. Regulation of placental metabolism by glucose supply. Reprod. Fertil. Dev. 7: 365-375. 
Henckel, P. N. Oksbierg, E. Erlandsen, P. Barton-Gade and C. Beierholm. 1997. Histo- and biochemical characteristics of the Longissimusdorsi muscle in pigs and their relationships to performance and meat quality. Meat Sci. 47:311-321.

Hui, T.Y. and D.A. Bernlohr. 1997. Fatty acid transporters in animal cells. Fron. Bioscience 2:d222-231.

Koch, J. M., J. S. Moritz, D. C. Lay, Jr. and M. E. Wilson. 2007. Effect of melengestrol acetate as an alternative to induce molting in hens on the expression of yolk proteins and turnover of oviductal epithelium. Anim. Reprod. Sci. 102:14-23.

Lammers, P.J., M.S. Honeyman, J.W. Mabry and J.D. Harmon. 2007. Performance of gestating sows in bedded hoop barns and confinement stalls. J. Anim. Sci. 85:1311-1317.

Leiser, R. and V. Dantzer. 1988. Structural and functional aspects of porcine placental microvasculature. Anat. and Embryol. 177:409-419.

Lekatz, L. A., J. S. Caton, J. B. Taylor, L. P. Reynolds, D. A. Redmer and K. A. Vonnahme. 2010. Maternal selenium supplementation and timing of nutrient restriction in pregnant sheep: Effects on maternal endocrine status and placental characteristics. J. Anim. Sci. 88:955-971.

Lengerken, G., M. Wicke, S. Maak. 1997. Stress susceptibility and meat quality-situation and prospects in animal breeding and research

Leskanich, C.O. and R.C. Noble. 1999. The comparative roles of polyunsaturated fatty acids in pig neonatal development. Brit. J. Nutr. 81:87-106.

Lotgering, F.K., R.D. Gilbert and L.D. Longo. 1985. Maternal and fetal responses to exercise during pregnancy. Physiol. Rev. 65(1):1-36 
McNanley, T. and J. Woods. 2008. Placental Pathology, Placental development and pathology. Glob.Libr. Women’s Med. ISSN 1756-2228.

Maccani, M. and C. Marsit. 2009. Epigenetics in the placenta. Am. J. Reprod. Immunol. 62(2):78-92.

Maltin, C.A., M.I. Delday, K.D. Sinclair, J. Steven and A.A. Sneddon. 2001. Impact of manipulations of myogenesis in utero on the performance of adult skeletal muscle. Reprod 122:359-374.

Milligan, B. N., D. Fraser and D.L. Kramer. 2002. Within-litter birth weight variation in the domestic pig and its relation to pre-weaning survival, weight gain, and variation in weaning weights. Liv Prod Sci 76:181-191.

Mintz, B. and W.W. Baker. 1967. Normal mammalian muscle differentiation and gene control of isocitrate dehydrogenase synthesis. Proc. Nat. Acad. Sci. 58(2):592-598.

Mottola, M., K.M. Bagnall and K.D. McFadden. 1983. The effects of maternal exercise on developing rat fetuses. Brit. J. Sports Med. 17(2):117-121.

NASS. 2011. March Hogs and Pigs Report. National Agricultural Statistics Service, USDA, Washington, D.C.

Perry, J.S. 1981. The mammalian fetal membranes. J. Reprod. Fert. 62:321-335.

Rehfeldt, C. and G. Kuhn. 2006. Consequences of birth weight for postnatal growth performance and carcass quality in pigs as related to myogenesis. J. Anim. Sci. 84:E113-123.

Rehfeldt, C., I, Fielder, G. Dietl and K. Ender. 2000. Myogenesis and postnatal skeletal muscle cell growth as influenced by selection. Liv Prod Sci 66:177-188. 
Reynolds, L. P., P. P. Borowicz, K. A. Vonnahme, M. L. Johnson, A. T. Grazul-Bilska, J. M. Wallace, J. S. Caton and D. A. Redmer. 2005. Animal models of placental angiogenesis. Placenta. 26:680-708.

Robertson, A.F. and W.B. Karp. 1976. Placental transport of nutrients. Southern Medical Journal 69(10):1358-1362.

Rosa, B.V., E.C. Firth, H.T. Blair, M.H. Vickers, P.C.H. Morel. 2011. Voluntary exercise in pregnant rats positively influences fetal growth without initiating a maternal physiological stress response. Am. J. Physiol. Regul. Integr. Comp. Physiol. 300:R1134R1141.

Self, J.T., T.E. Spencer, G.A. Johnson, J. Hu, F.W. Bazer and G. Wu. 2004. Glutamine synthesis in the developing porcine placenta. Biol. Reprod. 70:1444-1451.

Sibley, C., J. Glazier and S. D’Souza. 1997. Placental transport activity and expression in relation to fetal growth. Exp. Phys. 82:389-402.

Smith, C.H. and A.J. Moe. 1992. Nutrient transport pathways across the epithelium of the placenta. Annu. Rev. Nutr. 12:183-206.

Steven, D.H. (Ed.) (1975) Comparative placentation: Essays in structure and function. Academic Press, London.

Stickland, N.C. and G. Goldspink. 1975. A note on porcine skeletal muscle parameters and their possible use in early progeny testing. Anim. Prod. 21:93-96.

Suzuki, A. and R.G. Cassens. 1980. A histochemical study of myofiber types in muscle of the growing pig. J. Anim. Sci. 51(6):1449-1461.

Swatland, H.J. 1977. Transitional stages in the histochemical development of muscle fibers during post-natal growth. Histochem. J. 9:751-757. 
Tilley, R. E., C. J. McNeil, C. J. Ashworth, K. R. Page and H. J. McArdle. 2007. Altered muscle development and expression of the insulin-like growth factor system in growth retarded fetal pigs. Dom. Anim. Endocrinol. 32:167-177.

Town, S.C., C.T. Putnam, N.J. Turchinsky, W.T. Dixon and G.R. Foxcroft. 2004. Number of conceptuses in utero affects porcine fetal muscle development. Reprod. 128:443-454.

Underwood, M.A. and M.P. Sherman. 2006. Nutritional characteristics of amniotic fluid. New Reviews 7:e310-316.

Vaughn, P. R., C. Lobo, F. C. Battaglia, P. V. Fennessey, P. R. Wilkening and G. Meschia. 1995. Glutamine - glutamate exchange between placental and fetal liver. Am. J. Physiol. 268(4):E705-711.

Vonnahme, K.A., M.E. Wilson and S.P. Ford. 2001. Relationship between placental vascular endothelial growth factor expression and placental/endometrial vascularity in the pig. Biol. Reprod. 64:1821-1825.

Vonnahme, K.A. and S.P. Ford. 2003. Placental vascular endothelial growth factor receptor system mRNA expression in pigs selected for placental efficiency. J. Physiol. 554(1):194-201.

Wigmore, P.M.C. and N.C. Stickland. 1983. Muscle development in large and small pig fetuses. J. Anat. 137(2):235-245.

Wilmoth, T. (2009). Variation in, and contributing factors of placental efficiency in swine. (Master's thesis). Retrieved from ProQuest Dissertations and Theses. West Virginia University, 2009. 1471825. 
Wilson, M.E., N.J. Biensen, C.R. Youngs and S.P. Ford. 1998. Development of Meishan and Yorkshire littermate conceptuses in either a Meishan or Yorkshire uterine environment to day 90 of gestation and to term. Biol. Reprod. 58:905-910.

Wilson, M.E., N.J. Biensen and S.P. Ford. 1999. Novel insight into the control of litter size in pigs, using placental efficiency as a selection tool. J.Anim.Sci. 77:1654-1658.

Wollmann, H. A. 1998. Intrauterine growth restriction: definition and etiology. Horm. Res. 49:1-6.

Wolter, B. F., M. Ellis, B. P. Corrigan and J. M. DeDecker. 2002. The effect of low birth weight and feeding of supplemental milk replacer to piglets during lactation on pre-weaning and post-weaning growth performance and carcass characteristics. J. Anim. Sci. 80:301-308.

Wu, G., F.W. Bazer and W. Tou. 1995. Developmental changes of free amino acid concentrations in fetal fluids of pigs. J. Nutr. 125:2859-2868. 